\title{
Analysis of concussion management policies and procedures among athletic trainers in the four divisions of NCAA collegiate football
}

James D. Dorneman Jr. West Virginia University

Follow this and additional works at: https://researchrepository.wvu.edu/etd

\section{Recommended Citation}

Dorneman, James D. Jr., "Analysis of concussion management policies and procedures among athletic trainers in the four divisions of NCAA collegiate football" (2010). Graduate Theses, Dissertations, and Problem Reports. 4581.

https://researchrepository.wvu.edu/etd/4581

This Thesis is protected by copyright and/or related rights. It has been brought to you by the The Research Repository @ WVU with permission from the rights-holder(s). You are free to use this Thesis in any way that is permitted by the copyright and related rights legislation that applies to your use. For other uses you must obtain permission from the rights-holder(s) directly, unless additional rights are indicated by a Creative Commons license in the record and/ or on the work itself. This Thesis has been accepted for inclusion in WVU Graduate Theses, Dissertations, and Problem Reports collection by an authorized administrator of The Research Repository @ WVU. For more information, please contact researchrepository@mail.wvu.edu. 
Analysis of Concussion Management Policies and Procedures among Athletic Trainers in the Four Divisions of NCAA Collegiate Football

James D. Dorneman Jr., BS, ATC

Thesis submitted to the College of Physical Activity and Sport Sciences

At West Virginia University

In partial fulfillment of the requirements

for the degree of

Master of Science

in

Athletic Training

Michelle A. Sandrey, Ph.D, ATC, Chair

Lynn Housner, Ph.D.

Ben Moorehead, MD

Elizabeth Bunn, MEd, ATC

Division of Sport Sciences

Morgantown, WV

2010

Key Words: Concussion, Football, Management, Concussion Testing 


\begin{abstract}
Analysis of Concussion Management Policies and Procedures among Athletic Trainers in the Four Divisions of NCAA Collegiate Football
\end{abstract}

\author{
James D. Dorneman Jr., BS, ATC
}

Context: Cerebral concussions are a common injury in the sport of football. To evaluate, manage, and make return to play decisions for concussions, the sports medicine community has access to various protocols. These various protocols recommend a multifaceted approach to accurately diagnose and treat athletes with concussions, but it is questioned whether this occurs. Objective: To investigate current trends of head football certified athletic trainers in concussion evaluation, management, and return-to-play. The secondary purpose of this study was to examine head football athletic trainers use of the NATA position statement as it pertains to evaluation, management, and return-to-play. Design: This study was a prospective descriptive analysis, which identified the current trends in concussion evaluation, management, and return-to-play. Setting: National Collegiate Athletic Association Division I, II, III, and Sub-Division institutions. Patient and Participants: The study included the head football athletic trainers at 120 Division I, 116 Sub-Division, 148 Division II, and 240 Division III institutions for a total of 624. There were 197 athletic trainers returned the survey which accounts for a $32.6 \%$ return rate. This was a sample of convenience by including every NCAA institution in each Division that had a varsity football program. The participants were included because of their exposure to concussions. The subjects that were excluded were certified athletic trainers that were not head football athletic trainers for their institution. Intervention: Survey questions addressed topics including demographics, years of certification, number of concussions evaluated each year, methods of assessing concussions, management, and return-to-play. It also examined athletic trainers compliance with the NATA position statement on concussions. The subjects were contacted via e-mail. The e-mail directed the participants to the Survey Monkey website where they completed the electronic survey. The participants were again contacted two weeks later with a follow-up e-mail. Main Outcome Measures: Based on the responses there will be differences between all four divisions in regard to evaluation, management, and return to play decisions. There will also be a difference between athletic trainers who have been certified longer then ten years when compared to athletic trainers that have less then ten years of experience; as well as those with and without 10 years of experience as a head football athletic trainer. Results: Certified head football athletic trainers evaluated an average of $6.3 \pm 4.3$ concussions per year. To asses concussions, clinical examination (98\%), symptoms checklists (76\%), Standardized Assessment of Concussion (37\%), neuropsychological testing (57\%), and the Balance Error Scoring System (24\%) were used. The management of athletes consisted of rest, followed by neuropsychological testing. When deciding to return an athlete to play, certified athletic trainers most often used the clinical examination (98\%), symptom checklists (61\%), and player selfreport (40\%). Eighty-five percent of head football certified athletic trainers surveyed reported complying with the NATA position statement. Chi-Square results indicated that there was a significant difference between the divisions of NCAA collegiate football. Baseline testing and severity grading were shown to be significantly different between the four divisions with Division II having significantly lower rates of baseline testing and grading. 
Conclusion: Based on the results of the survey, head certified football athletic trainers are using most of the NATA recommended concussion guidelines. However, they are not following the recommendations of a Balance Error Scoring system and symptom checklists for return-to-play of an athlete following a concussion. 


\section{ACKNOWLEDGEMENTS}

To my mom, for all the love and support she has given me through my entire life. Without you I would not have become the man I am today.

I would like to thank Mike "Magic" Macejko for introducing me to the profession of athletic training.

I would like to thank Greg Janik for all his guidance and support he gave me during my time at King's College. Your passion for the profession inspired me to do my best everyday.

I would like to thank Carissa Knouse for all her guidance and wisdom she passed on to me while at King's College.

I would like to thank Dr. Sandrey for the opportunity she gave me to be a part of the West Virginia University Graduate Athletic Training Program and for all her help during my two years here.

I would like to thank Dr. Moorehead and Liz Bunn for being part of my committee, donating their time, and providing guidance through this research process.

I would like to thank Kevin Kotsko for all the guidance he has given me while at West Virginia University.

Finally, I would like to thank all of the athletes and coaches on the West Virginia University Men's Soccer and Swimming \& Diving teams. You have definitely made these past two years an interesting experience. 


\section{TABLE OF CONTENTS}

\section{Page}

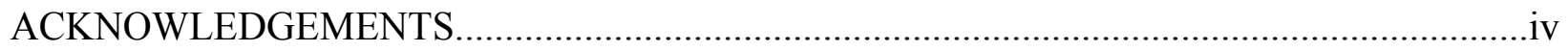

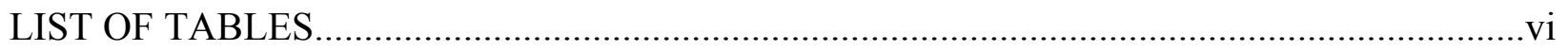

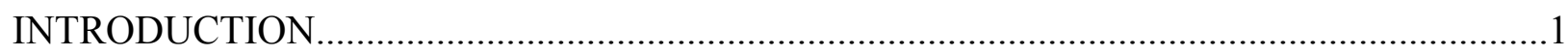

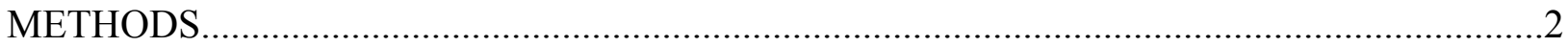

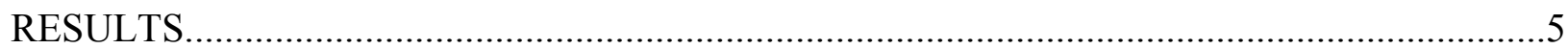

DISCUSSION

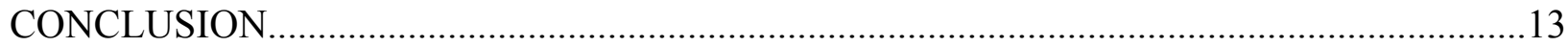

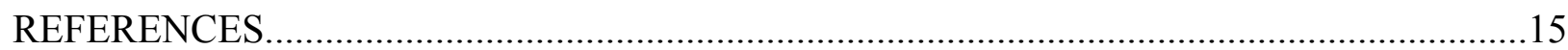

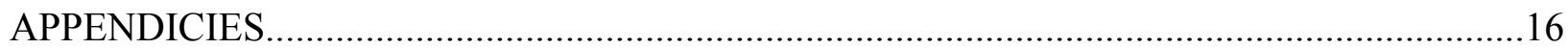

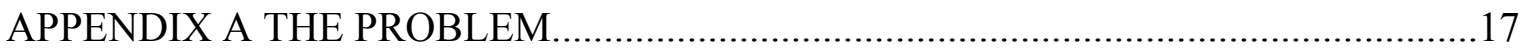

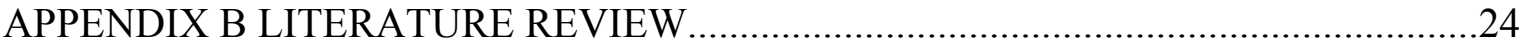

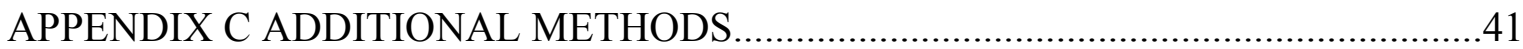

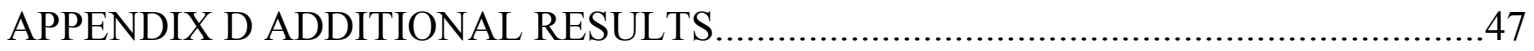

APPENDIX E RECOMMENDATIONS FOR FUTURE RESEARCH..............................90

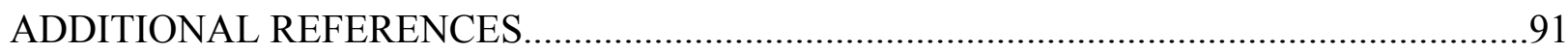




\section{LIST OF TABLES}

Table Page

C1. Initial E-mail to Recipients............................................. 41

C2. Follow-up E-mail to Recipients............................................42

C3. Survey.............................................................. 43

D1. Demographic by Division................................................47

D2. Demographic by Years Certified Athletic Trainer.................................48

D3. Demographic by Years Head Football Athletic Trainer................................49

D4. Evaluation by Division.................................................... 50

D5. Evaluation by Years Certified Athletic Trainer.....................................52

D6. Evaluation by Years Head Football Athletic Trainer................................54

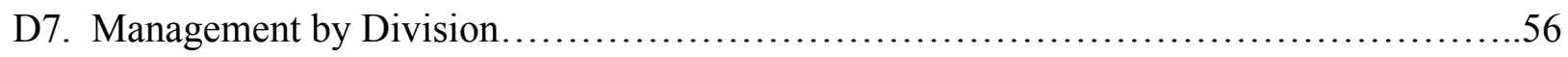

D8. Management by Years Certified Athletic Trainer................................59

D9. Management by Years Head Football Athletic Trainer...............................61

D10. Return-To-Play by Division............................................63

D11. Return-To-Play by Years Certified Athletic Trainer..............................65

D12. Return-To-Play by Years Head Football Athletic Trainer...........................67

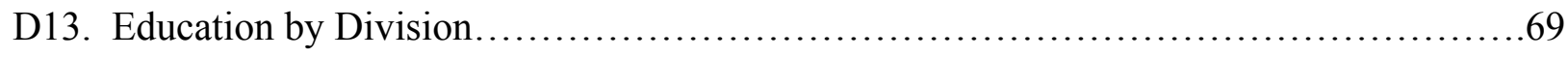

D14. Education by Years Certified Athletic Trainer................................... 71

D15. Education by Years Head Football Athletic Trainer................................73

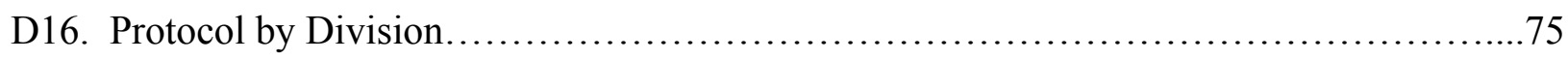

D17. Protocol by Years Certified Athletic Trainer................................... 77

D18. Protocol by Years Head Football Athletic Trainer.................................79 
D19. Grading of Concussions by Division..................................................

D20. Grading of Concussions by Years Certified Athletic Trainer..........................82

D21. Grading of Concussions by Years Head Football Athletic Trainer.........................83

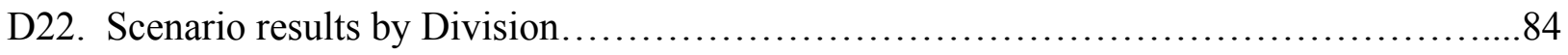

D23. Scenario results by Years Certified Athletic Trainer................................... 85

D24. Scenario results by Years Head Football Athletic Trainer..................................86

D25. Chi-Square results by Years Certified ATC \& Years Head Football ATC ...................87

D26. Chi-Square results by Division................................................. 88 


\section{INTRODUCTION}

Concussions are one of the most complex injuries a clinician will ever encounter. The term concussion is defined as a complex pathysiological process affecting the brain that is induced by traumatic biomechanical forces. ${ }^{1}$ The two most common forces are coup and contrecoup force. When these forces occur, the brain is violently thrust into motion and hits the skull. When the brain collides with the skull many structures such as brain cells and blood vessels are damaged. ${ }^{2}$ Concussions may present with a variety of signs and symptoms. The most common signs and symptoms are headaches, lightheadedness, dizziness, nausea, vomiting, fatigue, difficulty concentrating, amnesia, and anxiety. ${ }^{2,3,4}$ Concussions occur at a rate of about one million per year annually in the United States, with 300,000 of those being sport-related. ${ }^{1,5,6,7,8,9}$ It is estimated that 250,000 concussions occur annually in football alone. ${ }^{9}$

The concern with the complexity of concussion is that athletic trainers are not correctly identifying and managing these injuries. The number of management strategies and return-toplay protocols athletic trainers can utilize to make these decisions further complicates the management of concussions. The National Athletic Trainers Association position statement regarding concussions is one of many criteria the sports medicine team can consult when choosing a return-to-play protocol. The protocol details a multifaceted approach, which includes: neuropsychological testing, Balance Error Scoring System, clinical examination, and symptom checklists. There have been very few studies that have focused on the management of concussions following the NATA position statement. Only three studies ${ }^{10-12}$ have been conducted to determine whether certified athletic trainers are following the NATA position statement. Ferrara $^{10}$ stated that clinical examination (33\%) and symptom checklists (15\%) were the most common evaluative tools used to assess concussions in 1999. A study conducted five years later 
by Notebaert \& Guskiewicz ${ }^{11}$ concluded that athletic trainers utilized clinical examination (95\%), symptom checklists (85\%), Standardized Assessment of Concussion (48\%), and neuropsychological testing $(18 \%)$ as the four most common tools to evaluate a concussion. The

latest study on the topic of concussion management was conducted in 2009 by Covassin et al. ${ }^{12}$ This study concluded the four most common tools for concussion management were clinical examination (91\%), symptom checklists (78\%), concussion grading scales $(55 \%)$, and Standardized Assessment of Concussion (54\%).

Given these previous results, and the fact that head football athletic trainers have not been studied, the purpose of this investigation is to identify current concussion management techniques being utilized. Specifically, the focus of this research will investigate the differences in concussion evaluation, management, and return-to-lay procedures among head football athletic trainers in the four divisions of collegiate athletics. It will also examine the role experience plays in the decision making process. As well as whether head football athletic trainers are following the NATA position statement.

\section{METHODS}

Design

The design of this study was a descriptive analysis to identify whether certified athletic trainers from NCAA Division I, II, III, and sub-division football institutions are following the NATA position statement on concussion management. The analysis examined the independent variables of a 51-question survey consisting of evaluation, management, and return-to-play. The dependent variable was the responses from the head certified football athletic trainers completing the survey. 


\section{Participants}

The participants were 120 NCAA Division I, 148 II, 240 III, and 116 Subdivision head certified athletic trainers. A total of 624 NCAA institutions were surveyed, with 197 responding for a return rate of $32.6 \%$. Sampling the total number of NCAA institutions with football programs eliminated sampling bias and assured an equal numbers of schools are represented. Selection of the participants began by starting with the NCAA website so as to be directed to the official athletic website of each institution. From those websites, names and email addresses of head certified athletic trainers were determined. Participants were excluded if they were not the head certified football athletic trainer at a Division I, II, III, or sub-division NCAA institution. Instrumentation

The concussion management survey consisted of 51-questions including evaluation, management, and return-to-play. The survey was developed from the NATA position statement, previous surveys, team physicians, and athletic trainers at a Division I and Division III institutions. The survey demographic information included: division, years of experience, number of athletes on the football team, and number of concussions per year. The survey then asked participants to identify the concussion tools and procedures they currently utilize. The questions targeted the head football athletic trainers evaluation, management, and return-to-play procedures following an athletic concussion. There were 49 multiple-choice questions, and two short answer questions.

Two certified athletic trainers from NCAA Division I, and two certified athletic trainers from Division III reviewed the survey for clarity. A psychometric statistical expert experienced in questionnaire/survey writing also viewed the survey for face and content validity. There were no additional changes made to the questionnaire upon review. 
Procedures

The head certified athletic trainers from NCAA Division I, Division II, Division III, and SubDivision institutions were chosen from the NCAA website and the institutions official athletic website. All institutions with a football program were utilized to eliminate sampling bias for a total of 624 NCAA institutions; 120 NCAA Division I, 148 II, 240 III, and 116 from SubDivision.

The link to the survey was sent via e-mail to the head certified football athletic trainers through Survey Monkey. The e-mail consisted of a cover letter explaining their rights as a participant and what the head certified athletic trainer should do if willing to volunteer. Each of the head certified athletic trainers were asked to visit a website where the survey was located. If willing to participate, the head athletic trainer answered the survey questions and clicked submit when finished. If the head football athletic trainer was not willing to participate, he/she simply did not return the survey to the researchers. The certified head football athletic trainers were again contacted within two weeks to participate in the study. The survey was e-mailed once in January and then two weeks following.

The only instrument was a survey that was sent via email to the head certified football athletic trainers. The online survey was housed on the Survey Monkey server, which employs multiple firewalls and intrusion prevention technology. These security measures make sure that the information is protected from outside observation. All participants were kept anonymous. The researcher was the only person to have access to the results.

Data Analysis

For data analysis, the concussion management survey assessed evaluation, management, 
referral, and return-to-play procedures. The survey responses of head certified football athletic trainers from Division I, II, III, and Sub-Division institutions were compared to the NATA position statement to evaluate the compliance of the screenings. Data was grouped by evaluation, management, referral, and return-to-play. The data was compared by division, years of experience as a certified athletic trainer, and years of experience as a head football athletic trainer.

Statistical Analysis

Data from the surveys was collected and the answers from each question was evaluated using descriptive statistics. These descriptive statistics included: mean and standard deviation. The Chi-Square analysis was used to compare the frequency of NCAA Division I, II, III, and SubDivision institutions on there management, evaluation, referral, and return-to-play for concussions. Years of experience as a certified athletic trainer and as a certified head football athletic trainer were also compared using frequency of responses for evaluation, management, and return-to-play. The $\mathrm{P}$ values was $\mathrm{P}=0.05$. All data will be analyzed using SPSS Version 16.0 for Mac. (SPSS Inc. Chicago, IL.)

\section{RESULTS}

Demographic Information

A total of 197 head certified football athletic trainers completed the survey responding to concussion management policies and procedures for a return rate of $32.6 \%$. The numbers from each institution consisted of 48 (40\%) NCAA Division I, 21(18\%)Sub-Division, Division II 42(28\%), and Division III 86(36\%). Of the 197, 154 (78.2\%) were male and $43(21.8 \%)$ were female. The majority of the athletic trainers surveyed had greater than ten years of experience as a certified athletic trainer; $147(74.6 \%)$ were certified ten years or more compared to $50(25.5 \%)$ 
who were certified less than ten years. However, the majority of these athlete trainers have less than ten years of experience as the head football athletic trainer with 105 (53.3\%) having less than ten years, and $92(46.7 \%)$ having greater than ten years experience. The age of these certified athletic trainers was $40 \pm 9.44$. The average number of student athlete's on an NCAA football team was $102 \pm 24.98$. Refer to Tables D1, D2, and D3 for additional results.

Evaluation

Question seventeen was a single response question in which athletic trainers chose one method to make a return to play decision. The top four responses are as follows: clinical examination $(n=46,25.0 \%)$, physician recommendations $(n=42,22.8 \%)$, physical exertion protocol $(n=36,19.6 \%)$, and Neuropsychological testing computer based $(n=25,13.6 \%)$. Question twenty-two referred to how long after an initial evaluation athletic trainers perform a follow-up evaluation. The majority of athletic trainers across the divisions selected 24 hours $(n=107,58.5 \%)$, followed by 12 hours $(n=29,15.8 \%)$, and 1 -hour $(n=18,9.8 \%)$. Refer to Tables D4, D5, and D6 for additional results.

Management

The importance of performing baseline testing on athletes prior to the beginning of pre-season was asked in question fifteen. Of the responses, $(n=135,72.2 \%)$ performed baseline testing on athletes for subsequent use in post-concussion evaluations. By division the responses of athletic trainers performing baseline testing were as follows: Division $\mathrm{I}(\mathrm{n}=39,84.4 \%)$, Sub-Division $(\mathrm{n}=$ 14,70.0\%), Division II ( $\mathrm{n}=23,56.1 \%)$, and Division III $(\mathrm{n}=59,73.8 \%)$. Question twenty-seven evaluated how fast athletes are progressed through a concussion protocol. Across all four divisions the most common response was 24 -hours $(n=119,66.9 \%)$, followed by other $(n=30$, $16.9 \%)$. Question thirty evaluated the effectiveness of education on athletes and coaches about 
the severity of concussions and the signs and symptoms associated with the injury with 173 (94\%) reporting educating athletes and coaches on the topic, while $(n=11,6.0 \%)$ did not. Refer to Tables D7, D8, and D9 for additional results.

\section{Return-To-Play}

Question twenty-five referred to whether athletic trainers were following the NATA position statement regarding return-to-play. Of the responses $(n=153,85.0 \%)$ utilized the NATA position statement, with the following division responding: Division $\mathrm{I}(\mathrm{n}=38,84.4 \%)$, Sub-division $(\mathrm{n}=$ 17, 89.5\%), Division II ( $\mathrm{n}=29,78.4 \%)$, Division III $(n=69,87.3 \%)$. Question thirty-eight assessed the average length of time off before returning to full competition. The most common response was seven days followed by four to six days. Refer to Tables D10, D11, and D12 for additional results.

Scenarios

The results from the four scenario questions show that athletic trainers across all four divisions are conservative with their management and return-to-play of athletes following a concussion. The first scenario asked athletic trainers if they would return an athlete to competition one day following the injury if the athlete was asymptomatic and all assessment tests were normal. Eighty-three percent of the athletic trainers surveyed reported they would not return the athlete to competition. Scenario two asked the athletic trainers if they would return an athlete to competition that was still symptomatic. Ninety-nine percent of the athletic trainers responded no. The third scenario asked the athletic trainer to choose between a fast track and conservative approach to return-to-play. Seventy-two percent selected a conservative approach while $28 \%$ chose fast track. The fourth and final scenario asked what they would do if an athlete who just completed their concussion protocol was now complaining of a headache again. 
The most common response to this question was to consult the team physician (36\%), followed by conduct a quick concussion assessment (35\%). These responses demonstrate that athletic trainers are taking a more conservative approach to their management and return-to-play of athletes following a concussion. Refer to Tables D22, D23, and D24 for additional results.

\section{Chi-Square}

Results from the Chi-Square contingency table indicated that there was no significant difference between the four divisions of NCAA collegiate football on evaluation, management, and return-to-play decisions in regards to concussions. However, there were three questions that did show significant difference. Baseline testing and severity grading was shown to be significantly different between the four divisions with Division II having significantly lower rates of baseline testing. From the data presented in this study Division II is not utilizing the most current recommendations in regards to concussion management and grading scales.

There was a significant difference in the number of preseason baseline testing between the four divisions for question fifteen. The differences were between Division I and Division II $\left(\chi^{2}=\right.$ 8.71, $\mathrm{CC}=.302, \mathrm{P}=.003)$. A difference was also observed between Division II and Division III $\left(\chi^{2}\right.$ $=3.87, \mathrm{CC}=.179, \mathrm{P}=.049$ ). From these results Division II is not utilizing baseline testing as much as the other three divisions.

For question forty-one there was a significant difference between the divisions on severity of concussions. Between Division I and Division II there was a significant difference on the grading of concussions $\left(\chi^{2}=3.88, \mathrm{CC}=.219, \mathrm{P}=0.49\right)$. A significant difference was also observed between Division II and Division III $\left(\chi^{2}=4.67, \mathrm{CC}=.202, \mathrm{P}=0.31\right)$. Division II athletic trainers are attempting to grade the severity of the concussion while the athlete is still experiencing symptoms. Refer to Table D24 for additional Results. 
The final significant difference was between the years of experience as a head football athletic trainer on the topic of loss of consciousness and amnesia $\left(\chi^{2}=3.92, \mathrm{P}=.048, \mathrm{CC}=.145\right)$. Athletic trainers who have been head football athletic trainers for more than 10 years are utilizing loss of consciousness and amnesia as grading factors more than athletic trainers that have been head football athletic trainers for less than 10 years. Refer to Table D25 for additional results.

\section{DISCUSSION}

This is the first study to identify current concussion management techniques being utilized by head certified football athletic trainers at all four NCAA collegiate divisions. Other studies ${ }^{10-}$ ${ }^{12}$ have been conducted in the past using certified athletic trainers, but none of those studies specifically evaluated certified football athletic trainers at all NCAA divisions. Based on the results of the survey, head certified football athletic trainers are using most of the NATA recommended concussion guidelines. Athletic trainers are following the recommendations of a multifaceted approach for assessment and return-to-play of an athlete following a concussion. On average the four NCAA divisions are utilizing $5 \pm 1$ tools for the assessment and return-to-play. These tools consist of neuropsychological testing, clinical examination, Standardized Assessment of Concussion, and physical exertion protocols. However, they are not following the NATA position recommendation of incorporating Balance Error Scoring System into the approach. Furthermore, head football athletic trainer at NCAA Division II institutions are not following the current recommendations in regard to concussion management and grading scales, using baseline testing, and attempting to grade the severity of concussions while the athlete is still experiencing symptoms. Lastly, head football athletic trainers with more then than tens years of experience are using loss of consciousness and amnesia as grading factors. Evaluation 
In 2005, Notebaert and Guskiewicz ${ }^{11}$ conducted a study to determine what certified athletic trainers used to evaluate a concussion. In their study clinical examination (95\%), symptoms checklists (85\%), and neuropsychological testing (15\%) were used. The study excluded physician recommendations and physical exertion protocols. In a recent study conducted in 2009 Covassin ${ }^{12}$ found similar results in which clinical evaluation was the most utilized method of evaluation, followed by symptom checklists and neuropsychological testing.

In the current study, more certified athletic trainer are using concussion assessment tools then was reported in the Notebaert and Guskiewicz ${ }^{11}$ study. More than $97 \%$ of certified athletic trainers used clinical examination, $76 \%$ used a symptom checklist, and $62 \%$ reported using neuropsychological testing. With the reported increases in the use of these methods and tools, it seems that ATCs are now in better position to assess and manage concussions. These results help to describe the current trends in concussion management with an increase in the use of the symptom checklist and neuropsychological tests then in the previous studies.

It was suspected that there would be a difference between athletic trainers of the four divisions of NCAA collegiate football on their evaluation, management, and return-to-play of athletes following a concussion. There was a significant difference between the divisions in regards to pre-season baseline testing for use in follow-up evaluations. Baseline testing was shown to be significantly different between the four divisions with Division II having significantly lower rates of baseline testing. This may be a result of a lack of resources at the Division II level. Furthermore, Division II head football athletic trainers are attempting to grade the severity of a concussion while the athlete is still experiencing symptoms.

It was suspected that there would be a difference between athletic trainers with greater then 10 years of experience when compared to athletic trainers with less then 10 years of experience 
as a certified athletic trainer. Based on the subject population, there is little to no correlation with years of experience. This may be due to increased continuing education of the more experienced athletic trainers on current concussion protocols as obtained through workshops, journal articles, and other continuing education opportunities.

Neuropsychological assessment is recommended for athletes before participation and in guiding athletes return-to-play. The percentages of athletic trainers utilizing computer based neuropsychological testing have increased in the past five years since the Notebaert ${ }^{11}$ study was completed. In 2005 only $18 \%$ of athletic trainers surveyed reported using neuropsychological testing. The data from the current study shows that more then $57 \%$ of athletic trainers are utilizing neuropsychological testing to aid in management of concussions. Covassin ${ }^{14}$ conducted another study in 2009 on the use of ImPACT testing. That study identified several problems with the use of ImPact testing including: poor motivational efforts by the athletes, misinterpretation of instructions, and sports medicine professionals cannot accurately interpret neurogconitive status after a concussion. Another limitation to computerized neuropsychological testing is computer availability and the number of athletes that can be evaluated in a limited amount of time. For this reason it is not practical for many institutions. The percentages of use decreased from $92 \%$ at Division I institutions to a $74 \%$ average among the other three divisions.

Return-To-Play

There is no current consensus for any single preferred concussion return-to-play guidelines. Most concussion guidelines rely on loss of consciousness and amnesia to help grade the severity of a concussion. However, loss of consciousness and amnesia are seen in relatively few cases of concussions..$^{10,11,12,13}$ With that in mind, it was felt that use of concussion guidelines, other then the NATA position statement, have decreased in the years since 2005 with the Notebaert and 
Guskiewicz $^{11}$ study was published. From this study $84 \%$ reported using the NATA position statement, $40 \%$ used Cantu guidelines, 32\% used Zurich 2008 guidelines, 31\% used American Academy of Neurology guidelines, and 13\% reported using the Colorado guidelines. In fact, head football athletic trainers with 10 years or more experience are using loss of consciousness and amnesia as grading factors. A multifaceted approach is advocated and despite the variability, on average the four NCAA divisions are utilizing $5 \pm 1$ concussion assessment tools for return-toplay.

\section{NATA Position Statement}

The NATA position statement on concussion management recommends that all athletes, especially those playing sports with high concussion risks, be baseline tested before participation. ${ }^{13,14}$ These baseline tests should include cognitive and postural stability sections. The NATA recommends the use of a symptom checklist, neuropsychological testing, and the BESS for concussion assessment or return-to-play decisions. Of the athletic trainers surveyed, $72 \%$ reported performing baseline testing, $80 \%$ reported utilizing some sort of neuropsychological testing, 23\% used symptom checklists, and 23\% reported using BESS. However, when the participants were later asked if the followed NATA position statement $85 \%$ responded yes. The majority of the athletic trainers who responded to the scenario questions were compliant with the standards set forth by the NATA position statement. However, this is clearly not true since only $23 \%$ of them report utilizing symptom checklists and BESS before returning an athlete to competition. Increased awareness and knowledge of new concussion assessment methods and tools has improved the identification and management of concussions in the clinical setting. Although concussion experts disagree on a standardized assessment and management method for concussion, they do agree that a symptomatic athlete should not be 
allowed to return to participation. ${ }^{12}$

\section{Limitations}

The study was not without certain limitations inherent to survey research. This survey had a $32.6 \%$ response rate. In addition not all divisions were represented equally: Division I 48(40\%), Sub-Division 21(18\%), Division II 42(28\%), and Division III 86(36\%). One possible explanation for this low response rate may be that some head football athletic trainers did not wish to complete the survey. Another potential limitation was that some of the surveys were not fully completed. Information on any question submitted was used. This led to a variation in the number of responses used in analysis. Another limitation was the exclusive use of NCAA head football athletic trainers. This population was selected because of the prevalence of concussions in football. However, limiting the population in this manner and a low return rate for all four divisions may have a negative effect on the generalizability of this study.

\section{CONCLUSION}

In conclusion, recent research publications, continuing education efforts, and increased attention to sports-related concussion appear to have had a small but significant impact on the clinical practice of head football athletic trainers in the evaluation, management, and return-toplay of athletes following a concussion. On average the four NCAA divisions are utilizing $5 \pm 1$ tools for the assessment and return-to-play. These tools consist of neuropsychological testing, clinical examination, Standardized Assessment of Concussion, and physical exertion protocols. However, they are not following the NATA position recommendation of incorporating Balance Error Scoring System into the approach. Based on the responses in this study, head football athletic trainers are selectively following the NATA position statement in regards to evaluation, 
management, and return-to-play. Clinicians need to incorporate a multifaceted approach to concussion evaluation, management, and return-to-play decisions. This method will allow athletic trainers to ensure a safe return-to-play for their athletes. 


\section{REFERENCES}

1. McCrory P, Johnston K, Meeuwisse W, Aubry M, Cantu R, Dvorak J, M Mollory. Summary and agreement statement of the $3^{\text {rd }}$ International Conference on Concussion in Sport, Zurich 2008. British Journal of Sports Medicine. 2008;39:196-204.

2. Adirim TA. Concussions in sport and recreation. Clin Ped Emerg Med. 2007;8:2-6.

3. Heegaard W, Biros M. Traumatic brain injury. Emerg Med Clin N Am. 2007;25:655-678.

4. Giza CC, Hovda DA. The neurometabolic cascade of concussion. J Athl Train. 2001;36(3):228-235.

5. Thurman D, Guerrero J. Trends in hospitalization associated with traumatic brain injury. JAMA. 1999;282(10):954-957.

6. Oliaro S, Anderson S, Hooker D. Management of cerebral concussion in sports: the athletic trainer's perspective. J Athl Train. 2001;36(3):257-262.

7. Gessel LM, Fields SK, Collins CL, Dick RW, Comstock RD. Concussions among united states high school and collegiate athletes. J Athl Train. 2007;42:495-503.

8. Majerske CW, Mihalik JP, Ren D, Collins MW, Reddy CC, Lovell MR, Wagner AK. Concussion in sports: postconcussive activity levels, symptoms, and neurocognitive performance. J Athl Train. 2008;43(3):265-274.

9. McKeever C, Schatz P. Current Issues in the Identification, Assessment, and Management of Concussion in Sports-Related Injuries. Stereotact Funct Neurosurg. 2003; 1:4-11.

10. Ferrara M, $M_{c}$ Crea M, Peterson C, Guskiewicz K. A Survey of Practice Patterns in Concussion Assessment and Management. J Athl Train. 2001; 36:145-149.

11. Notebaert A, Guskiewicz K. Current Trends in Athletic Training Practice for Concussion Assessment and Management. J Athl Train. 2005; 40:320-325.

12. Covassin T, Elbin R, Ostrowski J. Current sport-related concussion teaching and clinical practices of sports medicine professionals. J Athl Train. 2009;44(4):400-404.

13. Guskiewicz K, Bruce S, Cantu R, Ferrara M, Kelly J, McCrea M, Putukian M, Tamara C, McLeod V. National Athletic Trainers' Association Position Statement: Management of Sports-Related Concussion. J Athl Train. 2004;39(3):280-297.

14. Covassin T, Elbin R, Kontos A. Immediate post-concussion assessment and cognitive testing (ImPACT) practices of sports medicine professionals. J Athl Train. 2009;44(6):639-644. 
APPENDICES 


\section{APPENDIX A}

\section{THE PROBLEM}

\section{Research Question}

Football is one of the most popular sports in America. It is estimated to have 1.2 million participants annually. ${ }^{10}$ Football is also associated with the highest number of direct catastrophic injuries for any sport reported to the National Center for Catastrophic Sports Injury Research. Traumatic brain injuries, or concussions, are common in contact sports such as football. It is estimated that 250,000 concussions occur every year in football alone. ${ }^{2,11}$ Studies from the 1970s report annual concussion incidence rates in football to be as high as $15 \%$ to $20 \%$ of all players in a season. By the 1980 s the reported incidence rate of concussions had fallen to $10 \%$. More recent studies involving collegiate players have reported even lower injury rates $(4.8 \% \text { and } 4.0 \%)^{12,13}$

Essentially, there is no universal agreement on the definition of concussion. The historical definition refers to the Latin origin, concutere, meaning "agitation or shaking" of the brain. ${ }^{11}$ The American Medical Association and the Committee of Head Injury Nomenclature of the Congress of Neurological Surgeons defined concussion as a clinical syndrome characterized by immediate and transient posttrumatic impairment of neurological function due to brainstem involvement. ${ }^{10}$ The American Academy of Neurology defines concussions as an altered mental state that may or may not include loss of consciousness. ${ }^{10}$ The third international conference on concussion, in sport, held in Zurich defines concussion as a complex pathophysiological process affecting the brain, induced by traumatic biomechanical forces. ${ }^{1}$

Concussions are one of the most complex injuries a clinician will ever encounter. The management of this injury is further complicated by the lack of a consensus guideline for returnto-play. The National Athletic Trainers Association position statement regarding concussions is 
one of many documents the sports medicine team can consult when choosing a return-to-play guideline. This lack of cohesiveness allows for a physician or clinician's personal preference to play a role in the management of a concussed athlete. Personal preference should be limited as it may influence a clinician to choose a protocol that is out-of-date or inaccurate.

For many years, the focus of concussion research revolved around the diagnosis and assessment segments. This has left a major gap in the literature on the management of a concussed athlete. It has been argued for years that the medical community needs a set of universal or standardized guidelines for an athlete's return-to-play following a concussion or mild traumatic brain injury.

In recent years, there has been considerable change in the way athletic trainers diagnose and manage concussions. The identification of second impact syndrome and post concussion symptoms in adolescent athletes has lead many researchers to further investigate how athletic trainers and team physicians diagnose and manage concussions in this age group and an older population. This has lead to the publication of several position statements on this topic. $^{1,13}$

A consensus statement on concussions in sport was first introduced in Vienna in 2001. It has been updated several times, the most recent update being in Zurich in November 2008. The statement was the first piece of literature published that dealt with all aspects of concussion management, and provided return to play criteria. It gave physicians a reference point for most clinical decisions regarding assessment, management, and return-to-play. ${ }^{1}$

In 2004, the National Athletic Trainers Association published a position statement on concussions that was designed specifically for athletic trainers. ${ }^{13}$ This position statement informed all athletic trainers about their role in the assessment and management of 
concussions. All aspects of concussion management were discussed from the evaluation to return-to-play, by providing clinical guidelines.

After the publication of the NATA position statement, several studies followed to determine protocol certified athletic trainers are using for concussion assessment and whether the NATA guidelines are being followed. These later studies were based on an earlier publication by Ferrara et $\mathrm{al}^{10}$ in 2001.The study was conducted to identify methods used by athletic trainers to assess concussions and the use of that information to assist in return-to-play decision using the NATA standardized methods of concussion assessment. The researches constructed a 21-item questionnaire and distributed it to approximately 900 attendees of a mini-course at the 1999 NATA Annual Meeting and Clinical Symposia. The attendees returned 339 completed surveys.

The study concluded that athletic trainers were using a variety of tools to evaluate concussions in athletes. Clinical evaluation and physician recommendations still appear to be the primary methods used for return-to-play. However, there is an increase of athletic trainers using standardized methods of concussion to evaluate these injuries and assess when an athlete can safely return-to-play.

In 2005 Notebaert and Guskiewicz ${ }^{11}$ conducted a follow-up of the Ferrara ${ }^{10}$ study using 2750 certified athletic trainers that were randomly selected from the National Athletic Trainers Association. This time the participants were asked to fill out a 32-item survey on concussion assessment and management. This research concluded that only a small percentage of certified athletic trainers were following the guidelines proposed by the NATA. ${ }^{13}$

$\operatorname{Covassin}^{12}$ conducted a similar study in 2009 , but used a different subject population. The purpose of that study was to identify concussion management methods and guidelines currently taught in the classroom and clinical setting of CAATE accredited undergraduate athletic training 
programs. The study concluded that the NATA position statement was the most widely used method being taught for assessing, managing, and making return-to-play decisions for athletes following a concussion. The second most widely used protocol being taught was the Vienna guidelines. The study was conducted using program directors and certified athletic trainers who held an educational position in an accredited program. ${ }^{12}$

These previous studies have been able to provide vital information to athletic trainers on the assessment, management, and return-to-play of athletes following a concussion. However, despite an increase in the number of athletic trainers relying on evidence based concussion assessment, some are still solely relying on best clinical practice and possibly still using outdated assessment techniques. The question still remains as to what athletic trainer are using, especially football athletic trainers, as this is where a majority of concussions occur. Therefore, are NCAA

Division I, II, III, and subdivision certified athletic trainers using current position statements for concussion evaluation, management, and return to play?

Therefore, the following research questions can be asked:

1. Do NCAA Division I, II, III, and Sub-division athletic trainers have a concussion management protocol in place?

2. Do NCAA Division I, II, III, and Sub-division athletic trainers follow the recommendations set forth by the National Athletic Trainers Association?

3. Have NCAA Division I, II, III, and Sub-division athletic trainers changed their concussion management strategies since 2005 to be more compliant with the NATA position statement.

Experimental Hypotheses

1. Based on responses there will be a difference between all 4 divisions in regard to evaluation, management, and return-to-play decisions.

2. There will be a difference between those certified athletic trainers that have been 10 years or more years of football experience compared to those certified athletic trainers with 10 years or less of football experience on evaluation, management, referral, and return-to-play. 
3. There will be a difference between those athletic trainers that have been certified 10 years or more compared to those certified 10 years or less on evaluation, management, referral, and return-to-play.

4. Certified athletic trainers from all NCAA Divisions are following the National Athletic Trainers Association position statement on concussion management.

Assumptions

1. The participants in this study will respond honestly to the questions in the survey.

2. The participants in this study will respond to the questions to the best of their ability.

3. The survey will be valid and reliable.

4. The survey will adequately represent the National Athletic Trainers Position statement on management of concussions.

Delimitations

1. The study was conducted from a population of NCAA Division I, II, III and sub-division head football athletic trainers.

2. The subjects were the head athletic trainers for their institutions football team.

3. The data may not be generalized to NAIA football programs on the collegiate level.

4. The data may not be generalized to any other sport, NCAA or NAIA.

Operational Definitions

1. Amnesia - The loss of or impairment of memory. ${ }^{15,16}$

Anterograde- Loss of memory of events occurring after the injury.

Retrograde- Loss of memory of events occurring prior to the injury.

2. Balance Error scoring System (BESS) - Concussion assessment tool designed to test the athletes balance and postural stability. ${ }^{17,18,19}$

3. Baseline Testing $-\mathrm{A}$ starting point that serves as a basis for comparison ${ }^{20}$

4. Central Nervous System - The part of the nervous system consisting of the brain and spinal cord. ${ }^{19,20,21}$

5. Contrecoup - Lesion within the skull opposite to the side in which the blow occurred. ${ }^{19,20,21}$ 
6. Coup - An injury that occurs when a relatively stationary skull is hit by an object traveling at a high velocity. This type of injury results in trauma on the side of the head that was struck. 19,21

7. ImPact - Immediate Post-concussion Assessment and Cognitive Testing. Computer based neuropsychological test. ${ }^{23}$

8. Nausea - A sick feeling characterized by the need to vomit. ${ }^{19,20,21}$

9. Nystagmus- Involuntary lateral movement of the eyes. ${ }^{19,21}$

10. Peripheral Nervous System (PNS)- The nervous system outside of the central nervous system, including the cranial nerves, spinal nerves, and all of the roots. ${ }^{19,21}$

11. Photophobia- Oversensitivity of the eyes to light. ${ }^{19,20,21}$

12. PEARL - Pupils equal and reactive to light. ${ }^{19,20}$

13. Sports Concussion - A complex pathophysiologicl process affecting the brain, induced by traumatic biomechanical forces. ${ }^{1}$

14. Standardized Assessment of Concussion - Concussion assessment tool designed to test the athletes neuropsychological function and postural stability. ${ }^{16}$

15. Tinnitus- Ringing in the ears. ${ }^{19,21}$

Limitations

1. Participants may not fill out the survey completely.

2. Participants may respond by what they feel the investigator would like to hear.

3. The participants will be trusted not to complete the survey based on time constraints.

4. Selection of participants - an external validity threat based on the choice of participants.

5. Some E-mail address may be undeliverable based on the webpage not being current.

Significance of the Study

Football is an extremely popular sport with an immense risk of injury to the head and neck.

The retirement of many high-profile athletes as a result of repetitive concussions and

post-concussion symptoms has brought the severity of these injuries to the forefront of the sports 
world.

The significance of this study is to examine how football athletic trainers from different divisions manage a concussed athlete from the point of medical diagnosis by a physician or athletic trainer. From past research on this topic, few athletic trainers have followed suggested NATA guidelines. This study is very important to athletic training because it will provide new insight as to how athletic trainers from different divisions, and levels of experience evaluate and manage concussions. It will also serve as a reference point for athletic trainers as they continue to search for a set of universal guidelines. This information can then be disseminated to medical professionals through conferences, workshops, presentations, or medical journals. 


\section{APPENDIX B}

\section{LITERATURE REVIEW}

Introduction

The term "concussion" is defined as a complex pathophysiological process affecting the Brain that is induced by traumatic biomechanical forces. ${ }^{1}$ For years concussions have been considered a common injury in contact and collision sports. ${ }^{15}$ In fact, concussions comprise nine percent of the sports related injuries each year. ${ }^{9}$ It is estimated that $10 \%$ of all college football players will sustain a concussion each year; that factors to an estimated 250,000 concussions annually. ${ }^{9}$ This increase in concussion prevalence and awareness can be partially attributed to the modern research being conducted. Between the years 1960 and 1969 , only five research studies were conducted. ${ }^{17}$ In the years since, the number of research studies has steadily grown by the decades. Between the years 2000 and 2004, 172 studies were conducted. ${ }^{17}$ With this information, athletic trainers now have many multifaceted protocols to use when determining return to play status. The emergence of these protocols and guidelines has been both beneficial and harmful to the athletic training profession. It has helped in the assessment of concussions, but many of the protocols differ in their management and return-toplay criteria. This lack of cohesiveness leaves room for interpretation as to which protocol to use leaving the burden of the decision on the team physician and the athletic trainer.

The mechanics of the injury can be a result of either a coup or contrecoup force that causes the brain to violently hit the skull, thereby causing damage to brain cells and blood vessels. ${ }^{2}$ Concussions often present with a variety of immediate and prolonged signs and symptoms. ${ }^{1}$ These signs and symptoms are categorized into three groups. The first group is cognitive function. Patients who present with amnesia, confusion, or loss of consciousness are believed to 
have cognitive imbalances. The second group includes physical signs. Common physical signs include balance problems, convulsions, slurred speech, and vomiting. ${ }^{1,16}$ These signs are generally an objective way to determine a concussion. The third group is subjective symptoms. These are symptoms the athlete tells the clinician they are experiencing. They include headache, nausea, double vision, and hearing problems. ${ }^{1,16}$ Evaluation of concussions needs to be a multifaceted approach. This approach should include a symptom checklist, neurpsychological testing, and balance testing. Neuropsychological testing includes: Standardized Assessment of Concussion (SAC), and ImPact. Balance testing is another component of concussion assessment. If the athlete is lacking balance or has symptoms with any of the balance testing it may mean the athletes injury is more significant then a concussion and they should be referred for further medical evaluation. Current literature states an athlete should be rested until asymptomatic for 24 hours. Following an asymptomatic 24 -hour period the athlete may begin easy exertional testing such as sit-up or push-ups. The athlete then rests for another 24-hour period. If still asymptomatic the athlete is allowed to run on a treadmill for predetermined amount of time, which is typically determined by the medical staff. Again, the athlete is rested for 24-hours following exertion. On day three if still asymptomatic the athlete can begin functional non-contact activities with the team. The medical staff then assesses the athlete on day four before he/she can begin contact activities. If the athlete suffers no set backs, they can returnto-play five days post concussion. The following literature review will give a detailed explanation of the anatomy, pathophysiology, biomechanics, epidemiology, evaluation, neuropsychological testing, management, and return-to-play associated with concussions. Anatomy of the Brain/Skull

Bony anatomy: The cranium is the skeleton of the head. The design of the cranium allows for 
maximum protection of the brain. ${ }^{21}$ The only opening is the Foramen Magnum, which is located at the base of the skull. This opening allows for the brain stem and spinal cord to pass into the brain. ${ }^{25}$ The cranium is divided into two areas, the neurocranium and viscerocranium. ${ }^{25,26}$ The neurocranium is the region of the skull that surrounds and encases the brain and sensory organs. It is composed of an inner and outer layer of bone that is separated by spongy tissue. The neurocranium has a roof, the calvaria, and a floor, the cranial base. The calvaria is the portion of the skull that overlies the brain, while the cranial base is the portion that underlies the brain. The calvaria is comprised of the parietal, frontal, temporal, and occipital. The base is formed by a combination of eight bones including the frontal, ethmoidal, sphenoidal, occipital, temporal (2), and parietal (2) ${ }^{21,25,26}$ In children and adolescents these bones are joined together by hyaline cartilage, as they mature into adulthood the hyaline cartilage becomes fused. This fusion forms strong fibrous sutures between the bones, and adds additional strength to the cranium. ${ }^{21,25}$

The viscerocranium is the region of the skull that makes up the bones of the face. It is comprised of 15 irregular facial bones. Three of these bones are singular bones, (mandible, ethmoid, and vomer), while the other six are bilateral pairs, (maxillae, inferior nasal conchae, zygomatic, palatine, nasal, and lacrimal bones). ${ }^{25}$ The visercranium also contains the only moving joint of the skull, the tempromandibular joint (TMJ), which is an articulation between the mandible and the maxillae.

Scalp: The scalp is composed of five layers, the first three of which are connected intimately and move as a single unit. ${ }^{25}$ The dermis is the outermost layer and is among the thickest layers of skin on the body. The underlying subcutaneous tissue contains the hair follicles and the rich blood supply of the scalp. The large blood vessels of the scalp do not fully constrict if they are lacerated and can be the source of significant blood loss. ${ }^{21,25}$ The middle scalp layer is the 
galea, which is made of tough fascial tissue. It contains the occipitofrontalis and temporoparietalis muscles, which move the scalp backward and forward, elevate the eyebrows, and wrinkle the forehead. Under the galea is a loose areolar tissue layer. Because the areolar attachments to the rest of the scalp are loose, scalp avulsions frequently occur through this layer. ${ }^{21,25}$ This is also the site for development of subgaleal hematomas, which can become quite large because blood easily dissects through the loose areolar tissue. The deepest layer of the scalp, the pericranium, is firmly adhered to the skull. The word "SCALP" serves as an acronym for the five layers of tissue: Skin, Connective tissue, Aponeurosis, Loose areolar tissue, and pericranium. These five layers of tissue add yet another dimension of strength to the cranium. $^{25}$

Brain: The brain is the primary component of the central nervous system (CNS). It occupies $80-85 \%$ of the intracerebral volume while the cerebrospinal fluid (CSF) occupies the rest of the space. ${ }^{21,25,26,27}$ The brain or encephalon is composed of four divisions: the cerebrum, cerebellum, diencephalon, and brainstem. The cerebrum, or cortex, has two hemispheres that are separated by a deep longitudinal fissure. The corpus callosum is a bundle of axons which connects these two hemispheres. ${ }^{21,25,28}$ The hemispheres of the cerebrum are each dividend into four lobes. The lobes of the cerebrum correspond to the flat bones of the cranium that surround them. They are the frontal, parietal, temporal, and occipital lobes. ${ }^{21,25,28}$ Each lobe is responsible for a highly specific neurobehaviour, and specific injury to each lobe can disrupt normal behavioral patterns. The frontal lobe is associated with reasoning, planning, parts of speech, movement, emotions and problem solving. The parietal lobe is associated with movement, orientation, recognition, and perception. The occipital lobe is associated with visual processing. The temporal lobe is associated with auditory stimuli, memory, and speech. ${ }^{25,26,27}$

The diencephalon is composed of the thalamus, and hypothalamus. Approximately $4 / 5$ of the diencephalon is made up of the thalamus. ${ }^{25,26,27}$ The thalamus is located above the hypothalamus and is composed primarily of dendrites and cell bodies of neurons that extend through axons to the cerebrum of the brain. The thalamus is responsible for the interpretation 
between the brain and the sensory receptors, with the exception of smell. ${ }^{25,26}$

The hypothalamus regulates body temperature, blood pressure, heartbeat, metabolism of fats and carbohydrates, and sugar levels in the blood. ${ }^{25,26}$ Through direct attachment to the pituitary gland, the hypothalamus controls secretions controlling water balance and milk production in the female. The hypothalamus also has a role in detecting pleasure and pain. It does so by sending impulses through axons to neurons located in the spinal cord, which in turn, relay the messages from muscles and glands throughout the body. ${ }^{25,26}$

The brainstem is divided into three sections: midbrain, pons, and the medulla oblongata. The pons controls sleep, posture, respiration, swallowing, and the bladder. ${ }^{19,25}$ The medulla oblongata is the lowest part of the brain stem and regulates heart rate, breathing, and blood pressure as well as coughing, sneezing, and vomiting. The midbrain is involved in functions such as vision, hearing, eye movement, and body movement. ${ }^{19,25}$

All motor information to and from the body passes through the brain stem on the way to or from the cerebellum and cerebrum. Like the frontal and temporal lobes, the brain stem is located in an area near bony protrusions making it vulnerable to damage during trauma. ${ }^{19,25}$

The cerebellum is the second largest mass of the brain. It lies inferior to the cerebrum, and posterior to the pons and medulla oblongata. The cerebellum is involved in the coordination of voluntary motor movement, balance and equilibrium and muscle tone. Cerebellar injury results in movements that are slow and uncoordinated. Individuals with cerebellar lesions tend to sway and stagger when walking. ${ }^{25}$

The ventricular system of the brain circulates cerebral spinal fluid (CSF) through two lateral ventricles and two midline ventricles. The lateral ventricles are the largest cavities of the system and occupy large areas of the cerebral hemispheres.

Meninges: The brain is covered by a strong, fluid-filled membrane called the meninges. The meninges consist of three layers including the dura mater, arachnoid mater, and the pia mater. ${ }^{25,26}$ 
The dura mater lines the inner table on the skull and is very inelastic. The strong dural layer has been described as a box. It protects the delicate structures within. The dura mater consits of 2 layers, the periosteal lining and the meningeal lining. Between these two layers are sinuses where CSF and venous blood drain into before exiting the skull. When the brain is violently shifted around the cranium as a result of a blow, it causes damage to the blood vessels. When these vessels are damaged, bleeding occurs within or around the brain causing pressure and damage to several areas of the brain. ${ }^{25,26}$

The middle layer of the meninges is called the arachnoid membrane. This is a thin, web-like structure that covers the brain and houses circulating CSF. The arachnoid is avascular in nature and is not attached to the dura mater, but instead is separated by a thin subdural space. It is held against the dura mater by the pressure of the CSF. The third and most inner layer of the meninges is the pia mater. It adhears to the brain and follows all of the gyri (folds) of the brain surface. Between each of the layers of the meninges are spaces or potential spaces. ${ }^{25,26}$

The meninges are predisposed to a variety of injuries. An epidural hematoma is an accumulation of blood between the dura and skull. The dura becomes detached and dissects to the point of dural attachment to the overlying cranium..$^{25,26,29}$ These injuries are usually caused by a head impact with acceleration/deceleration forces. This injury causes an inward pressure on the brain and leads to dural detachment and deformity. Patients who have sustained a blow to the head need to be monitored, because onset of symptoms may be delayed. A patient who initially appears to be asymptomatic may develop symptoms hours later, as a result of a slow accumulation of blood in the epidural space. ${ }^{25,26,29}$ The brain my remain asymptomatic until it reaches a critically large size and compresses the underlying tissue. The compression can be transmitted to the brain stem and rapidly progress to a brain herniation, and possible death.

Subdural hematomas are another form of intercranial hemorrhage. They can be divided up into two classifications; acute, which presents within 48-72 hours following injury, and chronic, which presents in a later time frame with more variable clinical manifestations. ${ }^{25,26,29}$ 
A chronic subdural hematoma is defined as a hematoma present 3 weeks or more after the initial injury occurred. ${ }^{29}$ Acute subdural hematoma is the most common major head injury and is associated with severe neurological disability and death. The hematoma results from bleeding within the subdural space as a result of stretching and tearing of subdural veins. These veins are responsible for draining the blood from the cerebral surface. Clinical presentation of patients with chronic or acute subdural hematomas may vary, but typically patients with this injury will have severe neurological deficits. ${ }^{25,26,29}$

Pathophysiology

Immediately after a cerebral concussion is sustained there is a complex cascade of ionic, metabolic, and physiologic changes that follows. ${ }^{30,31,32}$ First, there is a release of neurotransmitters and unchecked ionic fluxes occur. ${ }^{33}$ The binding of excitatory transmitters, such as glutamate, to N-methyl-D-aspartate receptor leads to further depolarization with an efflux of potassium and an influx of calcium. These shifts lead to acute changes in cellular physiology. In an effort to restore balance the sodium-potassium pump must work overtime..$^{30,31}$ The pump requires increasing amounts of adenosine triphosphate (ATP) to increase glucose metabolism. The jump in glucose metabolism triggers a cellular energy crisis. ${ }^{30,34}$ The cellular crisis is one mechanism for postconcussion syndrome and second impact syndrome, because the brain is less able to respond adequately to a second injury and leads to longer deficits following the initial injury.

Following the initial period of accelerated glucose utilization, the brain goes into a period of depressed metabolism. In this period calcium ions impair mitochondraial oxidative metabolism, which further depletes the energy stores. ${ }^{30,35}$ The unchecked calcium accumulation leads directly to cell death. Other important components include lactic acid build up, decreased intracellular magnesium, free radical production, inflammatory responses, and altered neurotransmission. ${ }^{30}$ 
The inflammatory response is a result of the release of glutamic acid. This acid is an excitatory amino acid which leads to the formation of free radicals, kinins and other products of the inflammatory response. ${ }^{32}$

Late events in the cascade include recovery of glucose metabolism and cerebral blood flow, delayed cell death, chronic alterations in neurotransmission, and axonal disconnection. ${ }^{35}$ Clinical signs and symptoms include impaired coordination, attention, memory, and cognition which are manifestations of underlying neuronal dysfunction secondary to the ionic, metabolic, and physiologic changes described above.

\section{Biomechanics}

Head injury is reported to account for up to $22 \%$ of all injuries in football, although this includes all severities of injury, and the injury mechanisms. With such a high incidence rate it is important for athletic trainers to understand the biomechanics behind concussions. The general biomechanical forces involved in the description and understanding of concussions are easily explained through Newton's laws of physics. ${ }^{36,37}$

A concussion begins with a mechanical force or load that sets the head and therefore brain in motion. The mechanical load occurs over milliseconds and causes the brain to move in ways that may be normal, but excessively accelerated or anatomically abnormal depending on the site and direction of the load. ${ }^{36,37,38}$ There are three types of loads that are discussed; impact, impulsive, and static. ${ }^{37,38}$

Impact loading occurs directly to the head and is generally high in magnitude and short in duration (less than 50 milliseconds). ${ }^{37,38}$ The stress that results from the impact causes a ripple effect through the brain. This can result in a quick acceleration and cause damage to the brain because the tissue will move and deform. Movement and deformation of tissue also occur, 
whether the loading happened when the brain was stationary or moving at the time of loading. Impact is usually associated with contact forces; deformation of the skull at a local or remote site is common. The acceleration that occurs is directly related to the force applied, as stated in Newton's second law (force $=$ acceleration X mass). ${ }^{37,38}$

Impulse loading occurs when another body region receives the impact, and the head moves as a result of that impact. ${ }^{37}$ The impact at the body segment causes an acceleration/deceleration phase at the head that occurs within 50 to $200 \mathrm{~ms}$. With this force the skull is set in motion, and the type of motion will determine the type of brain injury. A helmet does a poor job of protecting athletes from this type of force. ${ }^{37,38}$

Static loading occurs when compressive forces are exerted on the head. This type of loading has the longest duration at greater then $200 \mathrm{~ms} .{ }^{36,37,38}$ In this type of loading, the tissue cannot absorb any additional force and the skull fractures. As a result, the deformation of the skull by a fracture causes an injury to the brain tissue under the fracture site. ${ }^{37,38}$

The type of injury inflicted to the head will depend on the nature of the force delivered. A coup injury occurs when an object traveling at a high velocity hits a relatively stationary skull. ${ }^{19,21}$ The mechanism results in an injury to the side of the head that was struck. A contrecoup injury occurs when the skull is moving at a relatively high velocity and is suddenly stopped. This injury often occurs when an athlete's head strikes the ground following a collision. The cerebral spinal fluid within the skull fails to decrease the brain's momentum and allows the brain to strike the skull on the opposite side of the impact. ${ }^{19,21}$ The forth injury associated with concussions is shear or rotational injury. Sudden twisting forces or acceleration and deceleration can disrupt neural activity and result in cerebral concussion symptoms. ${ }^{21}$ 


\section{Epidemiology}

Football has historically been considered a high-risk sport for concussion. Although equipment and rule changes have occurred over the years in an attempt to make the game safer for participants, football is still believed to be responsible for the majority of sports related concussions today. ${ }^{31,32,39,40}$ Awareness has increased dramatically over the past ten years as new research on the topic has become available. As awareness grows, so does the estimates of injuries per year. The Center for Disease Control recently revised their estimates from approximately 300,000 injuries per year during the 1990 s to a current range of 1.6 to 2.3 million per year. ${ }^{31,39}$ Although there are several factors that explain this tenfold increase in injury prevalence, increased awareness at medical and public levels likely is responsible for increased identification and better reporting of injuries. Given this trend and the high probability that concussions are still under-reported, it is likely that increases in concussion rates over the next decade will continue to be seen. ${ }^{31,32,39}$

\section{Etiology}

Generally, concussions are regarded as a disruption of normal brain function as a result of a violent mechanical action affecting the head. ${ }^{19,23,27,31}$ The direct blow is the most common mechanism of injury for concussion. Direct blows usually occur when the athlete is struck in the head by some object or an opposing player. A direct blow might also occur when a moving head strikes a fixed object such as the field of play. ${ }^{19,23,27,31}$

The brain is a sesamoid that is surrounded by cerebrospinal fluid. This fluid gives the brain a certain amount of freedom within the skull. This freedom also makes the brain susceptible to injury. ${ }^{19,23,42}$ A direct blow can cause a sudden acceleration/deceleration or rotational movement to occur within the cerebral cavity. With these movements the brain can be injured a 
variety of ways. The three most common are compressive, tensile, or shear forces. ${ }^{19,27,42}$

Brain and nerve tissue have greater resistance to compressive and tensile forces, but low tolerance to shear forces. ${ }^{19,27,42}$ Shear forces cause injury by the straining and or tearing blood vessels and neural tissue. Acceleration/deceleration injuries occur as the cortical tissue abrades against the bony skull. Rotational injury reflects excessive torque applied about the brain around the brainstem, leading to straining or shearing of axons along the tracts through the white matter of the brain. In both cases, further damage accumulates as hemorrhage leading to ischemia, hypoxia, and necrosis. ${ }^{19,27,31,42}$

The severity of head injury depends on the amount of dysfunction and damage incurred by the mechanisms described above. ${ }^{19,31,42}$ A blow to the head may produce an injury to the brain either at the point of contact or on the opposite side of the head. Acceleration/deceleration forces and particularly rotational forces produce shaking of the brain within the skull, which results in shearing forces that disrupt diffuse axonal connections running between the cortex and midbrain. ${ }^{31,42}$ These mechanisms can lead to further complications characterized by intracranial hemorrhage, hematomas, and axonal injury. MTBI represents a condition with minimal damage and rarely involves any of the above complications, which are characteristic of more severe head trauma. ${ }^{23,27,31}$

Evaluation

The most important portion of a concussion evaluation is the history. When evaluating an athlete for a possible concussion it is important to establish how and when the injury occurred. ${ }^{1,16,21}$ Questions that are also pertinent include: if there was any loss of consciousness, any symptoms present, and history of concussions. Signs and symptoms can be assessed after a thorough history has been taken. The most common tool an athletic trainer can utilize to assess concussion symptoms is a checklist. ${ }^{16,21}$ Symptom checklists or score sheets are 
utilized by athletic trainers to gauge the severity of an athletes internal symptoms. These checklists are subjective, but often they serve as the only clue to the patients symptoms. The procedures to administer a baseline or follow-up test are the same. The athlete is given a sheet which lists the most common signs and symptoms associated with concussions. They are asked to assign a numerical value to each of the symptoms. ${ }^{16,22,43,44,45}$ The values range on a scale from zero to five. If the patient has no characteristics of that particular sign or symptom, the athlete would indicate a zero on that line of the score sheet. If the patient is experiencing intense characteristics of a sign or symptom, they would indicate a five on that line of the score sheet. $22,44,45$ Once the athlete has assigned a numerical value to all symptoms, the values are added. Following a concussion, the athlete must fill out a symptom score sheet again and reassign numerical values to these symptoms. In order for an athlete to progress though the stages of a concussion management protocol, the athletes total score must be less than or equal to the number indicated on the baseline test. ${ }^{22,45}$

There is often a question of validity associated with this method of assessment because the data is purely subjective and self-reported. A study conducted by Chen et a ${ }^{44}$ tested the validity of the self-reported symptom scale in 2007 . The study utilized twenty eight male athletes with and without a history of concussions. Athletes were asked to fill out a symptom score sheet. Once completed the athletes were grouped according to the presence of concussion symptoms. The tests utilized by the researchers to assess the relationship between self-reported symptoms and actual neuropsychological performance were computerized cognitive testing and functional MRI. The results of the study showed that nine of the sixteen signs/symptoms tested had a predictable scoring structure or direct relationship. For the researchers, this data proved to be significant enough to conclude symptom scales are valid instruments in the assessment and management of concussions.

A similar study conducted by Piland et al ${ }^{45}$ was conducted in 2006 . The study utilized 1,089 non-concussed male high school football players. All participants completed a symptom score sheet that was analyzed against previous research outcomes. The scale contained twenty 
symptoms. A Likert scale was established for the grading procedure. The scale contained seven numerical values ranging from zero (no symptoms) to six (very severe). The researchers tested the factorial validity of the measurements with a confirmatory factor analysis using LISREL. ${ }^{45}$ This study concluded that nine symptoms showed a predictable scoring structure. The researchers determined this structure by comparing their results with the results of similar studies. The study concluded that a cohesive group of nine symptoms show validity. By classifying this study as valid it provided additional evidence for the validity of self-reported measure of concussion-related symptoms. ${ }^{45}$

Once an athlete has identified symptoms it is important for an athletic trainer to assess the function of the cranial nerves. ${ }^{22,44}$ Cranial nerves can reveal if the athlete has any serious neurological deficiencies. To adequately assess the cranial nerves the athlete performs the following functions. Have the athlete smell something potent. Instruct the athlete to identify a word or an object. Examine the athlete's eye tracking and pupil reactivity. Have the athlete make facial expressions. ${ }^{22,44}$ Instruct the athlete to bit down or clinch their teeth. Check the athlete's sense of taste by allowing them to eat a piece of candy. Make sure they can swallow so they do not choke on the candy. Swallowing is another action that the athlete must perform as part of the cranial nerve assessment. The athlete will then be instructed to stick out their tongue and say "Ah". The final action the athlete must perform is a shoulder shrug. Deficiencies in any of the cranial nerves may indicate a severe head injury and the need for immediate advanced medical attention.

Balance Error Scoring System is a good special test for the evaluation phase. The BESS is a quantifiable version of a modified Romberg test. ${ }^{22}$ It consists of six tests lasting twenty seconds each. The tests are performed on firm and foam surfaces. The tests are first performed with the athlete on a firm surface. The athlete is asked to stand with their hands on their hips, and their feet together. The athlete is instructed to close their eyes and hold the position for twenty seconds. ${ }^{22,23,46,47}$ The clinician watches the athlete for balance errors. A balance error occurs when the eyes open, hands move from hips, any part of foot is lifted off the floor, or remains out 
of position for more then five seconds. The second test position involves a single leg stance using the non-dominant foot. The final position for the test is a tandem leg stance with the nondominant foot in the rear. Once the three tests have been performed on a firm surface they are repeated on a foam surface. The foam used for his test is a piece of medium-density foam. ${ }^{6}$ The foam piece is approximately $50 \mathrm{~cm}$ by $41 \mathrm{~cm}$ and is $6 \mathrm{~cm}$ thick. At the conclusion of the test, the clinician will add up the total number of errors from all six tests. This number becomes the athlete's BESS score. $22,23,46,47$

Neurpsychological Testing

Neurpsychological testing is used to evaluate cognitive aspects of the athlete that can be commonly disrupted with the athlete sustains a concussion. ${ }^{16}$ The Standardized Assessment of Concussion (SAC) was developed in accordance with guidelines set forth by the American Academy of Neurology and the National Athletic Trainers Association. ${ }^{16}$ The SAC is comprised of four major components that test the neuropsychological function and postural stability of an athlete. The components include orientation, immediate memory, concentration, and delayed recall. ${ }^{16}$ This is a useful sideline tool because it is a fast and easy assessment tool.

The SAC measures the neurocognitive effects of a concussion by testing the four major components listed above. The test is comprised of six sections including orientation, immediate memory, neurological function, concentration, delayed recall, and symptoms present during functional tests. ${ }^{16,22,31,44}$ For each section the athlete is scored and a numerical value is attached. At the end of the test, the values for each section are added and a total test value is assigned.

In recent years the topic of computerized neuropsychological testing has become popular. The University of Pittsburgh Medical Center (UPMC) has developed a specialized tool known as ImPACT. ${ }^{23,32,50,51}$ ImPACT stands for Immediate Post Concussion Assessment and Cognitive Testing. It was designed to aid in management issues associated with concussions. These issues include but are not limited to return-to-play and retirement decisions. The actual program consists of seven different sections. The sections include a variety of verbal memory, visual memory, processing speed, impulse control, and reaction time tests. ${ }^{23,31,50,51,52}$ These tests were 
designed to test multiple neurocognitive abilities within a twenty minute testing period. The program is also equipped with a symptom score sheet database. This allows one to access previous tests and baseline scores. Another feature associated with the ImPACT software is the normative database that has been established at UPMC. ${ }^{31,50-53}$ To date, the researchers at UPMC have collected baseline data on 5,000 non-concussed athletes and approximately 340 concussed athletes. ${ }^{52}$ This allows clients the opportunity to check their athlete's scores with average test scores that have been determined by the researchers at UPMC. ${ }^{52,53}$

Computer based assessment has several advantages and disadvantages. Advantages include the improved ability to capture and engage the patient. It also allows the examiner more freedom to not be physically present to administer the test. ${ }^{51,52}$ The ability to test multiple domains and precisely measure these domains would be impossible to recreate without the use of computers. Computers are also highly sensitive to subtle changes in stimuli. This increases their reliability because they can detect subtle changes that would go unnoticed by human examiners. $^{51,52}$

The programs are not free from criticism. Test developers have failed to meet established testing standards set forth by the American Psychological Association. ${ }^{51-53}$ These failures include not accounting for the timing synchronization between the computers microprocessor and the computer monitor. This delay allows for inaccurate data to be collected because all sections are timed to the millisecond. ${ }^{51-53}$ The program should be used as one component of a multifaceted approach. It should not be the sole determining factor in assessment of an athletes readiness for return-to-participation.

The scores from follow-up tests should be compared with baseline test scores. Again, as the symptom score sheet advancement through the protocol does not occur unless the score is less or equal to the baseline score.

Concussion Grading

Concussions are no longer graded with a numerical degree. The current literature concludes that all grading systems should be abandoned in favor of combined measures of recovery in 
order to determine injury severity. ${ }^{1,54}$ The reason for this modification centers on the latest research. The current grading scales generally use loss of consciousness or amnesia as a determining factor for a grade. ${ }^{1,54}$ The research has shown that loss of consciousness and amnesia are just contributing factors, and should not be the basis for which a severity decision is made. $^{1-54}$

\section{Return-To-Play}

Regardless of the assessment tools utilized the primary objective of an athletic trainer is to protect the athlete from future injury. The absence of a consensus guideline has made determining return-to-play a difficult task. ${ }^{55}$ In 2001 the first symposium on concussion in sport was held in Vienna. By the end of the symposium a consensus recommendation was established. No longer would concussions be graded on the basis of loss of consciousness or amnesia. ${ }^{55}$ Concussions would now be assessed using a multifaceted approach; the characteristics of this approach were detailed earlier.

The current literature suggests that each athlete should be handled as an individual basis. ${ }^{1,22,55-59}$ The literature presents several different philosophies on return-to-play. In the Zurich article it discusses same day return to play versus a stepwise protocol. Same day return to play is allowed if a team physician who is experienced in concussion management allows the athlete to return to competition after a thorough evaluation. If not cleared by a physician for return in that game, the athlete should begin a stepwise progression back to sport. The procedure outlined by the Vienna, Prague, and Zurich symposiums. It includes a six step protocol for return-to-play. ${ }^{1,22,55-59}$ Step one dictates that the athlete rest until asymptomatic. Once asymptomatic they can progress to level two. Level two includes light aerobic exercise, such as walking. No resistance training is allowed in this phase. If the athlete remains asymptomatic in this phase they can progress to phase three. ${ }^{1,55}$ The third phase includes sport specific activities and resistance training. Again, the athlete must remain asymptomatic in order 
to progress through the protocol. Level four includes non-contact drills. Once the athlete reaches this stage, a physician must medically clear the athlete for contact training. ${ }^{1,22,55-61}$

Contact training is considered level five. If the athlete is able to participate in contact drills and remains asymptomatic they can return to game competition. If at any time the athlete becomes symptomatic the athlete should drop back to the previous asymptomatic level and try to progress again in 24 hours. ${ }^{1,22,55-61}$

Summary

Concussions are one of the most complex injuries an athletic trainer will ever encounter. The lack of a consensus guideline adds to the complexity of the injury. The National Athletic Trainers Association has developed a position standard that should become the reference point for all athletic trainers. It states that all athletic trainers should manage concussions with a multifaceted approach. The evaluation should include a symptom score sheet, SAC, and BESS testing. These three factors will allow an athletic trainer to adequately assess the severity of the concussion. Once an assessment has been made the athlete must be placed in a step-by-step progression program to determine return-to-play status. The progression includes rest until the athlete is asymptomatic, followed by a series of exertional tests. If the athlete is able to complete each task without experiencing signs and symptoms then they can be cleared to participate. It is important to note that the team physician has the final say on wither or not an athlete can return to competition. 


\section{APPENDIX C}

\section{ADDITIONAL METHODS}

Table C1. Initial E-mail to Participants

January $1^{\text {st }}, 2010$

Dear Head Athletic Trainer,

This message is a request to participate in a research study being conducted by the primary investigator (PI) Michelle A. Sandrey PhD, ATC and Co-PI James Dorneman ATC, a Graduate Athletic Training Student. Both are affiliated with West Virginia University. Participation will require you to answer a 44-question survey. The main purpose of this study is to examine how certified athletic trainers make their return-to-play decisions and how their responses compare with the National Athletic Trainers Association guidelines for management of concussions. A secondary purpose of this study is to investigate the relationship between years of experience as an athletic trainer and the management procedure they follow. This thesis is being completed to fulfill requirements for the completion of a Master of Science Degree in Athletic Training at West Virginia University.

Your involvement in this survey will be kept completely anonymous for the duration of the study. I will not ask you to include your name on any of the questions nor will I present any information at any time that could allow for individual participants to be identified. You may withdrawal with no penalty at anytime throughout the study.

The following survey includes 44 multiple choice questions on assessment, management, and return-toplay guidelines. You do not have to answer all the questions. You may withdraw from the study at any time with no penalty. The survey should take approximately 30 minutes to complete. Please go to the following website to take the survey:

I request that you participate in this study, as it could be very beneficial for the academic and athletic communities alike to further knowledge and understanding of concussion management strategies. If you have any questions or concerns please contact James Dorneman (570) 401-5090 or by email at james.dorneman@mail.wvu.edu, Or Dr. Michelle Sandrey, Graduate Athletic Training Program Director at West Virginia University, at (304) 293-0870 or at msandrey@mail.wvu.edu.

Thanks you very much, in advance, for your participation in this study.

Sincerely,

James D. Dorneman Jr. ATC

*West Virginia University Institutional Review Board Acknowledgment of this study is on file 
January $24^{\text {th }}, 2010$

Dear Head Athletic Trainer,

This is a reminder that you can still participate in this study. For those of you who have already submitted your survey or are in the process, I apologize for this interruption and thank you for your participation. For those of you who no longer have the original information. I encourage all of you to take a few minutes to click on the link and complete the survey and submit it by January $31^{\text {st }}, 2010$.

This research study is being conducted by the primary investigator (PI) Michelle A. Sandrey PhD, ATC and Co-PI James Dorneman ATC, a Graduate Athletic Training Student. Both are affiliated with West Virginia University. Participation will require you to answer a 44-question survey. The main purpose of this study is to examine how certified athletic trainers make their return-to-play decisions and how their responses compare with the National Athletic Trainers Association guidelines for management of concussions. A secondary purpose of this study is to investigate the relationship between years of experience as an athletic trainer and the management procedure they follow. This thesis is being completed to fulfill requirements for the completion of a Master of Science Degree in Athletic Training at West Virginia University.

Your involvement in this survey will be kept completely anonymous for the duration of the study. I will not ask you to include your name on any of the questions nor will I present any information at any time that could allow for individual participants to be identified. You may withdrawal with no penalty at anytime throughout the study. You do not have to answer all the questions. You may withdraw from the study at any time with no penalty. The survey should take approximately 30 minutes to complete. Please go to the following website to take the survey:

I request that you participate in this study, as it could be very beneficial for the academic and athletic communities alike to further knowledge and understanding of concussion management strategies. If you have any questions or concerns please contact James Dorneman (570) 401-5090 or by email at james.dorneman@mail.wvu.edu, Or Dr. Michelle Sandrey, Graduate Athletic Training Program Director at West Virginia University, at (304) 293-0870 or at msandrey@mail.wvu.edu.

Thanks you very much, in advance, for your participation in this study.

Sincerely,

James D. Dorneman Jr. ATC

*West Virginia University Institutional Review Board Acknowledgment of this study is on file 
Table C3. Survey

Analysis of Concussion Management Policies and Procedures among Athletic Trainers in the Four Divisions of NCAA Collegiate Football

1. Please Check Division: $\square$ I $\square$ Subdivision $\square$ II $\square$ III

2. Age:

3. Gender: Male Female

4. Years of Experience as a Certified Athletic Trainer:

5. Years of Experience as Head Football Athletic Trainer:

6 Number of Student Athletes on the Football Team:

7. Number of Concussions/ Mild Traumatic Brain Injuries this year:

(Football Only)

8. Who fits your helmets? $\square$ Manufacture Representative $\square$ Athletic Trainer $\square$ Coaches $\square$ Equipment Manager $\square$ Physician $\square$ Other

\section{ANSWERS SHOULD BE GIVEN BASED ON YOUR CURRENT CLINICAL PRACTICES!!!!}

9. Have you received formal education/ training in how to:
A.) Identify a concussion YES NO
B.) Properly manage a concussion YES NO

10. From where did you receive your knowledge in concussion management? (Select all that apply)

\begin{tabular}{|c|c|c|c|c|c|c|}
\hline $\begin{array}{l}\text { Undergraduate } \\
\text { Education }\end{array}$ & $\begin{array}{l}\text { Post Graduate } \\
\text { Education }\end{array}$ & $\begin{array}{l}\text { Journal of } \\
\text { Athletic } \\
\text { Training }\end{array}$ & $\begin{array}{c}\text { NATA } \\
\text { Convention } \\
\text { Workshop }\end{array}$ & $\begin{array}{c}\text { Regional } \\
\text { Convention } \\
\text { Workshop }\end{array}$ & Other (Specify) & $\begin{array}{l}\text { No Formal } \\
\text { Training }\end{array}$ \\
\hline
\end{tabular}

11. Do you have a written protocol for concussions? YES NO

12. Who developed the written protocol?

Team Physician

Head ATC

Director of Athletic Training

Other sources

13. What is included in the written protocol?

NATA Position Statement

Zurich consensus statement 2008

14. Does your protocol contain:

A definition of a Sports Concussion

Referral guidelines

Take home instructions for athlete

Return-To-Play Assessment
Signs \& Symptoms of a Sports Concussion Guidelines for athlete release of supervision from ATC

Guidelines for delayed referral to physician

Oral \& Written instructions must be given to a responsible adult 
15. Do you perform preseason baseline testing on your athletes for subsequent use in post-concussion evaluations? YES NO

A.) If yes, Does your baseline testing include any of the following: (Please check all that apply)

Clinical examination

Balance Error Scoring System (BESS)

Sport Concussion Assessment Tool (SCAT)

Neuropsychological testing (Computerized)
Self-reported symptom checklist

Standardized Assessment of Concussion (SAC)

Neuropsychological testing (paper/pencil)

Other (Specify)

16. What methods do you regularly utilize to make decisions about return to play after a concussion? (Check all that apply)
Clinical examination
Return-to-play guidelines (Cantu, Colorado, etc)
Player self-report (I'm OK)
Standardized Assessment of Concussion (SAC)
Neuropsychological testing (paper/pencil)
Balance Error Scoring System (BESS)
Return to baseline score in symptom checklist, and neuropsychological testing.

Physician recommendations

Self-reported symptom checklist

Head CT/ Brain MRI

Sport Concussion Assessment Tool (SCAT)

Neuropsychological testing (Computerized)

Physical Exertion Protocol

Other (Specify)

17. If you had to rely on one single method to make a return to play decision; what would it be? (Select one)

\author{
Clinical examination \\ Return-to-play guidelines \\ Player self-report (I'm OK) \\ Standardized Assessment of Concussion (SAC) \\ Neuropsychological testing (paper/pencil) \\ Balance Error Scoring System (BESS)
}

Physician recommendations

Symptom checklist

Head CT/ Brain MRI

Sport Concussion Assessment Tool (SCAT)

Neuropsychological testing (Computerized)

Other (Specify)

18. Under what conditions would you refer an athlete to the Emergency Room on the same day as the injury? (Check All That Apply)
Athlete experiences amnesia
Deterioration of neurological function
Decrease in respirations
Unequal, dilated, or unreactive pupils
Cranial nerve deficits
Signs of skull fracture (Battle sign, etc)
Increase in blood pressure
Balance deficits
Symptoms worsen
No improvement of symptoms
Physician recommendation
Mental status changes
Motor deficits
Additional symptoms materialize
Athlete is still symptomatic at the end of
Headache
Seizure, Vomiting

competition (game/practice)

19. What assessment tools do you utilize for sideline assessment of concussions? (Please check all that apply)

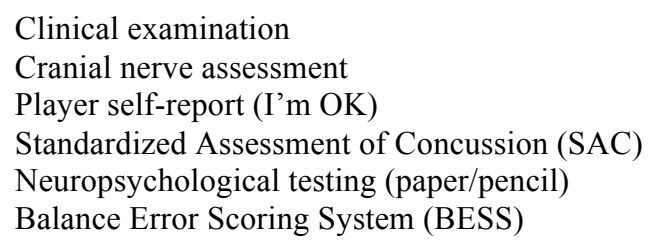

Clinical examination

Standardized Assessment of Concussion (SAC)

Balance Error Scoring System (BESS)
Physician recommendations

Self-reported symptom checklist

Special tests (Romberg Test, etc)

Sport Concussion Assessment Tool (SCAT)

Neuropsychological testing (Computerized)

Other (Specify)

20. Do you ever allow an athlete to return to play if they are still symptomatic? $\square$ YES $\square$ NO

21. Do you ever return an athlete to play without evaluation by a physician? YES NO

22. How long after a concussion has been diagnosed do you wait before you perform a follow-up evaluation?

$$
12 \text { hours } 15 \text { hours } 24 \text { hours } 2 \text { days } \quad 3 \text { days } 5 \text { days } 6 \text { days } 7 \text { days } \text { Other }
$$

23. In your secondary evaluation do you utilize testing tools that have baseline information that can be compared? YES NO

24. Do you use any of the following guidelines for return-to-play or assessment?
Cantu
Colorado
American Academy of
Zurich
Neurology
NATA Position Statement


26. Does your return to play protocol contain any of the following steps? (Please check all that apply)

No activity, Complete rest until asymptomatic

Light aerobic exercise (Walking or Stationary bike) No Resistance Training

Sport specific exercises with the addition of resistance training

Non-contact drills

Full contact training

Return to Game Ready!!!!

27. When are athlete progressed if you utilize a step by step progression?

12 Hours

24 Hours

36 Hours

2-3 Days

4-5 Days

Other

28. How would you grade your institutions management of concussions?

$\begin{array}{llll}\text { Poor } & \text { Fair } & \text { Gverage } & \text { Gery Good }\end{array}$

29. How comfortable are you in identifying signs and symptoms that may indicate severe head trauma? (Skull Fracture, etc.)

Poor Fair Average Good Good

30. Do you educate your athletes and coaches on the severity of concussions and the signs and symptoms associated with them?

YES NO

31. Are athletes instructed to avoid ingesting alcohol, illegal drugs or substances that might interfere with brain function and recovery?
Always
Most of the Time
Half the Time
Some of the Time
Never

32. Are athletes instructed to eat a well-balanced diet following a concussion?
Always
Most of the Time
Half the Time
Some of the Time
Never

33. Do you allow your athletes to take any of the following medications while signs and symptoms are present?
Acetaminophen
Ibuprofen
Advil
Aleve

Continue Prescription medication

Other

34. Are medications only give at the recommendation of the team physician? YES NO

35. In your documentation of a concussion do you record:
Date of initial injury
Mechanism of injury (If known)
State of consciousness at time of injury
Physician recommendations
Date of return to play

Time of initial injury

Initial Signs \& Symptoms

Clinical evaluation

Instructions given to the athlete \& responsible adult

Patient history of concussions

36. Do you monitor the athlete's vital signs until the patient's condition improves? YES NO

37. Do you monitor the athlete over the next few days for the presence of delayed signs and symptoms and to further assess the recovery process? YES NO 
38. On average how long do you hold your athletes out from the time of initial injury until they return to full competition? (Game Ready)
After Asymptomatic
1-3 days
4-6 days
7 days
Other

39. Do you return athletes to play the same day if the have been asymptomatic for 20 minutes, and test normal on all assessments? YES NO

40. Do you follow guidelines that use loss of consciousness as a grading factor for concussions? YES NO

41. Do you attempt to grade the severity of a concussion while the athlete is still experiencing sign's and symptoms? YES NO

42. Do you grade concussions on? On a scale of one to three YES NO/Simple vs. Complex YES NO/Neither of the grading scales YES NO

43. Do you think a new standardized numerical system is needed? YES NO

44. Loss of consciousness and amnesia are two symptoms that should be used in assessing the severity of a concussion? YES NO

\section{CONCUSSION SCENARIOS}

Your athlete was involved in a helmet to helmet collision. The athlete reported no loss of consciousness, but experienced nausea, dizziness, decrease coordination, and a headache. The athlete was evaluated and it was determined that they would no longer participate that day.

45. Day 1 after injury the athlete reported no symptoms, and all the standardized tests for concussion assessment were normal. (BESS, SAC, neuropsychological testing, etc.) Would you return this athlete to competition? YES NO

46. Day 1 after injury the athlete reported still having symptoms, but all the standardized tests (Performed that day) for concussion assessment were normal. Would you return this athlete to competition? YES NO

47. Day 2 after injury the athlete reports no symptoms, and all standardized tests for concussions are normal. Would you attempt a fast track concussion management approach, or would you stick with a conservative day by day progression. (Fast Track $=$ Completing multiple stages of your concussion protocol in one day, in an attempt to return the athlete to play faster.) (Conservative $=$ Completing protocol stages over a period of time, with a days rest between phases.)

Fast Track Conservative

48. The athlete has successfully completed your concussion protocol. The day before their first game back they ask you for Acetaminophen. When you ask for a reason they reply, because I have a headache. Your next step is to:
Give them
Acetaminophen
Ask them if they sustained another blow to the head
Perform a quick concussion assessment Consult the team
physician
Refer to the ER

49. Has your management of concussions changed from the time when you were first certified? If yes, what methods did you utilize previously and what procedure do you follow now?

50. If yes to 49 , What prompted you to change your protocol?

Continuing Education Courses Journal Articles

51. Please use this space to clarify any information about your protocol you feel is important to this study.
Increased media scrutiny of concussion management strategies
Other (Specify) 


\section{APPENDIX D}

\section{ADDITIONAL RESULTS}

Table D1. Demographic Characteristics by Division

\begin{tabular}{|c|c|c|c|c|c|}
\hline Question & Division I & Sub-Division & Division II & Division III & Overall \\
\hline 1. Division & $48 / 24.4 \%$ & $21 / 107 \%$ & $42 / 21.3 \%$ & $86 / 43.7 \%$ & $197 / 100 \%$ \\
\hline \multicolumn{6}{|l|}{ 2. Age } \\
\hline Mean/Standard Deviation & $42.89 \pm 9.93$ & $41.00 \pm 9.27$ & $37.97 \pm 7.74$ & $39.58 \pm 9.75$ & $40.00 \pm 9.44$ \\
\hline Minimum & 23.00 & 26.00 & 24.00 & 24.00 & 23.00 \\
\hline Maximum & 62.00 & 54.00 & 53.00 & 65.00 & 65.00 \\
\hline \multicolumn{6}{|l|}{ 3. Gender } \\
\hline Male & $39(81.3 \%)$ & $20(95.2 \%)$ & $30(71.4 \%)$ & $65(75.6 \%)$ & $154(78.2 \%)$ \\
\hline Female & $9(18.8 \%)$ & $1(4.8 \%)$ & $12(28.6 \%)$ & $21(24.4 \%)$ & $43(21.8 \%)$ \\
\hline \multicolumn{6}{|l|}{ 4. Years Certified } \\
\hline Less then 10 years ATC & $9(18.9 \%)$ & $5(23.8 \%)$ & $11(26.2 \%)$ & $25(29.1)$ & $50(25.5 \%)$ \\
\hline Greater then 10 years ATC & $39(81.3 \%)$ & $16(76.2 \%)$ & $31(73.8 \%)$ & $61(70.0 \%)$ & $147(74.6 \%)$ \\
\hline \multicolumn{6}{|l|}{ 5. Years Head FB ATC } \\
\hline Less then 10 years & $21(43.8 \%)$ & $14(66.7 \%)$ & $25(59.5 \%)$ & $45(52.3 \%)$ & $105(53.3 \%)$ \\
\hline Greater then 10 years & $27(56.3 \%)$ & $7(33.3 \%)$ & $17(40.5 \%)$ & $41(47.7 \%)$ & $92(46.7 \%)$ \\
\hline \multicolumn{6}{|l|}{ 6. Number of players } \\
\hline Mean/Standard Deviation & $107 \pm 12.77$ & $103 \pm 10.95$ & $104 \pm 21.45$ & $99 \pm 32.79$ & $102 \pm 24.98$ \\
\hline \multicolumn{6}{|l|}{ 7. Number of concussions } \\
\hline Mean/Standard Deviation & $7.95 \pm 6.23$ & $8 \pm 4.26$ & $5.32 \pm 2.56$ & $5.51 \pm 3.43$ & $6.34 \pm 4.36$ \\
\hline \multicolumn{6}{|l|}{ 8. Helmet fitting } \\
\hline Manufacture Representative & $7(14.9 \%)$ & $4(19.0 \%)$ & $9(21.4 \%)$ & $18(22.0 \%)$ & $38(19.8 \%)$ \\
\hline Athletic Trainer & $5(10.6 \%)$ & $4(19.0 \%)$ & $10(23.8 \%)$ & $29(35.4 \%)$ & $48(25.0 \%)$ \\
\hline Coaches & $2(4.3 \%)$ & $1(4.8 \%)$ & $13(31.0 \%)$ & $27(32.9 \%)$ & $43(22.4 \%)$ \\
\hline Equipment Manager & $43(91.5 \%)$ & $19(90.5 \%)$ & $23(54.8 \%)$ & $39(47.6 \%)$ & $124(64.5 \%)$ \\
\hline Physician & $0(0.0 \%)$ & $0(0.0 \%)$ & $0(0.0 \%)$ & $0(0.0 \%)$ & $0(0.0 \%)$ \\
\hline Other & $1(2.1 \%)$ & $0(0.0 \%)$ & $1(2.4 \%)$ & $0(0.0 \%)$ & $2(1.0 \%)$ \\
\hline
\end{tabular}

Key: Questions correspond to number on the questionnaire. 
Table D2. Demographic Characteristics by years certified athletic trainer

\begin{tabular}{|c|c|c|c|}
\hline Question & Less Then 10 Years ATC & Greater Then 10 Years ATC & Overall \\
\hline \multicolumn{4}{|l|}{ 1. Division } \\
\hline One & $21(20.0 \%)$ & $27(29.3 \%)$ & $48(24.4 \%)$ \\
\hline Subdivision & $14(13.3 \%)$ & $7(7.6 \%)$ & $21(10.7 \%)$ \\
\hline Two & $25(23.8 \%)$ & $17(18.5 \%)$ & $42(21.3 \%)$ \\
\hline Three & $45(42.9 \%)$ & $41(44.6 \%)$ & $86(43.7 \%)$ \\
\hline 2. Age & $28.85 \pm 2.56$ & $43.85 \pm 7.79$ & $40 \pm 9.44$ \\
\hline \multicolumn{4}{|l|}{ 3. Gender } \\
\hline Male & $70(66.7 \%)$ & $84(91.3 \%)$ & $154(78.2 \%)$ \\
\hline Female & $35(33.3 \%)$ & $8(8.7 \%)$ & $43(21.8 \%)$ \\
\hline \multicolumn{4}{|l|}{ 4. Years Certified } \\
\hline Less then 10 years & $50(47.6 \%)$ & $0(0.0 \%)$ & $50(25.4 \%)$ \\
\hline Greater then 10 years & $55(52.4)$ & $92(100 \%)$ & $147(74.6 \%)$ \\
\hline \multicolumn{4}{|l|}{ 5. Years Head FB ATC } \\
\hline Less then 10 years & $105(100 \%)$ & $0(0.0 \%)$ & $105(53.3 \%)$ \\
\hline Greater then 10 years & $0(0.0 \%)$ & $92(100 \%)$ & $92(46.7 \%)$ \\
\hline 6. Number of players & $102 \pm 28.5$ & $103 \pm 23.77$ & $102 \pm 24.98$ \\
\hline 7. Number of concussions & $6.40 \pm 3.79$ & $6.32 \pm 4.54$ & $6.34 \pm 4.36$ \\
\hline \multicolumn{4}{|l|}{ 8. Helmet Fitting } \\
\hline Manufacture Representative & $23(22.1 \%)$ & $15(17 \%)$ & $38(19.8 \%)$ \\
\hline Athletic Trainer & $27(26 \%)$ & $21(23.9 \%)$ & $48(25 \%)$ \\
\hline Coaches & $23(22.1 \%)$ & $20(22.7 \%)$ & $43(22.4 \%)$ \\
\hline Equipment Manager & $65(62.5 \%)$ & $59(67 \%)$ & $124(64.6 \%)$ \\
\hline Physician & $0(0.0 \%)$ & $0(0.0 \%)$ & $0(0.0 \%)$ \\
\hline Other & $0(0.0 \%)$ & $0(0.0 \%)$ & $0(0.0 \%)$ \\
\hline
\end{tabular}


Table D3. Demographic Characteristics by years as certified head football athletic trainer

\begin{tabular}{|c|c|c|c|}
\hline Question & Less Then 10 Years FB ATC & Greater Then 10 Years FB ATC & Overall \\
\hline \multicolumn{4}{|l|}{ 1. Division } \\
\hline One & $21(20.0 \%)$ & $27(29.3 \%)$ & $48(24.4 \%)$ \\
\hline Subdivision & $14(13.3 \%)$ & $7(7.6 \%)$ & $21(10.7 \%)$ \\
\hline Two & $25(23.8 \%)$ & $17(18.5 \%)$ & $42(21.3 \%)$ \\
\hline Three & $45(42.9 \%)$ & $41(44.6 \%)$ & $86(43.7 \%)$ \\
\hline 2. Age & $28.85 \pm 2.56$ & $43.85 \pm 7.79$ & $40 \pm 9.44$ \\
\hline \multicolumn{4}{|l|}{ 3. Gender } \\
\hline Male & $70(66.7 \%)$ & $84(91.3 \%)$ & $154(78.2 \%)$ \\
\hline Female & $35(33.3 \%)$ & $8(8.7 \%)$ & $43(21.8 \%)$ \\
\hline \multicolumn{4}{|l|}{ 4. Years Certified } \\
\hline Less then 10 years & $50(47.6 \%)$ & $0(0.0 \%)$ & $50(25.4 \%)$ \\
\hline Greater then 10 years & $55(52.4)$ & $92(100 \%)$ & $147(74.6 \%)$ \\
\hline \multicolumn{4}{|l|}{ 5. Years Head FB ATC } \\
\hline Less then 10 years & $105(100 \%)$ & $0(0.0 \%)$ & $105(53.3 \%)$ \\
\hline Greater then 10 years & $0(0.0 \%)$ & $92(100 \%)$ & $92(46.7 \%)$ \\
\hline 6. Number of players & $102 \pm 28.5$ & $103 \pm 23.77$ & $102 \pm 24.98$ \\
\hline 7. Number of concussions & $6.40 \pm 3.79$ & $6.32 \pm 4.54$ & $6.34 \pm 4.36$ \\
\hline \multicolumn{4}{|l|}{ 8. Helmet Fitting } \\
\hline Manufacture Representative & $23(22.1 \%)$ & $15(17 \%)$ & $38(19.8 \%)$ \\
\hline Athletic Trainer & $27(26 \%)$ & $21(23.9 \%)$ & $48(25 \%)$ \\
\hline Coaches & $23(22.1 \%)$ & $20(22.7 \%)$ & $43(22.4 \%)$ \\
\hline Equipment Manager & $65(62.5 \%)$ & $59(67 \%)$ & $124(64.6 \%)$ \\
\hline Physician & $0(0.0 \%)$ & $0(0.0 \%)$ & $0(0.0 \%)$ \\
\hline Other & $0(0.0 \%)$ & $0(0.0 \%)$ & $0(0.0 \%)$ \\
\hline
\end{tabular}


Table D4. Evaluation by Division

\begin{tabular}{|c|c|c|c|c|c|}
\hline Question & Division I & Sub-Division & Division II & Division III & Overall \\
\hline \multicolumn{6}{|l|}{ 15. Preseason baseline testing } \\
\hline Yes & $39(84.4 \%)$ & $14(70.0 \%)$ & $23(56.1 \%)$ & $59(73.8 \%)$ & $135(72.2 \%)$ \\
\hline No & $7(15.2 \%)$ & $6(30.0 \%)$ & $18(43.9 \%)$ & $21(26.3 \%)$ & $52(27.8 \%)$ \\
\hline \multicolumn{6}{|l|}{ 15a. Baseline testing includes: } \\
\hline Clinical Examination & $8(20.5 \%)$ & $3(21.4 \%)$ & $3(13.0 \%)$ & $9(15.3 \%)$ & $23(17.0 \%)$ \\
\hline BESS & $9(23.1 \%)$ & $3(21.4 \%)$ & $6(26.1 \%)$ & $14(23.7 \%)$ & $32(23.7 \%)$ \\
\hline SCAT & $3(7.7 \%)$ & $3(21.4 \%)$ & $1(4.3 \%)$ & $8(13.6 \%)$ & $15(11.1 \%)$ \\
\hline Neuropsychological (Comp) & $36(92.3 \%)$ & $11(78.6 \%)$ & $17(73.9 \%)$ & $44(74.6 \%)$ & $108(80.0 \%)$ \\
\hline Neuropsychological (Paper) & $1(2.6 \%)$ & $0(0.0 \%)$ & $1(4.3 \%)$ & $3(5.1 \%)$ & $5(3.7 \%)$ \\
\hline Symptom checklist & $14(35.9 \%)$ & $4(28.6 \%)$ & $2(8.7 \%)$ & $11(18.6 \%)$ & $31(23.0 \%)$ \\
\hline SAC & $14(35.9 \%)$ & $6(42.9 \%)$ & $9(39.1 \%)$ & $17(28.8 \%)$ & $46(34.1 \%)$ \\
\hline \multicolumn{6}{|l|}{ 19. Sideline assessment tools } \\
\hline Clinical Examination & $43(95.6 \%)$ & $19(95.0 \%)$ & $38(97.4 \%)$ & $74(91.4 \%)$ & $174(94.1 \%)$ \\
\hline Cranial nerve assessment & $32(71.1 \%)$ & $13(65.0 \%)$ & $27(69.2 \%)$ & $62(76.5 \%)$ & $134(72.4 \%)$ \\
\hline Player self-report & $17(37.8 \%)$ & $12(60.0 \%)$ & $18(46.2 \%)$ & $27(33.3 \%)$ & $74(40.0 \%)$ \\
\hline SAC & $16(35.6 \%)$ & $8(40.0 \%)$ & $12(30.8 \%)$ & $19(23.5 \%)$ & $55(29.7 \%)$ \\
\hline SCAT & $2(4.4 \%)$ & $2(10.0 \%)$ & $3(7.7 \%)$ & $9(11.1 \%)$ & $16(8.6 \%)$ \\
\hline BESS & $7(15.6 \%)$ & $2(10.0 \%)$ & $3(7.7 \%)$ & $12(14.8 \%)$ & $24(13.0 \%)$ \\
\hline Physician Recommendation & $31(68.9 \%)$ & $14(70.0 \%)$ & $27(69.2 \%)$ & $45(55.6 \%)$ & $117(63.2 \%)$ \\
\hline Symptom checklist & $26(57.8 \%)$ & $13(65.0 \%)$ & $26(66.7 \%)$ & $48(59.3 \%)$ & $113(61.1 \%)$ \\
\hline Special tests & $38(84.4 \%)$ & $16(80.0 \%)$ & $33(84.6 \%)$ & $67(82.7 \%)$ & $154(83.2 \%)$ \\
\hline Neuropsychological (Comp) & $3(6.7 \%)$ & $0(0.0 \%)$ & $0(0.0 \%)$ & $1(1.2 \%)$ & $4(2.2 \%)$ \\
\hline Neuropsychological (Paper) & $1(2.2 \%)$ & $1(5.0 \%)$ & $0(0.0 \%)$ & $1(1.2 \%)$ & $3(1.6 \%)$ \\
\hline
\end{tabular}




\begin{tabular}{|c|c|c|c|c|c|}
\hline 22. Follow-up exam & Division I & Sub-Division & Division II & Division III & Overall \\
\hline 1 Hour & $5(11.1 \%)$ & $4(20.0 \%)$ & $5(13.2 \%)$ & $4(5.0 \%)$ & $18(9.8 \%)$ \\
\hline 2 Hours & $0(0.0 \%)$ & $0(0.0 \%)$ & $0(0.0 \%)$ & $0(0.0 \%)$ & $0(0.0 \%)$ \\
\hline 3 Hours & $0(0.0 \%)$ & $0(0.0 \%)$ & $0(0.0 \%)$ & $0(0.0 \%)$ & $0(0.0 \%)$ \\
\hline 4 Hours & $0(0.0 \%)$ & $0(0.0 \%)$ & $0(0.0 \%)$ & $0(0.0 \%)$ & $0(0.0 \%)$ \\
\hline 6 Hours & $0(0.0 \%)$ & $0(0.0 \%)$ & $0(0.0 \%)$ & $0(0.0 \%)$ & $0(0.0 \%)$ \\
\hline 8 Hours & $0(0.0 \%)$ & $0(0.0 \%)$ & $0(0.0 \%)$ & $0(0.0 \%)$ & $0(0.0 \%)$ \\
\hline 10 Hours & $0(0.0 \%)$ & $0(0.0 \%)$ & $0(0.0 \%)$ & $0(0.0 \%)$ & $0(0.0 \%)$ \\
\hline 12 Hours & $6(13.3 \%)$ & $4(20.0 \%)$ & $6(15.8 \%)$ & $13(16.3 \%)$ & $29(15.8 \%)$ \\
\hline 15 Hours & $2(4.4 \%)$ & $1(5.0 \%)$ & $0(0.0 \%)$ & $3(3.8 \%)$ & $6(3.3 \%)$ \\
\hline 24 Hours & $27(60.0 \%)$ & $7(35.0 \%)$ & $23(60.5 \%)$ & $50(62.5 \%)$ & $107(58.5 \%)$ \\
\hline 2 Days & $1(2.2 \%)$ & $1(5.0 \%)$ & $2(5.3 \%)$ & $1(1.3 \%)$ & $5(2.7 \%)$ \\
\hline 3 Days & $0(0.0 \%)$ & $0(0.0 \%)$ & $0(0.0 \%)$ & $0(0.0 \%)$ & $0(0.0 \%)$ \\
\hline 4 Days & $0(0.0 \%)$ & $0(0.0 \%)$ & $0(0.0 \%)$ & $0(0.0 \%)$ & $0(0.0 \%)$ \\
\hline 5 Days & $0(0.0 \%)$ & $0(0.0 \%)$ & $0(0.0 \%)$ & $0(0.0 \%)$ & $0(0.0 \%)$ \\
\hline 6 Days & $0(0.0 \%)$ & $0(0.0 \%)$ & $0(0.0 \%)$ & $0(0.0 \%)$ & $0(0.0 \%)$ \\
\hline 7 Days & $0(0.0 \%)$ & $0(0.0 \%)$ & $0(0.0 \%)$ & $0(0.0 \%)$ & $0(0.0 \%)$ \\
\hline Other & $4(8.9 \%)$ & $3(15.0 \%)$ & $1(2.6 \%)$ & $6(7.5 \%)$ & $14(7.7 \%)$ \\
\hline \multicolumn{6}{|l|}{ 23. Secondary testing } \\
\hline YES & $36(80.0 \%)$ & $13(65.0 \%)$ & $24(63.2 \%)$ & $61(77.2 \%)$ & $134(73.6 \%)$ \\
\hline $\mathrm{NO}$ & $9(20.0 \%)$ & $7(35.0 \%)$ & $14(36.8 \%)$ & $18(22.8 \%)$ & $48(26.4 \%)$ \\
\hline
\end{tabular}


Table D5. Evaluation by Years Certified Athletic Trainer

\begin{tabular}{llll}
\hline Question & Less Then 10 Years ATC & Greater Then 10 Years ATC & Overall \\
\hline 15. Preseason baseline testing & & & $135(72.2 \%)$ \\
Yes & $71(71 \%)$ & $64(73.6 \%)$ & $52(27.8 \%)$ \\
No & $29(29 \%)$ & $23(26.4 \%)$ & $23(17 \%)$ \\
15a. Baseline testing includes: & & & $32(23.7 \%)$ \\
Clinical examination & $14(19.4 \%)$ & $9(14.3 \%)$ & $15(11.1 \%)$ \\
BESS & $13(18.1 \%)$ & $19(30.2 \%)$ & $108(80 \%)$ \\
SCAT & $6(8.3 \%)$ & $9(14.3 \%)$ & $5(3.7 \%)$ \\
Neuropsychological (Comp) & $54(75 \%)$ & $54(85.7 \%)$ & $31(23 \%)$ \\
Neuropsychological (Paper) & $4(5.6 \%)$ & $1(1.6 \%)$ & $46(34.1 \%)$ \\
Symptom checklist & $16(22.2 \%)$ & $15(23.8 \%)$ & $174(94.1 \%)$ \\
SAC & $24(33.3 \%)$ & $22(34.9 \%)$ & $134(72.4 \%)$ \\
19. Sideline assessment tools & & & $74(40 \%)$ \\
Clinical Examination & $94(95.9 \%)$ & $80(92 \%)$ & $55(29.7 \%)$ \\
Cranial nerve assessment & $81(82.7 \%)$ & $53(60.9 \%)$ & $16(8.6 \%)$ \\
Player self-report & $46(46.9 \%)$ & $28(32.2 \%)$ & $24(13 \%)$ \\
SAC & $30(30.6 \%)$ & $25(28.7 \%)$ & $117(63.2 \%)$ \\
SCAT & $6(6.1 \%)$ & $10(11.5 \%)$ & $113(60 \%)$ \\
BESS & $13(13.3 \%)$ & $11(12.6 \%)$ & $154(83 \%)$ \\
Physician Recommendation & $57(58.2 \%)$ & $60(69 \%)$ & $4(2.2 \%)$ \\
Symptom checklist & $62(63 \%)$ & $51(59 \%)$ & $3(1.6 \%)$ \\
Special tests & $89(91 \%)$ & $65(75 \%)$ & $2(2.3 \%)$ \\
Neuropsychological (Comp) & $2(2 \%)$ & $2(2.3 \%)$ & \\
Neuropsychological (Paper) & $1(1.0 \%)$ & & \\
& & &
\end{tabular}




\begin{tabular}{llll} 
Question & Less Then 10 Years ATC & Greater Then 10 Years ATC & Overall \\
22. Follow-up exam & $7(7.1 \%)$ & $11(12.9 \%)$ & $18(9.8 \%)$ \\
1 Hour & $1(1.0 \%)$ & $2(2.4 \%)$ & $3(1.6 \%)$ \\
2 Hours & $0(0.0 \%)$ & $1(1.2 \%)$ & $1(0.5 \%)$ \\
3 Hours & $(0.0 \%)$ & $0(0.0 \%)$ & $0(0.0 \%)$ \\
4 Hours & $0(0.0 \%)$ & $0(0.0 \%)$ & $0(0.0 \%)$ \\
6 Hours & $0(0.0 \%)$ & $0(0.0 \%)$ & $0(0.0 \%)$ \\
8 Hours & $0(0.0 \%)$ & $0(0.0 \%)$ & $29(15.8 \%)$ \\
10 Hours & $19(19.4 \%)$ & $10(11.8 \%)$ & $6(3.3 \%)$ \\
12 Hours & $2(2.0 \%)$ & $4(4.7 \%)$ & $107(58.5 \%)$ \\
15 Hours & $57(58.2 \%)$ & $50(58.8 \%)$ & $5(2.7 \%)$ \\
24 Hours & $3(3.1 \%)$ & $2(2.4 \%)$ & $0(0.0 \%)$ \\
2 Days & $0(0.0 \%)$ & $0(0.0 \%)$ & $0(0.0 \%)$ \\
3 Days & $0(0.0 \%)$ & $0(0.0 \%)$ & $0(0.0 \%)$ \\
4 Days & $0(0.0 \%)$ & $0(0.0 \%)$ & $0(0.0 \%)$ \\
5 Days & $0(0.0 \%)$ & $0(0.0 \%)$ & $0(0.0 \%)$ \\
6 Days & $0(0.0 \%)$ & $5(5.9 \%)$ & $14(7.7 \%)$ \\
7 Days & $9(9.2 \%)$ & & $134(73.6 \%)$ \\
Other & & $61(71.8 \%)$ & $48(26.4 \%)$ \\
23. Secondary testing & $73(75.3 \%)$ & $24(28.2 \%)$ & \\
YES & $24(24.7 \%)$ & & \\
NO & & & \\
\hline
\end{tabular}


Table D6. Evaluation by Years Head Football Athletic Trainer

\begin{tabular}{|c|c|c|c|}
\hline Question & Less Then 10 Years FB ATC & Greater Then 10 Years FB ATC & Overall \\
\hline \multicolumn{4}{|l|}{ 15. Preseason baseline testing } \\
\hline Yes & $71(71 \%)$ & $64(73.6 \%)$ & $135(72.2 \%)$ \\
\hline No & $29(29 \%)$ & $23(26.4 \%)$ & $52(27.8 \%)$ \\
\hline \multicolumn{4}{|l|}{ 15a. Baseline testing includes: } \\
\hline Clinical examination & $14(19.4 \%)$ & $9(14.3 \%)$ & $23(17 \%)$ \\
\hline BESS & $13(18.1 \%)$ & $19(30.2 \%)$ & $32(23.7 \%)$ \\
\hline SCAT & $6(8.3 \%)$ & $9(14.3 \%)$ & $15(11.1 \%)$ \\
\hline Neuropsychological (Comp) & $54(75 \%)$ & $54(85.7 \%)$ & $108(80 \%)$ \\
\hline Neuropsychological (Paper) & $4(5.6 \%)$ & $1(1.6 \%)$ & $5(3.7 \%)$ \\
\hline Symptom checklist & $16(22.2 \%)$ & $15(23.8 \%)$ & $31(23 \%)$ \\
\hline SAC & $24(33.3 \%)$ & $22(34.9 \%)$ & $46(34.1 \%)$ \\
\hline \multicolumn{4}{|l|}{ 19. Sideline assessment tools } \\
\hline Clinical Examination & $94(95.9 \%)$ & $80(92 \%)$ & $174(94.1 \%)$ \\
\hline Cranial nerve assessment & $81(82.7 \%)$ & $53(60.9 \%)$ & $134(72.4 \%)$ \\
\hline Player self-report & $46(46.9 \%)$ & $28(32.2 \%)$ & $74(40 \%)$ \\
\hline SAC & $30(30.6 \%)$ & $25(28.7 \%)$ & $55(29.7 \%)$ \\
\hline SCAT & $6(6.1 \%)$ & $10(11.5 \%)$ & $16(8.6 \%)$ \\
\hline BESS & $13(13.3 \%)$ & $11(12.6 \%)$ & $24(13 \%)$ \\
\hline Physician Recommendation & $57(58.2 \%)$ & $60(69 \%)$ & $117(63.2 \%)$ \\
\hline Symptom checklist & $62(63 \%)$ & $51(59 \%)$ & $113(60 \%)$ \\
\hline Special tests & $89(91 \%)$ & $65(75 \%)$ & $154(83 \%)$ \\
\hline Neuropsychological (Comp) & $2(2 \%)$ & $2(2.3 \%)$ & $4(2.2 \%)$ \\
\hline Neuropsychological (Paper) & $1(1.0 \%)$ & $2(2.3 \%)$ & $3(1.6 \%)$ \\
\hline
\end{tabular}




\begin{tabular}{lccc} 
Question & Less Then 10 Years FB ATC & Greater Then 10 Years FB ATC & Overall \\
22. Follow-up exam & $7(7.1 \%)$ & $11(12.9 \%)$ & $18(9.8 \%)$ \\
1 Hour & $1(1.0 \%)$ & $2(2.4 \%)$ & $3(1.6 \%)$ \\
2 Hours & $0(0.0 \%)$ & $1(1.2 \%)$ & $1(0.5 \%)$ \\
3 Hours & $0(0.0 \%)$ & $0(0.0 \%)$ & $0(0.0 \%)$ \\
4 Hours & $0(0.0 \%)$ & $0(0.0 \%)$ & $0(0.0 \%)$ \\
6 Hours & $0(0.0 \%)$ & $0(0.0 \%)$ & $0(0.0 \%)$ \\
8 Hours & $0(0.0 \%)$ & $0(0.0 \%)$ & $0(0.0 \%)$ \\
10 Hours & $19(19.4 \%)$ & $10(11.8 \%)$ & $29(15.8 \%)$ \\
12 Hours & $2(2.0 \%)$ & $4(4.7 \%)$ & $6(3.3 \%)$ \\
15 Hours & $57(58.2 \%)$ & $50(58.8 \%)$ & $107(58.5 \%)$ \\
24 Hours & $3(3.1 \%)$ & $2(2.4 \%)$ & $5(2.7 \%)$ \\
2 Days & $0(0.0 \%)$ & $0(0.0 \%)$ & $0(0.0 \%)$ \\
3 Days & $0(0.0 \%)$ & $0(0.0 \%)$ & $0(0.0 \%)$ \\
4 Days & $0(0.0 \%)$ & $0(0.0 \%)$ & $0(0.0 \%)$ \\
5 Days & $0(0.0 \%)$ & $0(0.0 \%)$ & $0(0.0 \%)$ \\
6 Days & $0(0.0 \%)$ & $0(0.0 \%)$ & $0(0.0 \%)$ \\
7 Days & $9(9.2 \%)$ & $5(5.9 \%)$ & $14(7.7 \%)$ \\
Other & & & $134(73.6 \%)$ \\
23. Secondary testing & $73(75.3 \%)$ & $61(71.8 \%)$ & $48(26.4 \%)$ \\
YES & $24(24.7 \%)$ & $24(28.2 \%)$ & \\
NO & & & \\
\hline
\end{tabular}


Table D7. Management by Division

\begin{tabular}{|c|c|c|c|c|c|}
\hline Question & Division I & Sub-Division & Division II & Division III & Overall \\
\hline \multicolumn{6}{|l|}{ 18. Emergency room referral } \\
\hline Amnesia & $12(26.7 \%)$ & $5(25.0 \%)$ & $14(34.1 \%)$ & $22(27.2 \%)$ & $53(28.3 \%)$ \\
\hline Unequal, dilated, pupils & $40(88.9 \%)$ & $17(85.0 \%)$ & $37(90.2 \%)$ & $70(86.4 \%)$ & $164(87.7 \%)$ \\
\hline Skull Fracture & $48(100 \%)$ & $21(100 \%)$ & $42(100 \%)$ & $86(100 \%)$ & $197(100 \%)$ \\
\hline Balance deficits & $12(26.7 \%)$ & $1(5.0 \%)$ & $9(22.0 \%)$ & $13(16.0 \%)$ & $35(18.7 \%)$ \\
\hline No improvement of symptom & $27(60.0 \%)$ & $7(35.0 \%)$ & $21(51.2 \%)$ & $30(37.0 \%)$ & $85(45.5 \%)$ \\
\hline Still symptomatic after event & $7(15.6 \%)$ & $1(5.0 \%)$ & $6(14.6 \%)$ & $8(9.9 \%)$ & $22(11.8 \%)$ \\
\hline Neurological deterioration & $43(95.6 \%)$ & $18(90.0 \%)$ & $39(95.1 \%)$ & $77(95.1 \%)$ & $177(94.7 \%)$ \\
\hline Cranial nerve deficits & $42(93.3 \%)$ & $16(80.0 \%)$ & $31(75.6 \%)$ & $67(82.7 \%)$ & $156(83.4 \%)$ \\
\hline Increased blood pressure & $27(60.0 \%)$ & $10(50.0 \%)$ & $26(63.4 \%)$ & $34(42.0 \%)$ & $97(51.9 \%)$ \\
\hline Symptoms worsen & $39(86.7 \%)$ & $19(95.0 \%)$ & $36(87.8 \%)$ & $71(87.7 \%)$ & $165(88.2 \%)$ \\
\hline Physician recommendation & $44(97.8 \%)$ & $19(95.0 \%)$ & $38(92.7 \%)$ & $76(93.8 \%)$ & $177(94.7 \%)$ \\
\hline Decrease in respirations & $33(73.3 \%)$ & $17(85.0 \%)$ & $36(87.8 \%)$ & $60(74.1 \%)$ & $146(78.1 \%)$ \\
\hline Mental status changes & $29(64.4 \%)$ & $9(45.0 \%)$ & $21(51.2 \%)$ & $57(70.4 \%)$ & $116(62.0 \%)$ \\
\hline Motor deficits & $31(68.9 \%)$ & $14(70.0 \%)$ & $26(63.4 \%)$ & $54(66.7 \%)$ & $125(66.8 \%)$ \\
\hline Additional symptoms present & $29(64.4 \%)$ & $14(70.0 \%)$ & $20(70.7 \%)$ & $58(71.6 \%)$ & $130(69.5 \%)$ \\
\hline Headache & $3(6.7 \%)$ & $1(5.0 \%)$ & $3(7.3 \%)$ & $3(3.7 \%)$ & $10(5.3 \%)$ \\
\hline Seizure & $42(93.3 \%)$ & $17(85.0 \%)$ & $42(100 \%)$ & $75(92.6 \%)$ & $175(93.6 \%)$ \\
\hline Vomiting & $22(48.9 \%)$ & $11(55.0 \%)$ & $22(53.7 \%)$ & $48(59.3 \%)$ & $103(55.1 \%)$ \\
\hline
\end{tabular}




\begin{tabular}{|c|c|c|c|c|c|}
\hline 33. Medications & Division I & Sub-Division & Division II & Division III & Overall \\
\hline Acetaminophen & $36(83.7 \%)$ & $16(88.9 \%)$ & $31(93.9 \%)$ & $50(71.4 \%)$ & $133(81.1 \%)$ \\
\hline Ibuprofen & $0(0.0 \%)$ & $1(5.6 \%)$ & $2(6.1 \%)$ & $4(5.7 \%)$ & $7(4.3 \%)$ \\
\hline Advil & $2(4.7 \%)$ & $0(0.0 \%)$ & $0(0.0 \%)$ & $2(2.9 \%)$ & $4(2.4 \%)$ \\
\hline Aleve & $1(2.3 \%)$ & $0(0.0 \%)$ & $0(0.0 \%)$ & $0(0.0 \%)$ & $1(0.6 \%)$ \\
\hline Continue Prescription Meds & $3(7.0 \%)$ & $0(0.0 \%)$ & $0(0.0 \%)$ & $9(12.9 \%)$ & $12(7.3 \%)$ \\
\hline Other & $1(2.3 \%)$ & $1(5.6 \%)$ & $0(0.0 \%)$ & $5(7.1 \%)$ & $7(4.3 \%)$ \\
\hline \multicolumn{6}{|l|}{ 34. Physician recommendations } \\
\hline YES & $33(73.3 \%)$ & $13(68.4 \%)$ & $21(56.8 \%)$ & $56(69.1 \%)$ & $123(67.6 \%)$ \\
\hline NO & $12(26.7 \%)$ & $6(31.6 \%)$ & $16(43.2 \%)$ & $25(30.9 \%)$ & $59(32.4 \%)$ \\
\hline \multicolumn{6}{|l|}{ 35. Documentation } \\
\hline Date of initial injury & $45(100 \%)$ & $20(100 \%)$ & $37(100 \%)$ & $81(100 \%)$ & $183(100 \%)$ \\
\hline MOI & $44(97.8 \%)$ & $20(100 \%)$ & $36(97.3 \%)$ & $79(97.5 \%)$ & $179(97.8 \%)$ \\
\hline State of consciousness & $43(95.6 \%)$ & $20(100 \%)$ & $36(97.3 \%)$ & $78(96.3 \%)$ & $177(96.7 \%)$ \\
\hline Time of injury & $34(75.6 \%)$ & $6(30 \%)$ & $25(67.6 \%)$ & $55(67.9 \%)$ & $120(65.6 \%)$ \\
\hline Signs \& Symptoms & $45(100 \%)$ & $20(100 \%)$ & $36(97.3 \%)$ & $81(100 \%)$ & $182(99.5 \%$ \\
\hline Clinical evaluation & $42(93.3 \%)$ & $20(100 \%)$ & $35(94.6 \%)$ & $80(98.8 \%)$ & $177(96.7 \%)$ \\
\hline Physician recommendations & $45(100 \%)$ & $20(100 \%)$ & $33(89.2 \%)$ & $65(80.2 \%)$ & $163(89.1 \%)$ \\
\hline Date of RTP & $35(77.8 \%)$ & $15(75.0 \%)$ & $30(81.1 \%)$ & $61(75.3 \%)$ & $141(77.0 \%)$ \\
\hline Instructions given & $32(71.1 \%)$ & $13(65.0 \%)$ & $29(78.4 \%)$ & $66(81.5 \%)$ & $140(76.5 \%)$ \\
\hline Patient history of concussion & $42(93.3 \%)$ & $18(90.0 \%)$ & $36(97.3 \%)$ & $70(86.4 \%)$ & $166(90.7 \%)$ \\
\hline \multicolumn{6}{|l|}{ 36. Monitor vital signs } \\
\hline YES & $30(66.7 \%)$ & $15(75.0 \%)$ & $30(81.1 \%)$ & $51(64.6 \%)$ & $126(69.6 \%)$ \\
\hline NO & $15(33.3 \%)$ & $5(25 \%)$ & $7(18.9 \%)$ & $28(35.4 \%)$ & $55(30.4 \%)$ \\
\hline
\end{tabular}




\begin{tabular}{|c|c|c|c|c|c|}
\hline 37. Delayed signs/symptoms & Division I & Sub-Division & Division II & Division III & Overall \\
\hline YES & $45(100 \%)$ & $20(100 \%)$ & $36(97.3 \%)$ & $79(100 \%)$ & $180(99.4 \%)$ \\
\hline $\mathrm{NO}$ & $0(0.0 \%)$ & $0(0.0 \%)$ & $1(2.7 \%)$ & $0(0.0 \%)$ & $1(0.6 \%)$ \\
\hline \multicolumn{6}{|l|}{ 38. Average time out } \\
\hline After asymptomatic & $8(17.8 \%)$ & $1(5.0 \%)$ & $13(35.1 \%)$ & $17(21.3 \%)$ & $39(21.4 \%)$ \\
\hline 1-3 Days & $6(13.3 \%)$ & $1(5.0 \%)$ & $4(10.8 \%)$ & $2(2.5 \%)$ & $13(7.1 \%)$ \\
\hline 4-6 Days & $11(24.4 \%)$ & $8(40.0 \%)$ & $11(29.7 \%)$ & $23(28.8 \%)$ & $53(29.1 \%)$ \\
\hline 7 Days & $15(33.3 \%)$ & $6(30.0 \%)$ & $6(16.2 \%)$ & $27(33.8 \%)$ & $54(29.7 \%)$ \\
\hline Other & $5(11.1 \%)$ & $4(20.0 \%)$ & $3(8.1 \%)$ & $11(13.8 \%)$ & $23(12.6 \%)$ \\
\hline \multicolumn{6}{|l|}{ 39. Asymptomatic RTP } \\
\hline YES & $26(59.1 \%)$ & $13(68.4 \%)$ & $20(54.1 \%)$ & $38(48.1 \%)$ & $97(54.2 \%)$ \\
\hline $\mathrm{NO}$ & $18(40.9 \%)$ & $6(31.6 \%)$ & $17(45.9 \%)$ & $41(51 . .9 \%)$ & $82(45.8 \%)$ \\
\hline
\end{tabular}


Table D8. Management by Years Certified Athletic Trainer

\begin{tabular}{|c|c|c|c|}
\hline Question & Less Then 10 Years ATC & Greater Then 10 Years ATC & Overall \\
\hline \multicolumn{4}{|l|}{ 18. Emergency room referral } \\
\hline Amnesia & $14(29 \%)$ & $39(28 \%)$ & $53(28 \%)$ \\
\hline Unequal, dilated, pupils & $38(79 \%)$ & $126(91 \%)$ & $164(88 \%)$ \\
\hline Skull Fracture & $46(96 \%)$ & $135(97 \%)$ & $181(97 \%)$ \\
\hline Balance deficits & $6(13 \%)$ & $29(21 \%)$ & $35(19 \%)$ \\
\hline No improvement of symptom & $14(29 \%)$ & $71(51 \%)$ & $85(46 \%)$ \\
\hline Still symptomatic after event & $4(8 \%)$ & $18(13 \%)$ & $22(12 \%)$ \\
\hline Neurological deterioration & $45(94 \%)$ & $132(95 \%)$ & $177(95 \%)$ \\
\hline Cranial nerve deficits & $40(83 \%)$ & $116(84 \%)$ & $156(84 \%)$ \\
\hline Increased blood pressure & $22(46 \%)$ & $75(54 \%)$ & $97(52 \%)$ \\
\hline Symptoms worsen & $40(84 \%)$ & $125(90 \%)$ & $165(88 \%)$ \\
\hline Physician recommendation & $45(94 \%)$ & $132(95 \%)$ & $177(95 \%)$ \\
\hline Decrease in respirations & $34(71 \%)$ & $112(81 \%)$ & $146(78 \%)$ \\
\hline Mental status changes & $30(63 \%)$ & $86(62 \%)$ & $116(62 \%)$ \\
\hline Motor deficits & $35(72.9 \%)$ & $90(65 \%)$ & $125(67 \%)$ \\
\hline Additional symptoms present & $29(61 \%)$ & $101(73 \%)$ & $130(70 \%)$ \\
\hline Headache & $1(2 \%)$ & $9(7 \%)$ & $10(4 \%)$ \\
\hline Seizure & $44(91 \%)$ & $131(94 \%)$ & $175(93 \%)$ \\
\hline Vomiting & $24(50 \%)$ & $79(57 \%)$ & $103(55 \%)$ \\
\hline \multicolumn{4}{|l|}{ 33. Medication } \\
\hline Acetaminophen & $35(80 \%)$ & $98(82 \%)$ & $133(81 \%)$ \\
\hline Ibuprofen & $2(5 \%)$ & $5(4 \%)$ & $7(4 \%)$ \\
\hline Advil & $1(3 \%)$ & $3(2 \%)$ & $4(3 \%)$ \\
\hline Aleve & $0(0.0 \%)$ & $1(0.8 \%)$ & $1(0.6 \%)$ \\
\hline Continue Prescription Meds & $3(7 \%)$ & $9(8 \%)$ & $12(7 \%)$ \\
\hline \multicolumn{4}{|l|}{ Other } \\
\hline \multicolumn{4}{|l|}{ 34. Physician recommendations } \\
\hline YES & $23(49 \%)$ & $100(74 \%)$ & $123(67 \%)$ \\
\hline NO & $24(51 \%)$ & $35(25 \%)$ & $59(32 \%)$ \\
\hline
\end{tabular}


Question

35. Documentation

Date of initial injury

MOI

State of consciousness

Time of injury

Signs \& Symptoms

Clinical evaluation

Physician recommendations

Date of RTP

Instructions given

Patient history of concussion

36. Monitor vital signs

$$
\text { YES }
$$

NO

37. Delayed signs/symptoms

$$
\text { YES }
$$

NO

38. Average time out

After asymptomatic

1-3 Days

4-6 Days

7 Days

Other

39. Asymptomatic RTP

YES
Less Then 10 Years ATC

$$
\begin{gathered}
47(100 \%) \\
46(98 \%) \\
46(98 \%) \\
30(64 \%) \\
46(98 \%) \\
44(94 \%) \\
40(85 \%) \\
37(79 \%) \\
38(81 \%) \\
42(90 \%) \\
\\
35(75 \%) \\
12(26 \%) \\
\\
47(100 \%) \\
0(0.0 \%) \\
\\
7(15 \%) \\
1(2 \%) \\
19(40 \%) \\
17(36 \%) \\
3(6 \%)
\end{gathered}
$$

$22(47 \%)$

$25(53 \%)$
Greater Then 10 Years ATC

\section{Overall}

$136(100 \%)$
$133(98 \%)$
$131(96 \%)$
$90(66 \%)$
$136(100 \%)$
$133(98 \%)$
$123(90 \%)$
$104(77 \%)$
$102(76 \%)$
$124(92 \%)$

$183(100 \%)$

$179(98 \%)$

$177(97 \%)$

$120(66 \%)$

$182(99 \%)$

$177(97 \%)$

$163(89 \%)$

$141(77 \%)$

$140(77 \%)$

$166(91 \%)$

$91(68 \%)$

$43(32 \%)$

$126(70 \%)$

$55(30 \%)$

133(99\%)

$180(99 \%)$

$1(0.7 \%)$

$1(0.6 \%)$

$32(24 \%)$

$39(21 \%)$

$13(7 \%)$

$53(29 \%)$

$54(30 \%)$

$23(13 \%)$

$37(27 \%)$

20(15\%)

97(54\%)

$75(57 \%)$

$57(43 \%)$

$82(46 \%)$ 
Table D9. Management by Years Head Football Athletic Trainer

\begin{tabular}{|c|c|c|c|}
\hline Question & Less Then 10 Years FB ATC & Greater Then 10 Years FB ATC & Overall \\
\hline \multicolumn{4}{|l|}{ 18. Emergency room referral } \\
\hline Amnesia & $30(30 \%)$ & $23(26.4 \%)$ & $53(28.3 \%)$ \\
\hline Unequal, dilated, pupils & $84(84 \%)$ & $80(92 \%)$ & $164(87.7 \%)$ \\
\hline Skull Fracture & $98(98 \%)$ & $95.4(83 \%)$ & $181(96.8 \%)$ \\
\hline Balance deficits & $12(12 \%)$ & $23(26.4 \%)$ & $35(18.7 \%)$ \\
\hline No improvement of symptom & $36(36 \%)$ & $49(56.3 \%)$ & $85(45.5 \%)$ \\
\hline Still symptomatic after event & $11(11 \%)$ & $11(12.6 \%)$ & $22(11.8 \%)$ \\
\hline Neurological deterioration & $96(96 \%)$ & $81(93 \%)$ & $177(94.7 \%)$ \\
\hline Cranial nerve deficits & $85(85 \%)$ & $71(81.6 \%)$ & $156(83.4 \%)$ \\
\hline Increased blood pressure & $49(49 \%)$ & $48(55.2 \%)$ & $97(51.9 \%)$ \\
\hline Symptoms worsen & $90(90 \%)$ & $75(86.2 \%)$ & $165(88.2 \%)$ \\
\hline Physician recommendation & $92(92 \%)$ & $85(97.7 \%)$ & $177(94.7 \%)$ \\
\hline Decrease in respirations & $75(75 \%)$ & $71(81.6 \%)$ & $146(78.1 \%)$ \\
\hline Mental status changes & $59(59 \%)$ & $57(65.5 \%)$ & $116(62 \%)$ \\
\hline Motor deficits & $68(68 \%)$ & $57(65.5 \%)$ & $125(66.8 \%)$ \\
\hline Additional symptoms present & $68(68 \%)$ & $62(71.3 \%)$ & $130(70 \%)$ \\
\hline Headache & $3(3 \%)$ & $7(8 \%)$ & $10(5 \%)$ \\
\hline Seizure & $94(94 \%)$ & $81(93.1 \%)$ & $175(93.6 \%)$ \\
\hline Vomiting & $55(55 \%)$ & $48(55.2 \%)$ & $103(55 \%)$ \\
\hline \multicolumn{4}{|l|}{ 33. Medication } \\
\hline Acetaminophen & $70(81 \%)$ & $63(81 \%)$ & $133(81 \%)$ \\
\hline Ibuprofen & $4(4 \%)$ & $3(3.8 \%)$ & $7(4 \%)$ \\
\hline Advil & $1(1.2 \%)$ & $3(3.8 \%)$ & $4(2.4 \%)$ \\
\hline Aleve & $1(1.2 \%)$ & $0(0.0 \%)$ & $1(0.6 \%)$ \\
\hline Continue Prescription Meds & $5(5.8 \%)$ & $7(9.0 \%)$ & $12(7.3 \%)$ \\
\hline Other & $5(5.8 \%)$ & $2(2.6 \%)$ & $7(4.3 \%)$ \\
\hline \multicolumn{4}{|l|}{ 34. Physician recommendations } \\
\hline YES & $60(62 \%)$ & $63(73.3 \%)$ & $123(67.6 \%)$ \\
\hline NO & $36(37.5 \%)$ & $23(26.7 \%)$ & $59(32.4 \%)$ \\
\hline
\end{tabular}


Question

35. Documentation

Date of initial injury

MOI

State of consciousness

Time of injury

Signs \& Symptoms

Clinical evaluation

Physician recommendations

Date of RTP

Instructions given

Patient history of concussion

36. Monitor vital signs

YES

NO

37. Delayed signs/symptoms

YES

NO

38. Average time out

After asymptomatic

1-3 Days

4-6 Days

7 Days

Other

39. Asymptomatic RTP

YES
Less Then 10 Years FB ATC

Greater Then 10 Years FB ATC

Overall

$\begin{array}{ccc}97(100 \%) & 86(100 \%) & 183(100 \%) \\ 95(97.9 \%) & 84(97.7 \%) & 179(97.8 \%) \\ 94(96.9 \%) & 83(96.5 \%) & 177(96.7 \%) \\ 62(63.9 \%) & 58(67.4 \%) & 120(65.6 \%) \\ 96(99 \%) & 86(100 \%) & 182(99.5 \%) \\ 94(96.9 \%) & 83(96.5 \%) & 177(96.7 \%) \\ 84(86.6 \%) & 79(91.9 \%) & 163(89 \%) \\ 81(83.5 \%) & 60(69.8 \%) & 141(77 \%) \\ 76(78 \%) & 64(74 \%) & 140(77 \%) \\ 90(93 \%) & 76(88 \%) & 166(91 \%) \\ & & \\ 66(68 \%) & 60(72 \%) & 126(70 \%) \\ 31(32 \%) & 24(29 \%) & 55(31 \%) \\ & & \\ 97(100 \%) & 83(99 \%) & 180(99 \%) \\ 0(0.0 \%) & 1(1.2 \%) & 1(0.6 \%) \\ 21(21.6 \%) & & \\ 6(6.2 \%) & 18(21 \%) & 39(21 \%) \\ 30(31 \%) & 7(8.2 \%) & 13(7.1 \%) \\ 30(31 \%) & 23(27 \%) & 53(29 \%) \\ 10(10 \%) & 24(28 \%) & 54(30 \%) \\ 55(57 \%) & 13(15 \%) & 23(12.6 \%) \\ 42(43 \%) & & 97(54 \%) \\ & 42(51 \%) & 82(46 \%)\end{array}$


Table D10. Return-To-Play by Division

\begin{tabular}{|c|c|c|c|c|c|}
\hline Question & Division I & Sub-Division & Division II & Division III & Overall \\
\hline \multicolumn{6}{|l|}{ 16. RTP methods } \\
\hline Clinical Examination & $45(100 \%)$ & $19(95.0 \%)$ & $40(97.6 \%)$ & $79(97.5 \%)$ & $183(97.9 \%)$ \\
\hline RTP Guidelines & $19(42.2 \%)$ & $12(60.0 \%)$ & $21(51.2 \%)$ & $41(50.6 \%)$ & $93(49.7 \%)$ \\
\hline Self-Report & $18(40.0 \%)$ & $12(60.0 \%)$ & $22(53.7 \%)$ & $33(40.7 \%)$ & $85(45.5 \%)$ \\
\hline SAC & $17(37.8 \%)$ & $10(50.0 \%)$ & $16(39.0 \%)$ & $26(32.1 \%)$ & $69(36.9 \%)$ \\
\hline Neuropsychological (Comp) & $34(75.6 \%)$ & $11(55.0 \%)$ & $18(43.9 \%)$ & $44(54.3 \%)$ & $107(57.2 \%)$ \\
\hline Neuropsychological (Paper) & $3(6.7 \%)$ & $0(0.0 \%)$ & $2(4.9 \%)$ & $5(6.2 \%)$ & $10(5.3 \%)$ \\
\hline BESS & $10(22.2 \%)$ & $4(20.0 \%)$ & $12(29.3 \%)$ & $18(22.2 \%)$ & $44(23.5 \%)$ \\
\hline Physician Recommendations & $43(95.6 \%)$ & $18(90.0 \%)$ & $30(73.2 \%)$ & $54(66.7 \%)$ & $142(75.9 \%)$ \\
\hline Symptoms Checklist & $33(73.3 \%)$ & $15(75.0 \%)$ & $30(73.2 \%)$ & $64(79.0 \%)$ & $142(75.9 \%)$ \\
\hline Head CT/Brain MRI & $5(11.1 \%)$ & $2(10.0 \%)$ & $6(14.6 \%)$ & $8(9.9 \%)$ & $21(11.2 \%)$ \\
\hline SCAT & $2(4.4 \%)$ & $3(15.0 \%)$ & $3(7.3 \%)$ & $6(7.4 \%)$ & $14(7.5 \%)$ \\
\hline Physical Exertion Protocol & $38(84.4 \%)$ & $16(80.0 \%)$ & $34(82.9 \%)$ & $67(82.7)$ & $155(82.9 \%)$ \\
\hline \multicolumn{6}{|l|}{ 17. Singe RTP method } \\
\hline Clinical Examination & $10(22.7 \%)$ & $8(42.1 \%)$ & $10(24.4 \%)$ & $18(22.5 \%)$ & $46(25.0 \%)$ \\
\hline RTP Guidelines & $0(0.0 \%)$ & $0(0.0 \%)$ & $1(2.4 \%)$ & $1(1.3 \%)$ & $2(1.1 \%)$ \\
\hline Self-Report & $0(0.0 \%)$ & $0(0.0 \%)$ & $0(0.0 \%)$ & $0(0.0 \%)$ & $0(0.0 \%)$ \\
\hline SAC & $1(2.3 \%)$ & $0(0.0 \%)$ & $0(0.0 \%)$ & $3(3.8 \%)$ & $4(2.2 \%)$ \\
\hline Neuropsychological (Comp) & $7(15.9 \%)$ & $0(0.0 \%)$ & $5(12.2 \%)$ & $13(16.3 \%)$ & $25(13.6 \%)$ \\
\hline Neuropsychological (Paper) & $0(0.0 \%)$ & $0(0.0 \%)$ & $0(0.0 \%)$ & $0(0.0 \%)$ & $0(0.0 \%)$ \\
\hline BESS & $0(0.0 \%)$ & $0(0.0 \%)$ & $0(0.0 \%)$ & $0(0.0 \%)$ & $0(0.0 \%)$ \\
\hline Physician Recommendations & $15(34.1 \%)$ & $6(31.6 \%)$ & $7(17.1 \%)$ & $14(17.5 \%)$ & $42(22.8 \%)$ \\
\hline Symptoms Checklist & $3(6.8 \%)$ & $1(5.3 \%)$ & $5(12.2 \%)$ & $8(10.0 \%)$ & $17(9.2 \%)$ \\
\hline Head CT/Brain MRI & $1(2.3 \%)$ & $0(0.0 \%)$ & $3(7.3 \%)$ & $5(5.0 \%)$ & $8(4.3 \%)$ \\
\hline
\end{tabular}




\begin{tabular}{|c|c|c|c|c|c|}
\hline SCAT & $1(2.3 \%)$ & $0(0.0 \%)$ & $1(2.4 \%)$ & $2(2.5 \%)$ & $4(2.2 \%)$ \\
\hline Physical Exertion Protocol & $6(13.6 \%)$ & $4(21.1 \%)$ & $9(22.0 \%)$ & $17(21.3 \%)$ & $36(19.6 \%)$ \\
\hline \multicolumn{6}{|l|}{ 0. Symptomatic RTP } \\
\hline YES & $0(0.0 \%)$ & $1(5.0 \%)$ & $2(5.1 \%)$ & $0(0.0 \%)$ & $3(1.6 \%)$ \\
\hline NO & $45(100 \%)$ & $19(95.0 \%)$ & $37(94.9 \%)$ & $81(100 \%)$ & $182(98.4 \%)$ \\
\hline \multicolumn{6}{|l|}{ 1. Physician evaluations } \\
\hline YES & $22(48.9 \%)$ & $14(73.7 \%)$ & $28(71.8 \%)$ & $59(72.8 \%)$ & $123(66.8 \%)$ \\
\hline NO & $23(51.1 \%)$ & $5(26.3 \%)$ & $11(28.2 \%)$ & $22(27.2 \%)$ & $61(33.2 \%)$ \\
\hline \multicolumn{6}{|l|}{ 4. Guidelines } \\
\hline Cantu & $15(36.6 \%)$ & $8(47.1 \%)$ & $15(40.5 \%)$ & $29(37.7 \%)$ & $67(39.9 \%)$ \\
\hline Colorado & $4(9.8 \%)$ & $3(17.6 \%)$ & $9(24.3 \%)$ & $7(9.1 \%)$ & $23(13.4 \%)$ \\
\hline AAN & $7(17.1 \%)$ & $6(35.3 \%)$ & $9(24.3 \%)$ & $22(28.6 \%)$ & $54(31.4 \%)$ \\
\hline Zurich 2008 & $17(41.5 \%)$ & $6(35.3 \%)$ & $9(24.3 \%)$ & $22(28.6 \%)$ & $54(31.4 \%)$ \\
\hline NATA Position Statement & $38(92.7 \%)$ & $15(88.2 \%)$ & $31(83.8 \%)$ & $60(77.9 \%)$ & $144(83.7 \%)$ \\
\hline
\end{tabular}


Table D11. Return-To-Play by Years Certified Athletic Trainer

\begin{tabular}{|c|c|c|c|}
\hline Question & Less Then 10 Years ATC & Greater Then 10 Years ATC & Overall \\
\hline \multicolumn{4}{|l|}{ 16. RTP methods } \\
\hline Clinical Examination & $47(98 \%)$ & $136(98 \%)$ & $183(98 \%)$ \\
\hline RTP Guidelines & $28(53 \%)$ & $65(47 \%)$ & $93(50 \%)$ \\
\hline Self-Report & $29(60 \%)$ & $56(40 \%)$ & $85(45 \%)$ \\
\hline $\mathrm{SAC}$ & $18(38 \%)$ & $51(37 \%)$ & $69(37 \%)$ \\
\hline Neuropsychological (Comp) & $23(48 \%)$ & $84(60 \%)$ & $107(57 \%)$ \\
\hline Neuropsychological (Paper) & $3(6 \%)$ & $7(5 \%)$ & $10(5.5 \%)$ \\
\hline BESS & $10(20 \%)$ & $34(25 \%)$ & $44(24 \%)$ \\
\hline Physician Recommendations & $36(75 \%)$ & $109(78 \%)$ & $145(78 \%)$ \\
\hline Symptoms Checklist & $37(77 \%)$ & $105(75 \%)$ & $142(76 \%)$ \\
\hline Head CT/Brain MRI & $5(10 \%)$ & $16(12 \%)$ & $21(11 \%)$ \\
\hline SCAT & $4(8 \%)$ & $10(7 \%)$ & $14(8 \%)$ \\
\hline Physical Exertion Protocol & $40(83 \%)$ & $115(83 \%)$ & $155(83 \%)$ \\
\hline \multicolumn{4}{|l|}{ 17. Singe RTP method } \\
\hline Clinical Examination & $11(23 \%)$ & $35(26 \%)$ & $46(25 \%)$ \\
\hline RTP Guidelines & $1(2 \%)$ & $1(0.7 \%)$ & $2(1 \%)$ \\
\hline Self-Report & $0(0.0 \%)$ & $0(0.0 \%)$ & $0(0.0 \%)$ \\
\hline SAC & $2(4 \%)$ & $2(2 \%)$ & $4(2 \%)$ \\
\hline Neuropsychological (Comp) & $10(21 \%)$ & $15(10 \%)$ & $25(14 \%)$ \\
\hline Neuropsychological (Paper) & $0(0.0 \%)$ & $0(0.0 \%)$ & $0(0.0 \%)$ \\
\hline BESS & $0(0.0 \%)$ & $0(0.0 \%)$ & $0(0.0 \%)$ \\
\hline Physician Recommendations & $6(13 \%)$ & $36(26 \%)$ & $42(23 \%)$ \\
\hline Symptoms Checklist & $4(9 \%)$ & $13(10 \%)$ & $17(9 \%)$ \\
\hline Head CT/Brain MRI & $2(4 \%)$ & $6(4 \%)$ & $8(4 \%)$ \\
\hline SCAT & $2(4 \%)$ & $2(2 \%)$ & $4(2 \%)$ \\
\hline Physical Exertion Protocol & $9(19 \%)$ & $27(20 \%)$ & $36(19.5 \%)$ \\
\hline \multicolumn{4}{|l|}{ 20. Symptomatic RTP } \\
\hline YES & $0(0.0 \%)$ & $3(2 \%)$ & $3(1 \%)$ \\
\hline NO & $47(100 \%)$ & $135(98 \%)$ & $182(98 \%)$ \\
\hline
\end{tabular}


Question

21. Physician evaluations

YES

NO

24. Guidelines

Cantu

Colorado

AAN

Zurich 2008

NATA Position Statement
Less Then 10 Years ATC

$36(77 \%)$

$11(24 \%)$

$16(35 \%)$

$5(11 \%)$

$8(17 \%)$

$12(26 \%)$

$37(81 \%)$
Greater Then 10 Years ATC

Overall

$87(64 \%)$

$50(37 \%)$

$51(41 \%)$

$18(14 \%)$

$20(16 \%)$

$42(33 \%)$

$107(85 \%)$
$123(67 \%)$

$61(33 \%)$

$67(39 \%)$

$23(14 \%)$

$28(16 \%)$

$54(31 \%)$

$144(85 \%)$ 
Table D12. Return-To-Play by Years Head Football Athletic Trainer

\begin{tabular}{|c|c|c|c|}
\hline Question & Less Then 10 Years FB ATC & Greater Then 10 Years FB ATC & Overall \\
\hline \multicolumn{4}{|l|}{ 16. RTP methods } \\
\hline Clinical Examination & $99(99 \%)$ & $84(97 \%)$ & $183(98 \%)$ \\
\hline RTP Guidelines & $48(48 \%)$ & $45(52 \%)$ & $93(50 \%)$ \\
\hline Self-Report & $51(51 \%)$ & $34(39 \%)$ & $85(45 \%)$ \\
\hline SAC & $37(37 \%)$ & $32(37 \%)$ & $69(37 \%)$ \\
\hline Neuropsychological (Comp) & $55(55 \%)$ & $52(60 \%)$ & $107(57 \%)$ \\
\hline Neuropsychological (Paper) & $6(6 \%)$ & $4(5 \%)$ & $10(5 \%)$ \\
\hline BESS & $24(24 \%)$ & $20(23 \%)$ & $44(24 \%)$ \\
\hline Physician Recommendations & $75(75 \%)$ & $70(81 \%)$ & $145(78 \%)$ \\
\hline Symptoms Checklist & $77(77 \%)$ & $65(75 \%)$ & $142(76 \%)$ \\
\hline Head CT/Brain MRI & $9(9 \%)$ & $12(14 \%)$ & $21(11 \%)$ \\
\hline SCAT & $7(7 \%)$ & $7(8 \%)$ & $14(7.5 \%)$ \\
\hline Physical Exertion Protocol & $88(88 \%)$ & $67(77 \%)$ & $155(83 \%)$ \\
\hline \multicolumn{4}{|l|}{ 17. Singe RTP method } \\
\hline Clinical Examination & $22(22 \%)$ & $24(28 \%)$ & $46(25 \%)$ \\
\hline RTP Guidelines & $1(1 \%)$ & $1(1.2 \%)$ & $2(1.1 \%)$ \\
\hline Self-Report & $0(0.0 \%)$ & $0(0.0 \%)$ & $0(0.0 \%)$ \\
\hline SAC & $4(4 \%)$ & $0(0.0 \%)$ & $4(2.2 \%)$ \\
\hline Neuropsychological (Comp) & $16(16.2 \%)$ & $9(11 \%)$ & $25(14 \%)$ \\
\hline Neuropsychological (Paper) & $0(0.0 \%)$ & $0(0.0 \%)$ & $0(0.0 \%)$ \\
\hline BESS & $0(0.0 \%)$ & $0(0.0 \%)$ & $0(0.0 \%)$ \\
\hline Physician Recommendations & $20(20 \%)$ & $22(26 \%)$ & $42(23 \%)$ \\
\hline Symptoms Checklist & $11(11 \%)$ & $6(7 \%)$ & $17(9 \%)$ \\
\hline Head CT/Brain MRI & $3(3 \%)$ & $5(6 \%)$ & $8(4 \%)$ \\
\hline SCAT & $2(2 \%)$ & $2(2.4 \%)$ & $4(2.2 \%)$ \\
\hline Physical Exertion Protocol & $20(20 \%)$ & $16(19 \%)$ & $36(19.5 \%)$ \\
\hline \multicolumn{4}{|l|}{ 20. Symptomatic RTP } \\
\hline YES & $2(2 \%)$ & $1(1.1 \%)$ & $3(1.6 \%)$ \\
\hline NO & $96(98 \%)$ & $86(99 \%)$ & $182(98.5 \%)$ \\
\hline
\end{tabular}


Question

21. Physician evaluations

YES

NO

24. Guidelines

Cantu

Colorado

AAN

Zurich 2008

NATA Position Statement
Less Then 10 Years FB ATC Greater Then 10 Years FB ATC

Overall

$69(70 \%)$

$29(30 \%)$

$32(34 \%)$

$8(8.5 \%)$

$14(15 \%)$

$31(33 \%)$

$79(84 \%)$
$54(63 \%)$

$32(37 \%)$

$35(45 \%)$

$15(19.2 \%)$

$14(18 \%)$

$23(30 \%)$

$65(83 \%)$
$123(67 \%)$

61(33\%)

$67(39 \%)$

$23(13 \%)$

$28(16 \%)$

$54(31 \%)$

$144(84 \%)$ 
Table D13. Education by Division

\begin{tabular}{|c|c|c|c|c|c|}
\hline Question & Division I & Sub-Division & Division II & Division III & Overall \\
\hline \multicolumn{6}{|l|}{ 9a. Identify a concussion } \\
\hline Yes & $48(100 \%)$ & $20(95.2 \%)$ & $42(100 \%)$ & $83(98.8 \%)$ & $193(99.0 \%)$ \\
\hline No & $0(0.0 \%)$ & $1(4.8 \%)$ & $0(0.0 \%)$ & $1(1.2 \%)$ & $2(1.0 \%)$ \\
\hline \multicolumn{6}{|l|}{ 9b. Manage a concussion } \\
\hline Yes & $48(100 \%)$ & $20(95.2 \%)$ & $42(100 \%)$ & $83(98.8 \%)$ & $193(99.0 \%)$ \\
\hline No & $0(0.0 \%)$ & $1(4.8 \%)$ & $0(0.0 \%)$ & $1(1.2 \%)$ & $2(1.0 \%)$ \\
\hline \multicolumn{6}{|l|}{ 10. Concussion education } \\
\hline Undergraduate Education & $41(85.4 \%)$ & $17(81.0 \%)$ & $33(78.6 \%)$ & $64(76.2 \%)$ & $155(79.5 \%)$ \\
\hline Post Grad Education & $27(56.3 \%)$ & $14(66.4 \%)$ & $26(61.9 \%)$ & $45(53.6 \%)$ & $112(57.4 \%)$ \\
\hline Journal of Athletic Training & $28(58.3 \%)$ & $15(71.4 \%)$ & $29(69.0 \%)$ & $41(48.8 \%)$ & $113(57.9 \%)$ \\
\hline NATA Convention & $25(52.1 \%)$ & $15(71.4 \%)$ & $30(71.4 \%)$ & $41(48.8 \%)$ & $111(56.9 \%)$ \\
\hline Regional Convention & $20(41.7 \%)$ & $12(57.1 \%)$ & $13(31.0 \%)$ & $39(46.4 \%)$ & $84(43.1 \%)$ \\
\hline Other & $17(35.4 \%)$ & $13(61.9 \%)$ & $11(26.2 \%)$ & $23(27.4 \%)$ & $64(32.8 \%)$ \\
\hline No Formal Training & $0(0.0 \%)$ & $0(0.0 \%)$ & $0(0.0 \%)$ & $1(1.2 \%)$ & $1(0.5 \%)$ \\
\hline \multicolumn{6}{|l|}{ 28. Institution management } \\
\hline Poor & $0(0.0 \%)$ & $0(0.0 \%)$ & $0(0.0 \%)$ & $0(0.0 \%)$ & $0(0.0 \%)$ \\
\hline Fair & $0(0.0 \%)$ & $0(0.0 \%)$ & $0(0.0 \%)$ & $0(0.0 \%)$ & $0(0.0 \%)$ \\
\hline Average & $2(4.4 \%)$ & $3(15.0 \%)$ & $9(23.7 \%)$ & $8(9.9 \%)$ & $22(12.0 \%)$ \\
\hline Good & $15(33.3 \%)$ & $10(50.0 \%)$ & $16(42.1 \%)$ & $39(48.1 \%)$ & $80(43.5 \%)$ \\
\hline Very good & $27(60 \%)$ & $7(35 \%)$ & $11(28.9 \%)$ & $31(38.3 \%)$ & $76(41.3 \%)$ \\
\hline
\end{tabular}




\begin{tabular}{|c|c|c|c|c|c|}
\hline 29. Severe head trauma & Division I & Sub-Division & Division II & Division III & Overall \\
\hline Poor & $0(0.0 \%)$ & $0(0.0 \%)$ & $0(0.0 \%)$ & $0(0.0 \%)$ & $0(0.0 \%)$ \\
\hline Fair & $0(0.0 \%)$ & $0(0.0 \%)$ & $0(0.0 \%)$ & $0(0.0 \%)$ & $0(0.0 \%)$ \\
\hline Average & $0(0.0 \%)$ & $1(0.5 \%)$ & $2(5.3 \%)$ & $7(8.6 \%)$ & $10(5.4 \%)$ \\
\hline Good & $22(48.9 \%)$ & $13(65.0 \%)$ & $21(55.3 \%)$ & $48(59.3 \%)$ & $104(56.5 \%)$ \\
\hline Very good & $23(51.1 \%)$ & $6(30.0 \%)$ & $15(39.5 \%)$ & $25(30.9 \%)$ & $69(37.5 \%)$ \\
\hline \multicolumn{6}{|c|}{ 30. Severity of concussions } \\
\hline YES & $43(95.6 \%)$ & $20(100 \%)$ & $35(92.1 \%)$ & $75(92.6 \%)$ & $173(94.0 \%)$ \\
\hline NO & $2(4.4 \%)$ & $0(0.0 \%)$ & $3(7.9 \%)$ & $6(7.4 \%)$ & $11(6.0 \%)$ \\
\hline \multicolumn{6}{|c|}{ 31. Avoid harmful substances } \\
\hline Always & $38(84.4 \%)$ & $18(90.0 \%)$ & $32(84.2 \%)$ & $64(79.0 \%)$ & $152(82.6 \%)$ \\
\hline Most of the time & $5(11.1 \%)$ & $1(5.0 \%)$ & $4(10.5 \%)$ & $15(18.5 \%)$ & $25(13.6 \%)$ \\
\hline Half the time & $0(0.0 \%)$ & $0(0.0 \%)$ & $0(0.0 \%)$ & $0(0.0 \%)$ & $0(0.0 \%)$ \\
\hline Some of the time & $1(2.2 \%)$ & $0(0.0 \%)$ & $2(5.3 \%)$ & $2(2.5 \%)$ & $5(2.7 \%)$ \\
\hline Never & $1(2.2 \%)$ & $1(5.0 \%)$ & $0(0.0 \%)$ & $0(0.0 \%)$ & $2(1.1 \%)$ \\
\hline \multicolumn{6}{|l|}{ 32. Well balanced diet } \\
\hline Always & $20(44.4 \%)$ & $10(50.0 \%)$ & $21(55.3 \%)$ & $31(38.3 \%)$ & $82(44.6 \%)$ \\
\hline Most of the time & $11(24.4 \%)$ & $5(25.0 \%)$ & $11(28.9 \%)$ & $29(35.8 \%)$ & $56(30.4 \%)$ \\
\hline Half the time & $3(6.7 \%)$ & $2(10.0 \%)$ & $1(2.6 \%)$ & $4(4.9 \%)$ & $10(5.4 \%)$ \\
\hline Some of the time & $6(13.3 \%)$ & $0(0.0 \%)$ & $3(7.9 \%)$ & $12(14.8 \%)$ & $21(11.4 \%)$ \\
\hline Never & $5(11.1 \%)$ & $3(15 \%)$ & $2(5.3 \%)$ & $5(6.2 \%)$ & $15(8.2 \%)$ \\
\hline
\end{tabular}


Table D14. Education by Years Certified Athletic Trainer

\begin{tabular}{|c|c|c|c|}
\hline Question & Less Then 10 Years ATC & Greater Then 10 Years ATC & Overall \\
\hline \multicolumn{4}{|l|}{ 9a. Identify a concussion } \\
\hline Yes & $50(100 \%)$ & $143(98 \%)$ & $193(99 \%)$ \\
\hline No & $0(0.0 \%)$ & $2(1 \%)$ & $2(1 \%)$ \\
\hline \multicolumn{4}{|l|}{ 9b. Manage a concussion } \\
\hline Yes & $50(100 \%)$ & $143(99 \%)$ & $193(99 \%)$ \\
\hline No & $0(0.0 \%)$ & $2(1 \%)$ & $2(1 \%)$ \\
\hline \multicolumn{4}{|l|}{ 10. Concussion education } \\
\hline Undergraduate Education & $43(86 \%)$ & $112(775)$ & $155(80 \%)$ \\
\hline Post Grad Education & $25(50 \%)$ & $87(60 \%)$ & $112(58 \%)$ \\
\hline Journal of Athletic Training & $30(60 \%)$ & $83(57 \%)$ & $13(58 \%)$ \\
\hline NATA Convention & $21(42 \%)$ & $90(62 \%)$ & $111(57 \%)$ \\
\hline Regional Convention & $15(30 \%)$ & $69(48 \%)$ & $84(43 \%)$ \\
\hline Other & $7(14 \%)$ & $57(39 \%)$ & $64(33 \%)$ \\
\hline No Formal Training & $0(0.0 \%)$ & $1(0.7 \%)$ & $1(0.5 \%)$ \\
\hline \multicolumn{4}{|l|}{ 28. Institution management } \\
\hline Poor & $0(0.0 \%)$ & $0(0.0 \%)$ & $0(0.0 \%)$ \\
\hline Fair & $1(2 \%)$ & $5(4 \%)$ & $6(3 \%)$ \\
\hline Average & $9(19 \%)$ & $13(10 \%)$ & $22(12 \%)$ \\
\hline Good & $23(49 \%)$ & $57(42 \%)$ & $80(44 \%)$ \\
\hline Very good & $14(30 \%)$ & $62(45 \%)$ & $76(41 \%)$ \\
\hline \multicolumn{4}{|l|}{ 29. Severe head trauma } \\
\hline Poor & $0(0.0 \%)$ & $0(0.0 \%)$ & $0(0.0 \%)$ \\
\hline Fair & $0(0.0 \%)$ & $0(0.0 \%)$ & $0(0.0 \%)$ \\
\hline Average & $2(4 \%)$ & $8(6 \%)$ & $10(6 \%)$ \\
\hline Good & $34(73 \%)$ & $70(51 \%)$ & $104(57 \%)$ \\
\hline Very good & $11(24 \%)$ & $58(43 \%)$ & $69(38 \%)$ \\
\hline \multicolumn{4}{|l|}{ 30. Severity of concussions } \\
\hline YES & $46(98 \%)$ & $127(93 \%)$ & $173(94 \%)$ \\
\hline NO & $1(2 \%)$ & $10(7 \%)$ & $11(6 \%)$ \\
\hline
\end{tabular}




\begin{tabular}{|c|c|c|c|}
\hline Question & Less Then 10 Years ATC & Greater Then Years FB ATC & Overall \\
\hline \multicolumn{4}{|c|}{ 31. Avoid harmful substances } \\
\hline Always & $38(81 \%)$ & $114(83 \%)$ & $152(83 \%)$ \\
\hline Most of the time & $8(17 \%)$ & $17(13 \%)$ & $25(14 \%)$ \\
\hline Half the time & $0(0.0 \%)$ & $0(0.0 \%)$ & $0(0.0 \%)$ \\
\hline Some of the time & $1(2 \%)$ & $4(3 \%)$ & $5(2.5 \%)$ \\
\hline Never & $0(0.0 \%)$ & $0(0.0 \%)$ & $0(0.0 \%)$ \\
\hline \multicolumn{4}{|l|}{ 32. Well balanced diet } \\
\hline Always & $22(48 \%)$ & $60(41 \%)$ & $82(45 \%)$ \\
\hline Most of the time & $11(29 \%)$ & $45(33 \%)$ & $56(30 \%)$ \\
\hline Half the time & $5(8 \%)$ & $5(2 \%)$ & $10(5.4 \%)$ \\
\hline Some of the time & $8(17 \%)$ & $13(10 \%)$ & $21(11 \%)$ \\
\hline Never & $1(2 \%)$ & $14(10 \%)$ & $15(8 \%)$ \\
\hline
\end{tabular}


Table D15. Education by Years Head Football Athletic Trainer

\begin{tabular}{|c|c|c|c|}
\hline Question & Less Then 10 Years FB ATC & Greater Then 10 Years FB ATC & Overall \\
\hline \multicolumn{4}{|l|}{ 9a. Identify a concussion } \\
\hline Yes & $104(100 \%)$ & $89(98 \%)$ & $193(99 \%)$ \\
\hline No & $0(0.0 \%)$ & $2(2.2 \%)$ & $2(1 \%)$ \\
\hline \multicolumn{4}{|l|}{ 9b. Manage a concussion } \\
\hline Yes & $104(100 \%)$ & $89(98 \%)$ & $193(99 \%)$ \\
\hline No & $0(0.0 \%)$ & $2(2.2 \%)$ & $2(1 \%)$ \\
\hline \multicolumn{4}{|l|}{ 10. Concussion education } \\
\hline Undergraduate Education & $90(87 \%)$ & $65(71 \%)$ & $155(79.5 \%)$ \\
\hline Post Grad Education & $60(57 \%)$ & $52(57 \%)$ & $112(57 \%)$ \\
\hline Journal of Athletic Training & $62(60 \%)$ & $51(56 \%)$ & $113(58 \%)$ \\
\hline NATA Convention & $55(53 \%)$ & $56(62 \%)$ & $111(57 \%)$ \\
\hline Regional Convention & $40(39 \%)$ & $44(49 \%)$ & $84(43 \%)$ \\
\hline Other & $27(26 \%)$ & $31(41 \%)$ & $64(33 \%)$ \\
\hline No Formal Training & $0(0.0 \%)$ & $1(1.1 \%)$ & $1(0.5 \%)$ \\
\hline \multicolumn{4}{|l|}{ 28. Institution management } \\
\hline Poor & $0(0.0 \%)$ & $0(0.0 \%)$ & $0(0.0 \%)$ \\
\hline Fair & $3(3.1 \%)$ & $3(3.5 \%)$ & $6(3.3 \%)$ \\
\hline Average & $14(14 \%)$ & $8(9 \%)$ & $22(12 \%)$ \\
\hline Good & $45(46 \%)$ & $35(41 \%)$ & $80(44 \%)$ \\
\hline Very good & $36(37 \%)$ & $40(47 \%)$ & $76(41 \%)$ \\
\hline \multicolumn{4}{|l|}{ 29. Severe head trauma } \\
\hline Poor & $0(0.0 \%)$ & $0(0.0 \%)$ & $0(0.0 \%)$ \\
\hline Fair & $0(0.0 \%)$ & $0(0.0 \%)$ & $0(0.0 \%)$ \\
\hline Average & $5(5.1 \%)$ & $5(5.8 \%)$ & $10(5.4 \%)$ \\
\hline Good & $60(61.2 \%)$ & $44(51.2 \%)$ & $104(57 \%)$ \\
\hline Very good & $33(34 \%)$ & $36(42 \%)$ & $69(38 \%)$ \\
\hline \multicolumn{4}{|l|}{ 30. Severity of concussions } \\
\hline YES & $92(93 \%)$ & $81(94 \%)$ & $173(94 \%)$ \\
\hline NO & $6(6 \%)$ & $5(6 \%)$ & $11(6 \%)$ \\
\hline
\end{tabular}


Question

31. Avoid harmful substances Always

Most of the time

Half the time

Some of the time

Never

32. Well balanced diet

Always

Most of the time

Half the time

Some of the time Never
Less Then 10 Years FB ATC Greater Then 10 Years FB ATC

Overall

$81(83 \%)$
$15(15 \%)$
$0(0.0 \%)$
$0(0.0 \%)$
$1(1 \%)$
$47(48 \%)$
$28(29 \%)$
$8(8 \%)$
$11(11 \%)$
$4(4 \%)$

$71(83 \%)$

$10(12 \%)$

$0(0.0 \%)$

$0(0.0 \%)$

$1(1.2 \%)$

$35(41 \%)$

$28(33 \%)$

$2(2 \%)$

$10(11 \%)$

$11(13 \%)$
$152(83 \%)$

$25(14 \%)$

$0(0.0 \%)$

$0(0.0 \%)$

$2(1.1 \%)$

$82(45 \%)$

$56(30 \%)$

$10(5.4 \%)$

$21(11 \%)$

$15(8 \%)$ 
Table D16. Protocol by Division

\begin{tabular}{|c|c|c|c|c|c|}
\hline Question & Division I & Sub-Division & Division II & Division III & Overall \\
\hline \multicolumn{6}{|l|}{ 11. Written protocol } \\
\hline Yes & $30(62.5 \%)$ & $13(61.9 \%)$ & $31(73.8 \%)$ & $64(77.1 \%)$ & $138(71.1 \%)$ \\
\hline No & $19(39.6 \%)$ & $8(38.1 \%)$ & $11(26.2 \%)$ & $19(22.9 \%)$ & $57(29.4 \%)$ \\
\hline \multicolumn{6}{|l|}{ 12. Who developed it } \\
\hline Team Physician & $25(69.4 \%)$ & $9(60.0 \%)$ & $16(50.0 \%)$ & $39(59.1 \%)$ & $89(59.7 \%)$ \\
\hline Head ATC & $22(61.1 \%$ & $10(66.7 \%)$ & $27(84.4 \%)$ & $59(89.4 \%)$ & $118(79.2 \%)$ \\
\hline Director of AT & $9(25.0 \%)$ & $5(33.3 \%)$ & $2(6.3 \%)$ & $6(9.1 \%)$ & $22(14.8 \%)$ \\
\hline Other & $7(19.4 \%)$ & $3(20.0 \%)$ & $5(15.6 \%)$ & $8(12.1 \%)$ & $23(15.4 \%)$ \\
\hline \multicolumn{6}{|l|}{ 13. Guidelines included } \\
\hline NATA Position Statement & $34(89.5 \%)$ & $13(86.7 \%)$ & $27(84.4 \%)$ & $55(83.3 \%)$ & $129(85.4 \%)$ \\
\hline Zurich 2008 & $15(39.5 \%)$ & $5(33.3 \%)$ & $9(28.1 \%)$ & $23(34.8 \%)$ & $52(34.4 \%)$ \\
\hline Cantu & $12(31.6 \%)$ & $5(33.3 \%)$ & $15(46.9 \%)$ & $26(39.4 \%)$ & $58(38.4 \%)$ \\
\hline Other & $23(60.5 \%)$ & $11(73.3 \%)$ & $15(46.9 \%)$ & $36(54.5 \%)$ & $85(56.3 \%)$ \\
\hline \multicolumn{6}{|l|}{ 14. Protocol contains } \\
\hline Definition of Concussion & $19(52.8 \%)$ & $7(53.8 \%)$ & $24(80.0 \%)$ & $57(87.7 \%)$ & $107(74.3 \%)$ \\
\hline Referral Guidelines & $28(77.8 \%)$ & $11(84.6 \%)$ & $25(83.3 \%)$ & $55(84.6 \%)$ & $119(82.6 \%)$ \\
\hline Take Home Instructions & $29(80.6 \%)$ & $12(92.3 \%)$ & $22(73.3 \%)$ & $52(80 \%)$ & $115(79.9 \%)$ \\
\hline RTP Assessment & $32(88.9 \%)$ & $11(84.6 \%)$ & $28(93.3 \%)$ & $58(89.2 \%)$ & $129(89.9 \%)$ \\
\hline Signs \& Symptoms & $32(88.9 \%)$ & $10(76.9 \%)$ & $28(93.3 \%)$ & $62(95.4 \%)$ & $132(91.7 \%)$ \\
\hline Guidelines for release & $18(50.0 \%)$ & $6(46.2 \%)$ & $14(46.7 \%)$ & $32(49.2 \%)$ & $70(48.6 \%)$ \\
\hline Delayed Referral & $14(38.9 \%)$ & $8(61.5 \%)$ & $15(50.0 \%)$ & $31(47.7 \%)$ & $74(51.4 \%)$ \\
\hline Oral \& Written Instructions & $20(55.6 \%)$ & $8(61.5 \%)$ & $15(50.0 \%)$ & $31(47.7 \%)$ & $74(51.4 \%)$ \\
\hline
\end{tabular}




\begin{tabular}{|c|c|c|c|c|c|}
\hline 25. NATA position statement & Division I & Sub-Division & Division II & Division III & Overall \\
\hline YES & $38(84.4 \%)$ & $17(89.5 \%)$ & $29(78.4 \%)$ & $69(87.3 \%)$ & $153(85.0 \%)$ \\
\hline $\mathrm{NO}$ & $7(15.6 \%)$ & $2(10.5 \%)$ & $8(21.6 \%)$ & $10(12.7 \%)$ & $27(15.0 \%)$ \\
\hline \multicolumn{6}{|l|}{ 26. RTP progression } \\
\hline No activity & $44(97.8 \%)$ & $19(95.0 \%)$ & $37(97.4 \%)$ & $79(97.5 \%)$ & $179(97.3 \%)$ \\
\hline Light aerobic exercise & $40(88.9 \%)$ & $16(80.0 \%)$ & $37(97.4 \%)$ & $75(92.6 \%)$ & $168(91.3 \%)$ \\
\hline Sport specific exercises & $35(77.8 \%)$ & $16(80.0 \%)$ & $31(81.6 \%)$ & $68(84.0 \%)$ & $150(81.5 \%)$ \\
\hline Non-contact & $42(93.3 \%)$ & $17(85.0 \%)$ & $36(94.7 \%)$ & $76(93,8 \%)$ & $171(92.9 \%)$ \\
\hline Full contact & $35(77.8 \%)$ & $15(75.0 \%)$ & $32(84.2 \%)$ & $67(82.7 \%)$ & $149(81.0 \%)$ \\
\hline Return to game & $34(75.6 \%)$ & $14(70.0 \%)$ & $34(89.5 \%)$ & $64(79.0 \%)$ & $146(79.3 \%)$ \\
\hline \multicolumn{6}{|l|}{ 27. Step progression } \\
\hline 12 Hours & $0(0.0 \%)$ & $0(0.0 \%)$ & $1(2.6 \%)$ & $0(0.0 \%)$ & $1(0.6 \%)$ \\
\hline 24 Hours & $28(63.6 \%)$ & $11(61.1 \%)$ & $26(68.4 \%)$ & $54(69.2 \%)$ & $119(66.9 \%$ \\
\hline 36 Hours & $0(0.0 \%)$ & $0(0.0 \%)$ & $1(2.6 \%)$ & $3(3.8 \%)$ & $4(2.2 \%)$ \\
\hline 2-3 Days & $3(6.8 \%)$ & $2(11.1 \%)$ & $2(5.3 \%)$ & $6(7.7 \%)$ & $13(7.3 \%)$ \\
\hline 4-5 Days & $1(2.3 \%)$ & $3(16.7 \%)$ & $3(7.9 \%)$ & $4(5.1 \%)$ & $11(6.2 \%)$ \\
\hline Other & $12(27.2 \%)$ & $2(11.1 \%)$ & $5(13.2 \%)$ & $11(14.1 \%)$ & $30(16.9 \%)$ \\
\hline \multicolumn{6}{|l|}{ 50. Protocol changes } \\
\hline CEU Courses & $22(52.4 \%)$ & $8(42.1 \%)$ & $14(43.8 \%)$ & $36(55.4 \%)$ & $80(50.6 \%)$ \\
\hline Journal Articles & $27(64.3 \%)$ & $13(68.4 \%)$ & $21(65.6 \%)$ & $43(66.2 \%)$ & $104(65.8 \%)$ \\
\hline Increased scrutiny & $10(23.8 \%)$ & $3(15.8 \%)$ & $11(34.4 \%)$ & $18(27.7 \%)$ & $42(26.6 \%)$ \\
\hline Other & $20(47.6 \%)$ & $9(47.7 \%)$ & $11(34.4 \%)$ & $29(44.6 \%)$ & $69(43.7 \%)$ \\
\hline
\end{tabular}


Table D17. Protocol by Years Certified Athletic Trainer

\begin{tabular}{|c|c|c|c|}
\hline Question & Less Then 10 Years ATC & Greater Then 10 Years ATC & Overall \\
\hline \multicolumn{4}{|l|}{ 11. Written protocol } \\
\hline Yes & $36(74 \%)$ & $102(70 \%)$ & $138(71 \%)$ \\
\hline No & $14(29 \%)$ & $43(30 \%)$ & $57(30 \%)$ \\
\hline \multicolumn{4}{|l|}{ 12. Who developed it } \\
\hline Team Physician & $18(49 \%)$ & $71(63 \%)$ & $89(60 \%)$ \\
\hline Head ATC & $27(73 \%)$ & $91(81 \%)$ & $118(80 \%)$ \\
\hline Director of AT & $6(16 \%)$ & $16(14 \%)$ & $22(15 \%)$ \\
\hline Other & $7(19 \%)$ & $16(15 \%)$ & $23(15.4 \%)$ \\
\hline \multicolumn{4}{|l|}{ 13. Guidelines included } \\
\hline NATA Position Statement & $34(90 \%)$ & $95(84 \%)$ & $129(85 \%)$ \\
\hline Zurich 2008 & $12(32 \%)$ & $40(34 \%)$ & $52(34 \%)$ \\
\hline Cantu & $11(29 \%)$ & $47(42 \%)$ & $58(38 \%)$ \\
\hline Other & $18(47 \%)$ & $67(59 \%)$ & $85(56 \%)$ \\
\hline \multicolumn{4}{|l|}{ 14. Protocol contains } \\
\hline Definition of Concussion & $25(76 \%)$ & $82(74 \%)$ & $107(74 \%)$ \\
\hline Referral Guidelines & $25(76 \%)$ & $94(85 \%)$ & $119(83 \%)$ \\
\hline Take Home Instructions & $26(79 \%)$ & $89(80 \%)$ & $115(80 \%)$ \\
\hline RTP Assessment & $32(97 \%)$ & $97(88 \%)$ & $129(90 \%)$ \\
\hline Signs \& Symptoms & $30(91 \%)$ & $102(92 \%)$ & $132(92 \%)$ \\
\hline Guidelines for release & $18(55 \%)$ & $52(47 \%)$ & $70(49 \%)$ \\
\hline Delayed Referral & $16(49 \%)$ & $42(28 \%)$ & $58(40 \%)$ \\
\hline Oral \& Written Instructions & $21(64 \%)$ & $53(48 \%)$ & $74(52 \%)$ \\
\hline \multicolumn{4}{|l|}{ 25. NATA position statement } \\
\hline YES & $43(96 \%)$ & $110(82 \%)$ & $153(85 \%)$ \\
\hline NO & $2(4 \%)$ & $25(19 \%)$ & $27(15 \%)$ \\
\hline
\end{tabular}




\begin{tabular}{|c|c|c|c|}
\hline Question & Less Then 10 Years ATC & Greater Then 10 Years ATC & Overall \\
\hline \multicolumn{4}{|l|}{ 26. RTP progression } \\
\hline No activity & $46(98 \%)$ & $133(97 \%)$ & $179(97 \%)$ \\
\hline Light aerobic exercise & $46(98 \%)$ & $122(90 \%)$ & $168(91 \%)$ \\
\hline Sport specific exercises & $40(85 \%)$ & $110(80 \%)$ & $150(82 \%)$ \\
\hline Non-contact & $43(92 \%)$ & $128(94 \%)$ & $171(93 \%)$ \\
\hline Full contact & $38(81 \%)$ & $111(81 \%)$ & $149(81 \%)$ \\
\hline Return to game & $39(83 \%)$ & $107(78 \%)$ & $146(79 \%)$ \\
\hline \multicolumn{4}{|l|}{ 27. Step progression } \\
\hline 12 Hours & $0(0.0 \%)$ & $0(0.0 \%)$ & $0(0.0 \%)$ \\
\hline 24 Hours & $31(69 \%)$ & $88(66 \%)$ & $119(67 \%)$ \\
\hline 36 Hours & $0(0.0 \%)$ & $0(0.0 \%)$ & $0(0.0 \%)$ \\
\hline 2-3 Days & $1(2 \%)$ & $12(9 \%)$ & $13(7 \%)$ \\
\hline 4-5 Days & $5(11 \%)$ & $6(5 \%)$ & $11(6 \%)$ \\
\hline Other & $8(18 \%)$ & $22(17 \%)$ & $30(17 \%)$ \\
\hline \multicolumn{4}{|l|}{ 50. Protocol changes } \\
\hline CEU Courses & $16(41 \%)$ & $64(54 \%)$ & $80(51 \%)$ \\
\hline Journal Articles & $28(72 \%)$ & $76(64 \%)$ & $104(66 \%)$ \\
\hline Increased scrutiny & $15(39 \%)$ & $27(23 \%)$ & $42(27 \%)$ \\
\hline Other & $14(36 \%)$ & $55(46 \%)$ & $69(44 \%)$ \\
\hline
\end{tabular}


Table D18. Protocol by Years Head Football Athletic Trainer

\begin{tabular}{|c|c|c|c|}
\hline Question & Less Then 10 Years FB ATC & Greater Then 10 Years FB ATC & Overall \\
\hline \multicolumn{4}{|l|}{ 11. Written protocol } \\
\hline Yes & $72(70 \%)$ & $66(73 \%)$ & $138(71 \%)$ \\
\hline No & $32(31 \%)$ & $25(28 \%)$ & $57(30 \%)$ \\
\hline \multicolumn{4}{|l|}{ 12. Who developed it } \\
\hline Team Physician & $37(49 \%)$ & $52(70 \%)$ & $89(60 \%)$ \\
\hline Head ATC & $55(74 \%)$ & $63(85 \%)$ & $118(80 \%)$ \\
\hline Director of AT & $14(19 \%)$ & $8(10 \%)$ & $22(15 \%)$ \\
\hline Other & $12(16 \%)$ & $11(15 \%)$ & $23(15.4 \%)$ \\
\hline \multicolumn{4}{|l|}{ 13. Guidelines included } \\
\hline NATA Position Statement & $67(87 \%)$ & $62(84 \%)$ & $129(86 \%)$ \\
\hline Zurich 2008 & $29(38 \%)$ & $23(31 \%)$ & $52(34 \%)$ \\
\hline Cantu & $24(31 \%)$ & $34(46 \%)$ & $58(38 \%)$ \\
\hline Other & $41(53 \%)$ & $44(60 \%)$ & $85(56 \%)$ \\
\hline \multicolumn{4}{|l|}{ 14. Protocol contains } \\
\hline Definition of Concussion & $51(71 \%)$ & $56(78 \%)$ & $107(74 \%)$ \\
\hline Referral Guidelines & $61(85 \%)$ & $58(81 \%)$ & $119(83 \%)$ \\
\hline Take Home Instructions & $59(82 \%)$ & $56(78 \%)$ & $115(80 \%)$ \\
\hline RTP Assessment & $68(95 \%)$ & $61(85 \%)$ & $129(90 \%)$ \\
\hline Signs \& Symptoms & $63(88 \%)$ & $69(96 \%)$ & $132(92 \%)$ \\
\hline Guidelines for release & $41(56 \%)$ & $29(40 \%)$ & $70(49 \%)$ \\
\hline Delayed Referral & $32(45 \%)$ & $26(36 \%)$ & $58(51 \%)$ \\
\hline Oral \& Written Instructions & $39(54 \%)$ & $35(49 \%)$ & $74(52 \%)$ \\
\hline \multicolumn{4}{|l|}{ 25. NATA position statement } \\
\hline YES & $85(89 \%)$ & $68(81 \%)$ & $153(85 \%)$ \\
\hline NO & $11(11.5 \%)$ & $16(19 \%)$ & $27(15 \%)$ \\
\hline
\end{tabular}


Question

26. RTP progression

No activity

Light aerobic exercise

Sport specific exercises

Non-contact

Full contact

Return to game

27. Step progression

12 Hours

24 Hours

36 Hours

2-3 Days

4-5 Days

Other

50. Protocol changes

CEU Courses

Journal Articles

Increased scrutiny

Other
Less Then 10 Years FB ATC Greater Then 10 Years FB ATC

Overall

$96(98 \%)$
$95(97 \%)$
$83(85 \%)$
$93(95 \%)$
$83(85 \%)$
$82(84 \%)$

$0(0.0 \%)$
$66(69 \%)$
$0(0.0 \%)$
$6(6.3 \%)$
$7(7 \%)$
$17(18 \%)$

$35(43 \%)$
$56(69 \%)$
$26(32 \%)$
$33(41 \%)$

$83(97 \%)$

$179(97 \%)$

$73(85 \%)$

$67(78 \%)$

$78(91 \%)$

$66(77 \%)$

$64(75 \%)$

$168(91 \%)$

$150(82 \%)$

$171(93 \%)$

$149(81 \%)$

$146(80 \%)$

$1(1.2 \%)$

$53(65 \%)$

$4(4.9 \%)$

$7(8.5 \%)$

$4(5 \%)$

$13(16 \%)$

$1(0.6 \%)$

$119(67 \%)$

$4(2.2 \%)$

$13(7.3 \%)$

$11(6.2 \%)$

$30(17 \%)$

$45(58 \%)$

$80(51 \%)$

$48(62 \%)$

$104(66 \%)$

$42(27 \%)$

$69(44 \%)$ 
Table D19. Grading by Division

\begin{tabular}{|c|c|c|c|c|c|}
\hline Question & Division I & Sub-Division & Division II & Division III & Overall \\
\hline \multicolumn{6}{|l|}{ 40. Grade on LOC } \\
\hline YES & $28(62.2 \%)$ & $11(55.0 \%)$ & $21(56.8 \%)$ & $43(55.1 \%)$ & $103(57.2 \%)$ \\
\hline NO & $17(37.8 \%)$ & $9(45.0 \%)$ & $16(43.2 \%)$ & $35(44.9 \%)$ & $77(42.8 \%)$ \\
\hline \multicolumn{6}{|l|}{ 41. Grade severity } \\
\hline YES & $14(31.1 \%)$ & $11 \%)$ & $19(52.8 \%)$ & $25(31.6 \%)$ & $69(38.3 \%)$ \\
\hline NO & $31(68.9 \%)$ & $6(31.6 \%$ & $17(47.2 \%)$ & $54(68.4 \%)$ & $111(61.7 \%)$ \\
\hline \multicolumn{6}{|l|}{ 42. Graded on } \\
\hline 1 to 3 & $18(40.0 \%)$ & $13(65.0 \%)$ & $21(56.8 \%)$ & $37(46.3 \%)$ & $89(48.9 \%)$ \\
\hline Simple Vs. Complex & $6(13.3 \%)$ & $3(15.0 \%)$ & $3(8.1 \%)$ & $9(11.3 \%)$ & $21(11.5 \%)$ \\
\hline Neither & $21(46.7 \%)$ & $4(20.0 \%)$ & $13(35.1 \%)$ & $34(42.5 \%)$ & $72(39.6 \%)$ \\
\hline \multicolumn{6}{|l|}{ 43. New numerical system } \\
\hline YES & $8(17.8 \%)$ & $9(45.0 \%)$ & $16(44.4 \%)$ & $28(35.0 \%)$ & $61(33.7 \%)$ \\
\hline NO & $37(82.2 \%)$ & $11(55.0 \%)$ & $20(55.6 \%)$ & $52(65.0 \%)$ & $120(66.3 \%)$ \\
\hline \multicolumn{6}{|l|}{ 44. Symptoms severity } \\
\hline YES & $32(71.1 \%)$ & $17(85.0 \%)$ & $30(81.1 \%)$ & $61(76.3 \%)$ & $140(76.9 \%)$ \\
\hline NO & $13(28.9 \%)$ & $3(15.0 \%)$ & $7(18.9 \%)$ & $19(23.8 \%)$ & $42(23.1 \%)$ \\
\hline
\end{tabular}


Table D20. Grading by Years Certified Athletic Trainer

\begin{tabular}{|c|c|c|c|}
\hline Question & Less Then 10 Years ATC & Greater Then 10 Years ATC & Overall \\
\hline \multicolumn{4}{|l|}{ 40. Grade on LOC } \\
\hline YES & $23(49 \%)$ & $80(60 \%)$ & $103(57 \%)$ \\
\hline $\mathrm{NO}$ & $24(51 \%)$ & $53(40 \%)$ & $77(43 \%)$ \\
\hline \multicolumn{4}{|l|}{ 41. Grade severity } \\
\hline YES & $17(37 \%)$ & $52(39 \%)$ & $69(38 \%)$ \\
\hline NO & $29(63 \%)$ & $82(61 \%)$ & $111(62 \%)$ \\
\hline \multicolumn{4}{|l|}{ 42. Graded on } \\
\hline 1 to 3 & $23(49 \%)$ & $66(49 \%)$ & $89(49 \%)$ \\
\hline Simple Vs. Complex & $6(13 \%)$ & $15(11 \%)$ & $21(12 \%)$ \\
\hline Neither & $18(39 \%)$ & $54(40 \%)$ & $72(40 \%)$ \\
\hline \multicolumn{4}{|l|}{ 43. New numerical system } \\
\hline YES & $20(43 \%)$ & $41(31 \%)$ & $61(34 \%)$ \\
\hline $\mathrm{NO}$ & $27(57 \%)$ & $93(70 \%)$ & $120(66 \%)$ \\
\hline \multicolumn{4}{|l|}{ 44. Symptoms severity } \\
\hline YES & $36(76 \%)$ & $104(77 \%)$ & $140(77 \%)$ \\
\hline $\mathrm{NO}$ & $11(23 \%)$ & $31(23 \%)$ & $42(23 \%)$ \\
\hline
\end{tabular}


Table D21. Grading by Years Head Football Athletic Trainer

\begin{tabular}{|c|c|c|c|}
\hline Question & Less Then 10 Years FB ATC & Greater Then 10 Years FB ATC & Overall \\
\hline \multicolumn{4}{|l|}{ 40. Grade on LOC } \\
\hline YES & $49(51 \%)$ & $54(65 \%)$ & $103(57 \%)$ \\
\hline NO & $48(50 \%)$ & $29(35 \%)$ & $77(43 \%)$ \\
\hline \multicolumn{4}{|l|}{ 41. Grade severity } \\
\hline YES & $38(40 \%)$ & $31(37 \%)$ & $69(38 \%)$ \\
\hline NO & $58(60 \%)$ & $53(63 \%)$ & $111(62 \%)$ \\
\hline \multicolumn{4}{|l|}{ 42. Graded on } \\
\hline 1 to 3 & $47(49 \%)$ & $42(49 \%)$ & $89(49 \%)$ \\
\hline Simple Vs. Complex & $12(12 \%)$ & $9(10 \%)$ & $21(12 \%)$ \\
\hline Neither & $38(39 \%)$ & $34(40 \%)$ & $72(40 \%)$ \\
\hline \multicolumn{4}{|l|}{ 43. New numerical system } \\
\hline YES & $38(40 \%)$ & $23(27 \%)$ & $61(34 \%)$ \\
\hline NO & $59(61 \%)$ & $61(73 \%)$ & $120(66 \%)$ \\
\hline \multicolumn{4}{|l|}{ 44. Symptoms severity } \\
\hline YES & $69(71 \%)$ & $71(84 \%)$ & $140(77 \%)$ \\
\hline $\mathrm{NO}$ & $28(29 \%)$ & $14(17 \%)$ & $42(23 \%)$ \\
\hline
\end{tabular}


Table D22. Scenarios by Division

\begin{tabular}{|c|c|c|c|c|c|}
\hline Question & Division I & Sub-Division & Division II & Division III & Overall \\
\hline \multicolumn{6}{|l|}{ 45. Scenario \#1 } \\
\hline YES & $10(23.8 \%)$ & $4(20.0 \%)$ & $9(25.7 \%)$ & $7(9.2 \%)$ & $30(17.3 \%)$ \\
\hline NO & $32(76.2 \%)$ & $16(80.0 \%)$ & $26(74.3 \%)$ & $69(90.8 \%)$ & $143(82.7 \%)$ \\
\hline \multicolumn{6}{|l|}{ 46. Scenario \#2 } \\
\hline YES & $2(4.7 \%)$ & $0(0.0 \%)$ & $0(0.0 \%)$ & $0(0.0 \%)$ & $2(1.1 \%)$ \\
\hline NO & $41(95.3 \%)$ & $20(100 \%)$ & $35(100 \%)$ & $76(100 \%)$ & $172(98.9 \%)$ \\
\hline \multicolumn{6}{|l|}{ 47. Scenario \#3 } \\
\hline Fast Track & $16(38.1 \%)$ & $5(25.0 \%)$ & $14(40.0 \%)$ & $12(16.0 \%)$ & $47(27.3 \%)$ \\
\hline Conservative & $26(61.9 \%)$ & $15(75.0 \%)$ & $21(60.0 \%)$ & $63(84.0 \%)$ & $125(72.7 \%)$ \\
\hline \multicolumn{6}{|l|}{ 48. Scenario \# 4} \\
\hline Complete a full exam & $6(15.0 \%)$ & $1(5.0 \%)$ & $5(14.3 \%)$ & $10(13.2 \%)$ & $22(12.9 \%)$ \\
\hline Acetaminophen & $2(5.0 \%)$ & $0(0.0 \%)$ & $0(0.0 \%)$ & $0(0.0 \%)$ & $2(1.2 \%)$ \\
\hline Another head injury & $3(7.5 \%)$ & $5(25.0 \%)$ & $8(22.9 \%)$ & $10(13.2 \%)$ & $26(15.2 \%)$ \\
\hline Quick concussion assessment & $8(20.0 \%)$ & $6(30.0 \%)$ & $12(34.3 \%)$ & $34(44.7 \%)$ & $60(35.1 \%)$ \\
\hline Team Physician & $21(52.5 \%)$ & $8(40.0 \%)$ & $10(28.6 \%)$ & $22(28.9 \%)$ & $61(35.7 \%)$ \\
\hline Emergency Room & $0(0.0 \%)$ & $0(0.0 \%)$ & $0(0.0 \%)$ & $0(0.0 \%)$ & $0(0.0 \%)$ \\
\hline
\end{tabular}


Table D23. Scenarios by Years Certified Athletic Trainer

\begin{tabular}{|c|c|c|c|}
\hline Question & Less Then 10 Years ATC & Greater Then 10 Years ATC & Overall \\
\hline \multicolumn{4}{|l|}{ 45. Scenario \#1 } \\
\hline YES & $8(17 \%)$ & $22(17 \%)$ & $30(17 \%)$ \\
\hline NO & $38(83 \%)$ & $105(83 \%)$ & $143(83 \%)$ \\
\hline \multicolumn{4}{|l|}{ 46. Scenario \#2 } \\
\hline YES & $0(0.0 \%)$ & $2(2 \%)$ & $2(1.1 \%)$ \\
\hline $\mathrm{NO}$ & $46(100 \%)$ & $126(98 \%)$ & $172(99 \%)$ \\
\hline \multicolumn{4}{|l|}{ 47. Scenario \#3 } \\
\hline Fast Track & $12(26 \%)$ & $35(28 \%)$ & $47(27 \%)$ \\
\hline Conservative & $34(74 \%)$ & $91(73 \%)$ & $125(73 \%)$ \\
\hline \multicolumn{4}{|l|}{ 48. Scenario \# 4} \\
\hline Complete a full exam & $10(22 \%)$ & $12(10 \%)$ & $22(13 \%)$ \\
\hline Acetaminophen & $0(0.0 \%)$ & $2(1.6 \%)$ & $2(1 \%)$ \\
\hline Another head injury & $11(24 \%)$ & $15(12 \%)$ & $26(15 \%)$ \\
\hline Quick concussion assessment & $19(41 \%)$ & $41(33 \%)$ & $60(35 \%)$ \\
\hline Team Physician & $6(13 \%)$ & $55(44 \%)$ & $61(36 \%)$ \\
\hline Emergency Room & $0(0.0 \%)$ & $0(0.0 \%)$ & $0(0.0 \%)$ \\
\hline
\end{tabular}


Table D24. Scenarios by Years Head Football Athletic Trainer

\begin{tabular}{|c|c|c|c|}
\hline Question & Less Then 10 Years FB ATC & Greater Then 10 Years FB ATC & Overall \\
\hline \multicolumn{4}{|l|}{ 45. Scenario \#1 } \\
\hline YES & $16(17 \%)$ & $14(17 \%)$ & $30(17 \%)$ \\
\hline NO & $76(83 \%)$ & $67(83 \%)$ & $143(83 \%)$ \\
\hline \multicolumn{4}{|l|}{ 46. Scenario \#2 } \\
\hline YES & $1(1.1 \%)$ & $1(1.2 \%)$ & $2(1.1 \%)$ \\
\hline NO & $92(99 \%)$ & $80(99 \%)$ & $172(99 \%)$ \\
\hline \multicolumn{4}{|l|}{ 47. Scenario \#3 } \\
\hline Fast Track & $25(27 \%)$ & $22(27 \%)$ & $47(27 \%)$ \\
\hline Conservative & $67(73 \%)$ & $58(73 \%)$ & $125(73 \%)$ \\
\hline \multicolumn{4}{|l|}{ 48. Scenario \# 4} \\
\hline Complete a full exam & $14(15 \%)$ & $8(10 \%)$ & $22(13 \%)$ \\
\hline Acetaminophen & $1(1.1 \%)$ & $1(1.3 \%)$ & $2(1.2 \%)$ \\
\hline Another head injury & $18(20 \%)$ & $8(10 \%)$ & $26(15 \%)$ \\
\hline Quick concussion assessment & $36(39 \%)$ & $24(30 \%)$ & $60(35 \%)$ \\
\hline Team Physician & $23(25 \%)$ & $38(48 \%)$ & $61(36 \%)$ \\
\hline Emergency Room & $0(0.0 \%)$ & $0(0.0 \%)$ & $0(0.0 \%)$ \\
\hline
\end{tabular}


Table D25. Chi Square Results (Year ATC \& Years FB ATC Only)

\begin{tabular}{lllll}
\hline Question & Association & $\chi^{2}$ & CC & P \\
\hline Q15: & Years Certified & .528 & .053 & .468 \\
& Years FB ATC & .152 & .029 & .696 \\
Q17: & Years Certified & 10.22 & .236 & .250 \\
& Years FB ATC & 7.53 & .202 & .480 \\
Q22: & Years Certified & 8.96 & .221 & .255 \\
& Years FB ATC & 6.59 & .190 & .427 \\
Q25: & Years Certified & 4.99 & .167 & .025 \\
& Years FB ATC & 2.02 & .106 & .155 \\
Q27: & Years Certified & 6.35 & .189 & .273 \\
& Years FB ATC & 6.78 & .195 & .237 \\
Q30: & Years Certified & 1.57 & .093 & .209 \\
& Years FB ATC & .008 & .006 & .930 \\
Q38: & Years Certified & 1.05 & .076 & .902 \\
& Years FB ATC & 1.05 & .076 & .902 \\
Q39: & Years Certified & 1.01 & .075 & .315 \\
& Years FB ATC & .538 & .055 & .463 \\
Q41: & Years Certified & .196 & .033 & .658 \\
& Years FB ATC & .136 & .027 & .712 \\
Q42: & Years Certified & .042 & .015 & .979 \\
& Years FB ATC & .141 & .028 & .932 \\
Q44: & Years Certified & .024 & .012 & .876 \\
& Years FB ATC & 3.92 & .145 & $.048^{*}$ \\
\hline
\end{tabular}

KEY: $\chi^{2}=$ Chi-Square; $\mathrm{CC}=$ Contingency Coefficient; $\mathrm{P}=\mathrm{P}$-value; $*=$ Significant at $\mathrm{P}=0.05$ 
Table 26. Chi Square Results (Division)

\begin{tabular}{|c|c|c|c|c|}
\hline Question & Association & $\chi^{2}$ & $\mathrm{CC}$ & $P$ \\
\hline \multirow[t]{6}{*}{ Q15: } & D1 \& D2 & 8.71 & .302 & $.003 *$ \\
\hline & D1 \& D3 & 2.05 & .127 & .152 \\
\hline & D1 \& Sub-D & 1.92 & .171 & .165 \\
\hline & D2 \& D3 & 3.87 & .179 & $.049 *$ \\
\hline & D2 \& Sub-D & 1.08 & .134 & 297 \\
\hline & D3 \& Sub & .144 & .034 & .735 \\
\hline \multirow[t]{6}{*}{ Q17: } & D1 \& D2 & 7.24 & .292 & .510 \\
\hline & D1 \& D3 & 5.83 & .212 & .667 \\
\hline & D1 \& Sub-D & 6.59 & .324 & 472 \\
\hline & D2 \& D3 & 2.49 & .144 & .962 \\
\hline & D2 \& Sub-D & 7.88 & .362 & .343 \\
\hline & D3 \& Sub & 9.59 & .311 & 295 \\
\hline \multirow[t]{6}{*}{ Q22: } & D1 \& D2 & 4.89 & .243 & .557 \\
\hline & D1 \& D3 & 3.65 & .171 & .820 \\
\hline & D1 \& Sub-D & 3.68 & .238 & .596 \\
\hline & D2 \& D3 & 6.83 & .241 & 447 \\
\hline & D2 \& Sub-D & 7.51 & .360 & .276 \\
\hline & D3 \& Sub & 9.69 & .311 & 207 \\
\hline \multirow[t]{6}{*}{ Q25: } & D1 \& D2 & .500 & .078 & 480 \\
\hline & D1 \& D3 & .203 & .040 & .652 \\
\hline & D1 \& Sub-D & .280 & .066 & .597 \\
\hline & D2 \& D3 & 1.54 & .115 & 214 \\
\hline & D2 \& Sub-D & 1.05 & 137 & .305 \\
\hline & D3 \& Sub & .065 & .026 & .799 \\
\hline \multirow[t]{6}{*}{ Q27: } & D1 \& D2 & 5.74 & .265 & .331 \\
\hline & D1 \& D3 & 5.0 & .202 & . 287 \\
\hline & D1 \& Sub-D & 5.88 & .308 & .117 \\
\hline & D2 \& D3 & 2.72 & .153 & .743 \\
\hline & D2 \& Sub-D & 2.55 & .213 & .769 \\
\hline & D3 \& Sub & 3.80 & .199 & .433 \\
\hline \multirow[t]{6}{*}{ Q30: } & D1 \& D2 & .433 & .072 & .510 \\
\hline & D1 \& D3 & .427 & .058 & .513 \\
\hline & D1 \& Sub-D & .971 & .119 & .338 \\
\hline & D2 \& D3 & .009 & .009 & .925 \\
\hline & D2 \& Sub-D & 1.66 & 169 & 197 \\
\hline & D3 \& Sub & 1.57 & .125 & 209 \\
\hline \multirow[t]{6}{*}{ Q38: } & D1 \& D2 & 5.43 & .259 & .246 \\
\hline & D1 \& D3 & 6.13 & .217 & .190 \\
\hline & D1 \& Sub-D & 4.89 & .227 & .298 \\
\hline & D2 \& D3 & 8.13 & .264 & .087 \\
\hline & D2 \& Sub-D & 8.37 & .383 & .079 \\
\hline & D3 \& Sub & 4.27 & .207 & .370 \\
\hline
\end{tabular}




\begin{tabular}{|c|c|c|c|c|}
\hline \multirow[t]{6}{*}{ Q39: } & D1 \& D2 & .208 & .051 & .649 \\
\hline & D1 \& D3 & 1.37 & .105 & .242 \\
\hline & D1 \& Sub-D & .490 & .088 & .484 \\
\hline & D2 \& D3 & .357 & .055 & .550 \\
\hline & D2 \& Sub-D & 1.07 & .138 & .301 \\
\hline & D3 \& Sub & 2.53 & .161 & .111 \\
\hline \multirow[t]{6}{*}{ Q41: } & D1 \& D2 & 3.88 & .219 & $.049 *$ \\
\hline & D1 \& D3 & .004 & .006 & .951 \\
\hline & D1 \& Sub-D & 3.33 & .227 & .068 \\
\hline & D2 \& D3 & 4.67 & .202 & $.031 *$ \\
\hline & D2 \& Sub-D & .026 & .021 & .873 \\
\hline & D3 \& Sub & 3.76 & .195 & .052 \\
\hline \multirow[t]{6}{*}{ Q42: } & D1 \& D2 & 2.35 & .169 & .308 \\
\hline & D1 \& D3 & .473 & .061 & .789 \\
\hline & D1 \& Sub-D & 4.40 & .260 & .111 \\
\hline & D2 \& D3 & 1.14 & .099 & .563 \\
\hline & D2 \& Sub-D & 1.73 & .174 & .421 \\
\hline & D3 \& Sub & 3.44 & .186 & .179 \\
\hline \multirow[t]{6}{*}{ Q44: } & D1 \& D2 & 1.09 & .116 & .295 \\
\hline & D1 \& D3 & .399 & .056 & .527 \\
\hline & D1 \& Sub-D & .143 & .149 & .230 \\
\hline & D2 \& D3 & .342 & .054 & .559 \\
\hline & D2 \& Sub-D & .138 & .049 & .710 \\
\hline & D3 \& Sub & .714 & .084 & .398 \\
\hline
\end{tabular}




\section{APPENDIX E}

\section{RECOMMENDATIONS FOR FUTURE RESEARCH}

1. Repeat the study comparing responses of team physicians to certified athletic trainers.

2. Repeat the study using athletic trainers from all four NCAA institutions with the focus on noncontact sports.

3. Repeat the study using more open-ended questions in the scenario section. 


\section{ADDITIONAL REFERENCES}

15. Dick RW, Football injury report. In:2001-2002 NCAA Injury Surveillance System. Indianapolis, Ind: National Collegiate Athletic Association; 2002.

16. Boden BP, Tacchetti RL, Cantu RC, Knowles SB, Mueller FO. Catastrophic head injuries in high school and college football players. Am J Sports Med. 2007;35(7):1075-1081.

17. Gerberich SG, Priest JD, Boen JR, Straub CP, Maxwell RE. Concussion incidences and severity in secondary school varsity football players. Am J Public Health. 1983;73:13701375.

18. Guskiewicz KM, Weaver N, Padua DA, Garrett WE. Epidemiology of concussion in collegiate and high school football players. Am J Sports Med. 2000; 28:643-650.

19. Maroon, J., Lovell, M., Norwig, J., Podell, K., Powell, J., \& Hartl, R. (2000). Cerebral concussion in athletes:Evaluation and neu- ropsychological testing. Neurosurgery,47, 659672.

20. Notebaert A, Guskiewicz K. Current Trends in Athletic Training Practice for Concussion Assessment and Management. J Athl Train. 2005; 40:320-325.

21. Covassin T, Elbin R, Ostrowski J. Current sport-related concussion teaching and clinical practices of sports medicine professionals. J Athl Train. 2009;44(4):400-404.

22. Prentice WE. Arnheim's Principles of Athletic Training: A Competency-Based Approach. 11th ed. New York, NY. McGraw-Hill Higher Education. 2003:878-900.

23. Bernier JN. Quick Reference Dictionary for Athletic Training. 2nd ed. Thorofare, NJ. Slack, Inc. 2005.

24. Starkey C, Ryan J. Evaluation of Orthopedic and Athletic Injuries. 2nd ed. Philadelphia, PA. F.A. Davis Company. 2002:610-652.

25. Oliaro S, Anderson S, Hooker d. Management of cerebral concussion in sports: the athletic trainer's perspective. J Athl Train. 2004;39(3):280-297.

26. Lovell M, Collins M, Bradley J. Return to play following sports-related concussion. Clin Sports Med. 2004;23:421-441.

27. Moore KL, Dalley AF, Agur AM. Clinically Oriented Anatomy. 5th ed. Baltimore, Md. Lippincott Williams \& Wilkins. 2006:886-1043.

28. Eigsti J, Henke K. Anatomy and physiology of neurological compensatory mechanisms. Dimens Crit Care Nurs. 2006;25(5):197-202. 
29. Lovell M. The neurophysiology and assessment of sports-related head injuries. Neurol Clin. 2008;26:45-62.

30. Cantu RC. Athletic head injuries. Clin Sports Med. 1997;16:531-542.

31. Bailes JE, Hudson V. Classification of sport-related head trauma: a spectrum of mild to severe injury. $J$ Athl Train. 2001;36(3):236-243.

32. Giza C, Hovda D. The neurometabolic cascade of concussion. J Athl Train. 2001;36(3):228-235.

33. Lovell M. The management of sports-related concussion: current status and future trends. Clin Sports Med. 2009;28:95-111.

34. Sturmi J, Smith C, Lombardo J. Mild brain trauma in sports. Sports Med. 1998;25(6):351358.

35. Terrell T. Concussion in athletes. Southern Med J. 2004;97(9):837-842.

36. Reddy C, Collins M. Sports concussion: management and predictors of outcome. American college of sports medicine. 2009;8(1):10-15.

37. Heegaard W, Biros M. Traumatic brain injury. Emerg Med Clin N Am. 2007;25:655-678.

38. Withnall C, Shewchenko N, Gittens R, Dvorak J. Biomechanical investigation of head impacts in football. Br J Sports Med. 2005;39:49-57.

39. Park M, Levy M. Biomechanical aspects of sports-related head injuries. Neurol Clin. 2008;26:33-43.

40. Davis A. Mechanisms of traumatic brain injury: biomechanical, structural, and cellular considerations. J Emerg Med. 2000;23(3):1-13.

41. Guskiewicz K, Weaver N, Padua D, Garrett W. Epidemiology of concussion in collegiate and high school football players. Amer J Sports Med. 2000;28(5):643-650.

42. Cooper M, McGee K, Anderson G. Epidemiology of athletic head and neck injuries. Clin Sports Med. 2003;22:427-443.

43. Barth J, Freman J, Broshek D, Varney R. Acceleration-deceleration sport-related concussion: the gravity of it all. J Athl Train. 2001;36(3):253-256.

44. Wojtys E, Hovda D, Landry G, Boland A, Lovell M, McCrea M, Minkoff J. Concussion in sports. Amer J Sports Med. 1999;27(5):676-687. 
45. Moser R, Iverson G, Echemendia R, Lovell M, Schatz P, Webbe F, Ruff R, Barth J. Neuropsychological evaluation in the diagnosis and management of sports-related concussion. Clin Neuropsych. 2007;22:909-916.

46. Chen J, Johnston K, Collie A, McCrory P. A validation of the post concussion symptom scale in the assessment of complex concussion using cognitive testing and functional MRI. Am J Sports Med. 2006;38:27-32.

47. Piland S, Motl R, Guskiewicz K, McCrea M, Ferrara M. Structural validity of a self-report concussion-related symptom scale. Am J Sports Med. 2006;38:27-32.

48. Valovich T, Perrin D, Gansneder B. Repeat administration elects a practice effect with the balance error scoring system but not with the standardized assessment of concussion in high school athletes. J Athl Train. 2003;38(1):51-56.

49. Iverson G, Kaarto M, Koehle M. Normative data for the balance error scoring system: Implications for brain injury evaluations. Brain Injury. 2008; 22(2):147-152.

50. Collins M, Grindel S, Lovell M. Relationship between concussion and neuropsychological performance in college football. JAMA. 1999;282(10):964-970.

51. Randolph C, McCrea M, Barr W. Is neuropsychological testing useful in the management of sport-related concussion? J Athl Train. 2005;40(3):139-154.

52. Miller J, Adamson G, Pink M. Comparison of preseason, midseason, and postseason neurocognitive scores in uninjured collegiate football players. Amer J Sports med. 2007;35(8):1284-1288.

53. Schatz P, Pardini J, Lovell M, Collins M, Podell K. Sensitivity and specific of the ImPACT test for concussion in athletes. Neuropsychology. 2006;21:91-99.

54. Schatz P, Zillmer E. Computer-based assessment of sports-related concussion. Applied Neuropsychology. 2003; 23:421-441.

55. Iverson $\mathrm{G}$, Lovell M, Collins $\mathrm{M}$. Interpreting change on ImPACT following sport concussion. Am J Sports Med. 2003;17(4):460-467.

56. Guskiewicz K. Concussion in sport: The Grading-system dilemma. Athl Ther Today. 2001;38(1). 18-26.

57. Goldenberg L, Dimeff R. Sideline management of sport-related concussion. J Orthop Sports Phys Ther. 2006;14(4):199-205.

58. McKinley J. New challenges in assessing and managing concussion in sports. Amer Fam Phys. 2007;76(7):948-949. 
59. Muller F, Catastrophic head injuries in high school and collegiate sports. $J$ Athl Train. 2001;36(3):312-315

60. Mendez C, Hurley R, Lassonde M, Zhang L, Taber K. Mild traumatic brain injury. Amer Fam Phys.. 2005;17:297-303.

61. King K, Hough M, Walker M, Rastatter M. Mild traumatic brain injury: Effects on naming in word retrieval and disclosure. Brain Injury. 2006;20(7):725-732. 